Extração de conhecimento simbólico em técnicas de aprendizado de máquina caixa-preta por similaridade de rankings

Rodrigo Elias Bianchi 

SERVIÇO DE PÓS-GRADUAÇÃO DO ICMCUSP

Data de Depósito: 07.07.2008

Assinatura:

\section{Extração de conhecimento simbólico em técnicas de aprendizado de máquina caixa-preta por similaridade de rankings}

\section{Rodrigo Elias Bianchi}

Orientador: Prof. Dr. André Carlos Ponce de Leon Ferreira de Carvalho

Tese apresentada ao Instituto de Ciências Matemáticas e de Computação - ICMC-USP, como parte dos requisitos para obtenção do título de Doutor em Ciências - Ciências de Computação e Matemática Computacional. 

Este documento foi preparado utilizando-se o formatador de textos $\mathrm{ET}_{\mathrm{E}} \mathrm{X}$. Sua bibliografia é gerada automaticamente pelo $\mathrm{BIBT}_{\mathrm{E}} \mathrm{X}$, utilizando o estilo Apalike. O estilo dos títulos dos capítulos foi gentilmente cedido pelo amigo Ronaldo C. Prati.

(C) Copyright 2008 - Rodrigo Elias Bianchi Todos os direitos Reservados ${ }^{1}$

\footnotetext{
${ }^{1}$ Este trabalho conta com apoio financeiro da FAPESP processo $n^{\circ}$ 03/00099-5
} 



\section{Agradecimentos}

Gostaria de agradecer ao André, meu orientador, pela oportunidade, orientação e toda a paciência que ele teve comigo durante esses anos. Gostaria de agradecer também aos amigos Gustavo e Cláudia, pois sem eles a parte experimental desse trabalho não teria sido possível. Agradeço aos meus pais, Neida e Roberto por tudo o que fizeram por mim desde o dia em que nasci e todo o carinho que sempre me deram. Isso foi essencial ao meu desenvolvimento. Tudo o que sou se deve ao esforço deles. Muito obrigado! Agradeço à minha namorada Miyuki, por todos os momentos que tivemos juntos, que me deram força para ir em frente, e por me agüentar e entender a minha ausência nos momentos dificeis que tive no doutorado. Também quero agradecer a todos os meus amigos, os que estão perto e os que estão longe, do LABIC/BIOCOM, dos outros laboratórios e departamentos da USP, professores e funcionários do ICMC e da Unioeste, do Kendo, de Foz do Iguaçu, de São Paulo, enfim, todos os meus amigos e familiares que sempre me apoiaram incondicionalmente. Doumo arigatou gozaimashita! 



\section{Resumo}

Técnicas de Aprendizado de Máquina não-simbólicas, como Redes Neurais Artificiais, Máquinas de Vetores de Suporte e combinação de classificadores têm mostrado um bom desempenho quando utilizadas para análise de dados. A grande limitação dessas técnicas é a falta de compreensibilidade do conhecimento armazenado em suas estruturas internas. Esta Tese apresenta uma pesquisa realizada sobre métodos de extração de representações compreensíveis do conhecimento armazenado nas estruturas internas dessas técnicas não-simbólicas, aqui chamadas de caixa preta, durante seu processo de aprendizado. A principal contribuição desse trabalho é a proposta de um novo método pedagógico para extração de regras que expliquem o processo de classificação seguido por técnicas não-simbólicas. Esse novo método é baseado na otimização (maximização) da similaridade entre rankings de classificação produzidos por técnicas de Aprendizado de Máquina simbólicas e não simbólicas (de onde o conhecimento interno esta sendo extraído). Experimentos foram realizados com vários conjuntos de dados e os resultados obtidos sugerem um bom potencial para o método proposto. 



\section{Abstract}

Non-symbolic Machine Learning techniques, like Artificial Neural Networks, Support Vector Machines and Ensembles of classifiers have shown a good performance when they are used in data analysis. The strong limitation regarding the use of these techniques is the lack of comprehensibility of the knowledge stored in their internal structure. This Thesis presents an investigation of methods capable of extracting comprehensible representations of the knowledge acquired by these non-symbolic techniques, here named black box, during their learning process. The main contribution of this work is the proposal of a new pedagogical method for rule extraction that explains the classification process followed by non-symbolic techniques. This new method is based on the optimization (maximization) of the similarity between classification rankings produced by symbolic and non-symbolic (from where the internal knowledge is being extracted) Machine Learning techniques. Experiments were performed for several datasets and the results obtained suggest a good potential of the proposed method. 



\section{Sumário}

Sumário

11

Lista de Algoritmos

Lista de Figuras

Lista de Tabelas

1 Introdução $\quad 23$

1.1 Justificativa . . . . . . . . . . . . . . . . 24

1.2 Organização da Tese . . . . . . . . . . . . . . . 25

2 Aprendizado de Máquina $\quad 27$

2.1 Paradigmas de Aprendizado . . . . . . . . . . . . . 28

2.1.1 Aprendizado Supervisionado . . . . . . . . . . . 28

2.1.2 Aprendizado Não-Supervisionado . . . . . . . . . . . 30

2.1.3 Aprendizado por Reforço . . . . . . . . . . . . 31

2.2 Aprendizado de Máquina Simbólico . . . . . . . . . . . . . 31

2.2.1 Árvores de Decisão . . . . . . . . . . . . . . . . 32

2.2.2 Regras de Decisão . . . . . . . . . . . . . . . 33

2.3 Aprendizado de Máquina Não-Simbólico . . . . . . . . . . . . 36

2.3.1 Redes Neurais Artificiais . . . . . . . . . . . 36

2.3.2 Classificadores de Margens Largas . . . . . . . . . . . 40

2.4 Algoritmos Genéticos . . . . . . . . . . . . . . . . 43

2.4.1 Características Gerais . . . . . . . . . . . 45

2.4.2 Representação . . . . . . . . . . . . . . 47

2.4 .3 Seleção . . . . . . . . . . . . . . . . . . 48

2.4.4 Operadores Genéticos . . . . . . . . . . . . . 49

2.4.5 Parâmetros Genéticos ... . . . . . . . . . 51

2.5 Considerações Finais . . . . . . . . . . . . . . . 52 
3 Extração de Conhecimento em Técnicas de AM Caixa-Preta

3.1 Métodos Pedagógicos . . . . . . . . . . . . . . . . 54

3.2 Métodos Decomposicionais . . . . . . . . . . . . . 55

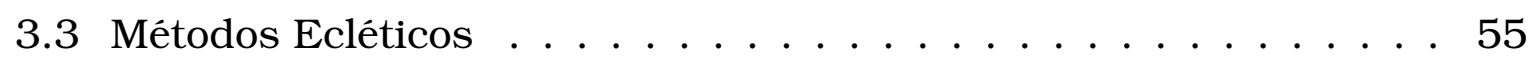

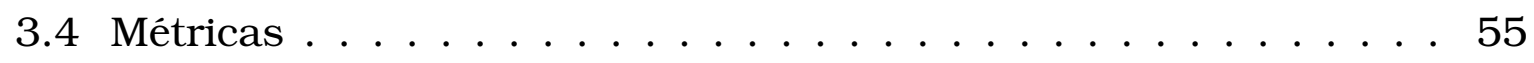

3.5 Extração de Conhecimento de SVMs . . . . . . . . . . . . . . 56

3.6 Sistema NNRules . . . . . . . . . . . . . . . . . . 58

3.6.1 Método baseado em Aprendizado de Máquina Simbólico . . 58

3.6.2 Método Baseado em Algoritmos Genéticos . . . . . . . . 59

3.7 Considerações Finais . . . . . . . . . . . . . . . 60

4 Método Proposto $\quad 61$

4.1 Descrição do Método RankSim . . . . . . . . . . . . . . . . 62

4.2 Função de Avaliação . . . . . . . . . . . . . . . . . . 64

4.3 Características do Algoritmo Genético . . . . . . . . . . . . 64

4.4 Considerações Finais . . . . . . . . . . . . . . . 65

5 Experimentos Realizados $\quad 67$

5.1 Fase I - Estudo preliminar de extração de regras de RNAs e SVMs por métodos de AM e AGs . . . . . . . . . . . . . . . 67

5.1.1 Identificação de Promotores e Sítios de Splice . . . . . . . 67

5.1 .2 Conjuntos de Dados . . . . . . . . . . . . . . 68

5.1 .3 Experimentos . . . . . . . . . . . . . . 69

5.1 .4 Resultados ....................... 70

5.2 Fase II - Experimentos com o método RankSim . . . . . . . . 75

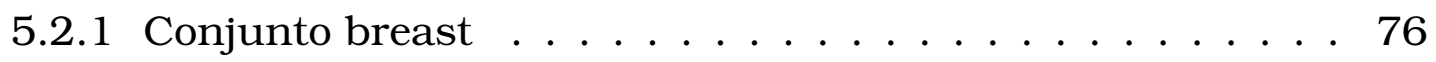

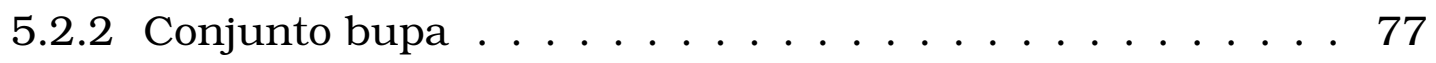

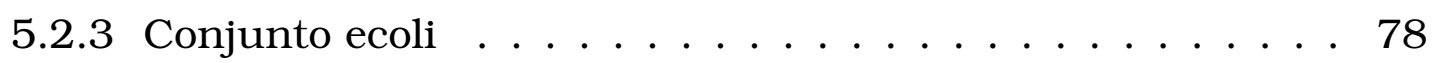

5.2 .4 Conjunto flag . . . . . . . . . . . . . . 79

5.2 .5 Conjunto flare $\ldots \ldots \ldots \ldots$. . . . . . 80

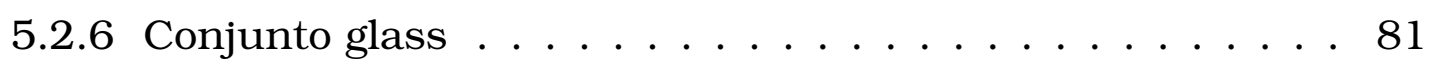

5.2 .7 Conjunto haberman . . . . . . . . . . . 81

5.2 .8 Conjunto heart . . . . . . . . . . . . . . 82

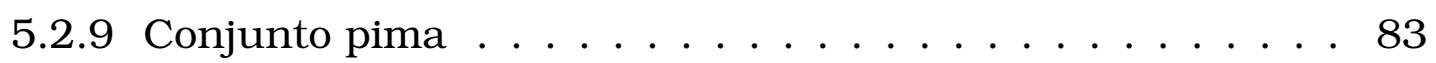

5.2 .10 Conjunto ionosphere . . . . . . . . . . 84

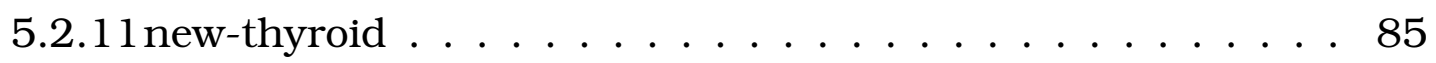

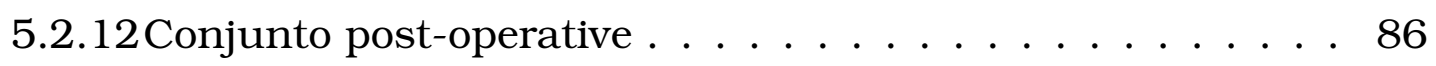

5.2 .13 Conjunto satimage $\ldots \ldots \ldots \ldots 6$

5.2 .14 Conjunto spliceN $\ldots \ldots \ldots \ldots$. . . . . . . . 87

5.2 .15 Conjunto spliceEI $\ldots \ldots \ldots \ldots$ 


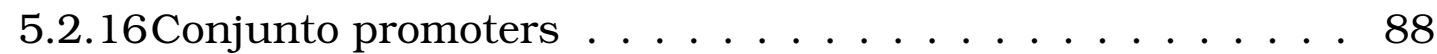

5.2 .17 Conjunto german . . . . . . . . . . . . . . 89

5.3 Considerações Finais $\ldots \ldots \ldots$. . . . . . . . . . . 90

6 Conclusão 95

6.1 Resumo dos objetivos e resultados . . . . . . . . . . . 95

6.2 Limitações . . . . . . . . . . . . . . . . . 96

6.3 Trabalhos futuros . . . . . . . . . . . . . . 96

$\begin{array}{ll}\text { Referências } & 97\end{array}$ 



\section{Lista de Algoritmos}

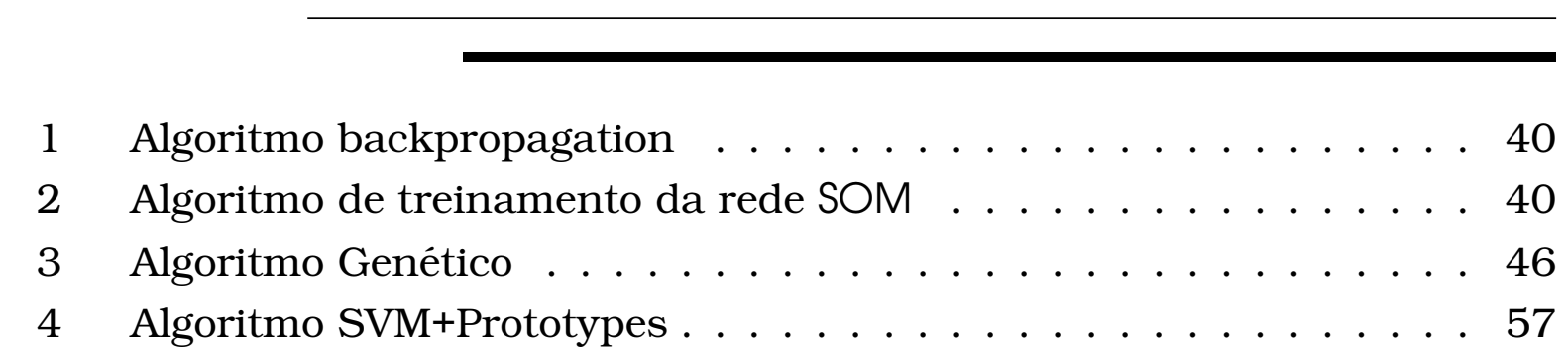





\section{Lista de Figuras}

2.1 Árvore de Decisão. . . . . . . . . . . . . . . . . . . . . . . . . . . . 32

2.2 Rede Perceptron. . . . . . . . . . . . . . . . . . . . 38

2.3 Rede Neural MLP. . . . . . . . . . . . . . . . . . . . . . . . . . 39

2.4 Rede Neural SOM. . . . . . . . . . . . . . . . . . . . . . 41

2.5 Um conjunto de dados linearmente separável. . . . . . . . . . . . 41

2.6 Duas formas de separar o mesmo conjunto de dados. O hiperplano de a) não maximiza as margens de separação enquanto do de b) determina uma grande margem de separação entre a fronteira de decisão e os exemplos. . . . . . . . . . . . . . . . . 42

2.7 Método de seleção por torneio. . . . . . . . . . . . . . . . . . . . 49

2.8 Exemplo de mutação. . . . . . . . . . . . . . . . . . . 50

2.9 Exemplo de cruzamento de um ponto. . . . . . . . . . . . . 50

2.10 Exemplo de cruzamento de dois pontos. . . . . . . . . . 51

2.11 Um exemplo de Cruzamentouniforme. . . . . . . . . . . . . . 51

3.1 Esquema geral do método baseado em sistemas de AM simbólicos. 58

3.2 Esquema geral do método baseado em AGs. . . . . . . . . . . . . 59

4.1 Método RankSim . . . . . . . . . . . . . . . . . . . . . 66 



\section{Lista de Tabelas}

2.1 Tabela atributo valor com exemplos para classificação. . . . . . . 29

2.2 Tabela atributo valor com exemplos para regressão. . . . . . . . . 30

2.3 Tabela atributo valor com exemplos para agrupamento. . . . . . . 31

2.4 Conjunto de dados Viagem. . . . . . . . . . . . . . . . . . . 34

2.5 Conjunto de regras ordenadas para o conjunto de dados Viagem. 35

2.6 Conjunto de regras não ordenadas para o conjunto de dados Vi-

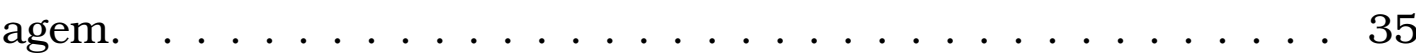

2.7 Regras não ordenadas com o índice do poder de predição das regras. . . . . . . . . . . . . . . . . 36

4.1 Operação de Cruzamento . . . . . . . . . . . . . . . . 65

5.1 Taxa de Erro (média e desvio padrão)(\%). . . . . . . . . . . . . . 70

5.2 Taxa de infidelidade (RNAs - média e desvio padrão)(\%). . . . . . . 71

5.3 Taxa de infidelidade (SVMs - média e desvio padrão)(\%). . . . . . . 71

5.4 Número de regras induzidas (RNAs - média e desvio padrão). . . . 71

5.5 Número de regras induzidas (SVMs - média e desvio padrão). . . . 71

5.6 Número médio de condições por regra induzida (RNAs - média e desvio padrão) . . . . . . . . . . . . . . . . . . . . . 72

5.7 Número médio de condições por regra induzida (SVMs - média e desvio padrão) . . . . . . . . . . . . . . . . . . . . . 72

5.8 Resultados do 10-Fold Cross-Validated Paired t Test (RNAs). . . . . 73

5.9 Resultados do 10-Fold Cross-Validated Paired t Test (SVMs). . . . . 74

5.10 Comparação da aplicação de métodos de extração de regras em RNAs e em SVMs). . . . . . . . . . . . . . . . . . . . . . . . . . . . 74

5.11 Descrição dos Conjuntos de Dados . . . . . . . . . . . . . 76

5.12 Conjunto breast - Acurácia e Fidelidade (\%). . . . . . . . . . . . 77

5.13 Conjunto breast - Número de Regras. . . . . . . . . . . . . . 77

5.14 Conjunto breast - Número de Condições por Regra. . . . . . . . . 77

5.15Conjunto bupa - Acurácia e Fidelidade (\%). . . . . . . . . . . 77

5.16 Conjunto bupa - Número de Regras. . . . . . . . . . . . . . . 78

5.17 Conjunto bupa - Número de Condições por Regra. . . . . . . . . . 78 
5.18Conjunto ecoli - Acurácia e Fidelidade (\%). . . . . . . . . . 78

5.19 Conjunto ecoli - Número de Regras. . . . . . . . . . . . . . . . . 79

5.20 Conjunto ecoli - Número de Condições por Regra. . . . . . . . . 79

5.21 Conjunto flag - Acurácia e Fidelidade (\%). . . . . . . . . . . . 79

5.22 Conjunto flag - Número de Regras. . . . . . . . . . . . . . . 79

5.23 Conjunto flag - Número de Condições por Regra. . . . . . . . . . 80

5.24 Conjunto flare - Acurácia e Fidelidade (\%). . . . . . . . . . . 80

5.25 Conjunto flare - Número de Regras. . . . . . . . . . . . . 80

5.26 Conjunto flare - Número de Condições por Regra. . . . . . . . . 81

5.27 Conjunto glass - Acurácia e Fidelidade (\%). . . . . . . . . . . 81

5.28 Conjunto glass - Número de Regras. . . . . . . . . . . . . . 81

5.29 Conjunto glass - Número de Condições por Regra. . . . . . . . . 81

5.30 Conjunto haberman - Acurácia e Fidelidade (\%). . . . . . . . . 82

5.31 Conjunto haberman - Número de Regras. . . . . . . . . . . . 82

5.32 Conjunto haberman - Número de Condições por Regra. . . . . . . 82

5.33 Conjunto heart - Acurácia e Fidelidade (\%). . . . . . . . . 83

5.34 Conjunto heart - Número de Regras. . . . . . . . . . . . . 83

5.35 Conjunto heart - Número de Condições por Regra. . . . . . . . . 83

5.36 Conjunto pima - Acurácia e Fidelidade (\%). . . . . . . . . . 83

5.37 Conjunto Pima - Número de Regras. . . . . . . . . . . . . 84

5.38 Conjunto Pima - Número de Condições por Regra. . . . . . . . . 84

5.39 Conjunto ionosphere - Acurácia e Fidelidade (\%). . . . . . . . . 84

5.40 Conjunto ionosphere - Número de Regras. . . . . . . . . . . . 84

5.41 Conjunto ionosphere - Número de Condições por Regra. . . . . . . 85

5.42 Conjunto new-thyroid - Acurácia e Fidelidade (\%). . . . . . . 85

5.43 Conjunto new-thyroid - Número de Regras. . . . . . . . . . . 85

5.44 Conjunto new-thyroid - Número de Condições por Regra. . . . . . 85

5.45 Conjunto post-operative - Acurácia e Fidelidade (\%). . . . . . . 86

5.46 Conjunto post-operative - Número de Regras. . . . . . . . . . 86

5.47 Conjunto post-operative - Número de Condições por Regra. . . . . 86

5.48 Conjunto satimage - Acurácia e Fidelidade (\%). . . . . . . . 87

5.49 Conjunto satimage - Número de Regras. . . . . . . . . . . 87

5.50 Conjunto satimage - Número de Condições por Regra. . . . . . . 87

5.51 Conjunto spliceN - Acurácia e Fidelidade (\%). . . . . . . . . . 87

5.52 Conjunto spliceN - Número de Regras. . . . . . . . . . . . 88

5.53 Conjunto spliceN - Número de Condições por Regra. . . . . . . . 88

5.54 Conjunto spliceEI - Acurácia e Fidelidade (\%). . . . . . . . . . 88

5.55 Conjunto spliceEI - Número de Regras. . . . . . . . . . . . . 88

5.56 Conjunto spliceEI - Número de Condições por Regra. . . . . . . 89 
5.57 Conjunto promoters - Acurácia e Fidelidade (\%). . . . . . . . . . . 89

5.58 Conjunto promoters - Número de Regras. . . . . . . . . . . . . . . 89

5.59 Conjunto promoters - Número de Condições por Regra. . . . . . . 89

5.60 Conjunto german - Acurácia e Fidelidade (\%) . . . . . . . . . . . . 90

5.61 Conjunto german - Número de Regras. . . . . . . . . . . . . . . . . 90

5.62 Conjunto german - Número de Condições por Regra. . . . . . . . . 90

5.63 Acurácia e Fidelidade(\%) . . . . . . . . . . . . . 91

5.64 Número de Regras . . . . . . . . . . . . . . . . . . . 91

5.65 Número de Condições por Regra . . . . . . . . . . . . . . . . . . 92

5.66 Fidelidade: RankSim Original, RankSim Rotulado e NNRules . . . 93 



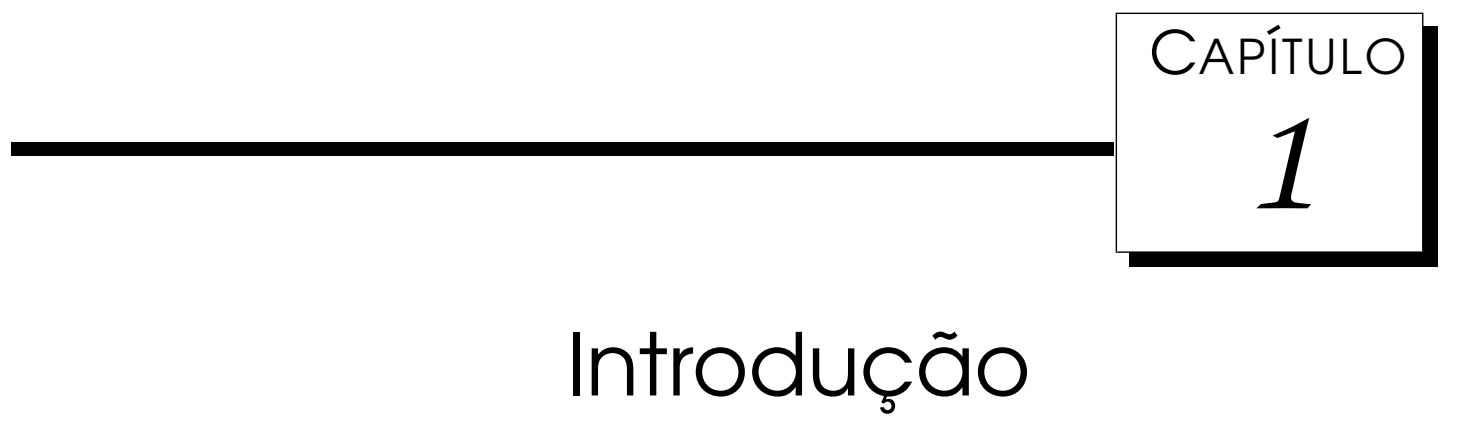

écnicas de Inteligência Artificial têm sido amplamente utilizadas para
a resolução de problemas em diversos domínios. Como exemplo, po-
demos citar a análise de dados biológicos. Dentre elas, destacamse as técnicas de Aprendizado de Máquina, que são capazes de formular descrições de conceitos a partir de exemplos (Mitchel, 1997).

Redes Neurais Artificiais (RNAs) (Braga et al., 2000; Haykin, 1998) e Classificadores de Margens Largas (Lorena and de Carvalho, 2003), como as Máquinas de Vetores de Suporte (Support Vector Machines - SVM) (Cristianini and Shawe-Taylor, 2000), são técnicas não-simbólicas de aprendizado de máquina que têm sido utilizadas com sucesso para a solução de diversos problemas reais. Essas técnicas são consideradas como "caixas-pretas", pela dificuldade em explicar como elas chegam aos seus resultados.

Muitos problemas de análise de dados podem ser modelados como problemas de classificação ${ }^{1}$. Em certos casos, explicitar o conhecimento utilizado para a classificação é mais importante do que a própria classificação. Por isso, em técnicas não-simbólicas de aprendizado de máquina, é possível realizar uma explicação do conhecimento armazenado internamente por essas técnicas com base na extração de representações simbólicas desse conhecimento.

Existem diversos trabalhos que abordam esse tema (Fu, 1991; Hayashi, 1991; Towell and Shavlik, 1993; Craven and Shavlik, 1994b; Fu, 1994; Sethi and Yoo, 1994; Tan, 1994; Thrun, 1994; Tickle et al., 1994; Alexander and Dietterich, 1995; Setiono and Liu, 1995; Thrun, 1995; Craven, 1996; Milaré et al., 1997; Schellharmmer et al., 1997; Tickle et al., 1998; Martineli, 1999; Schmitz et al., 1999; Duch et al., 2000; Behloul et al., 2002; Zhou and Jiang, 2002; Milaré et al., 2002; Núñez et al., 2002; Fung et al., 2008).

\footnotetext{
${ }^{1}$ Dados exemplos de um conceito, um algoritmo de Aprendizado de Máquina induz um classificador que é então utilizado para predizer a classe de novos exemplos.
} 
Porém, os métodos propostos possuem um grande número de deficiências. Craven and Shavlik (1999) identificaram que a escalabilidade ${ }^{2}$ e a generalidade $^{3}$ são métricas que não foram contempladas na grande maioria dos métodos desenvolvidos. Milaré et al. (2002) também relatou que essas ainda são questões em aberto. Além disso, existem outras deficiências relacionadas à qualidade das representações extraídas por esses métodos, que são descritas na Seção 1.1.

Portanto, é necessário investigar alternativas para melhorar a qualidade das representações obtidas e reduzir o tempo de execução dos algoritmos atualmente utilizados para este fim. Essa qualidade pode ser medida por meio de métricas como compreensibilidade, fidelidade, precisão, escalabilidade e generalidade, além de outras que serão descritas na Seção 3.4 dessa Tese.

Essa Tese investiga métodos para explicar como os classificadores induzidos por técnicas não-simbólicas de aprendizado de máquina realizam as classificações e propõe um novo método pedagógico que utiliza um algoritmo genético para extrair regras de modelos de aprendizado de máquina caixapreta. A novidade do método está na avaliação da similaridade entre rankings de confiabilidade gerados para o modelo caixa-preta e os rankings gerados para os indivíduos do algoritmo genético, que representam os possíveis conjuntos de regras extraídos.

Dentre as técnicas não-simbólicas de aprendizado de máquina, a enfase foi conferida aos Classificadores de Margens Largas, em especial às Support Vector Machines - SVMs, pois sua aplicação em diversos domínios como Bioinformática e Mineração de Textos é promissora, possuindo diversos resultados relevantes publicados (Jackson, 1995; Furey et al., 2000; Zien et al., 2000; Ben-Hur et al., 2000; Ding and Dubchak, 2001; Huss et al., 2001; Mukherjee and Mukherjee, 2002; Lorena et al., 2002) e a extração de representações simbólicas de conhecimento para essas técnicas ainda está em sua infância.

\section{1 Justificativa}

É de grande importância para várias aplicações reais investigar alternativas eficientes para a extração de conhecimento para técnicas não-simbólicas de Aprendizado de Máquina, pois podem elevar a compreensibilidade do conhecimento adquirido por essas técnicas.

Em vários domínios, as SVMs, que induzem classificadores não-simbólicos,

\footnotetext{
${ }^{2} \mathrm{~A}$ escalabilidade se refere a como o tempo de execução e a compreensibilidade dos modelos extraídos variam em função de fatores como dimensionalidade, tamanho do conjunto de treinamento e complexidade do método de aprendizado de máquina.

${ }^{3}$ Generalidade é a proporção em que o algoritmo de extração de conhecimento não requer treinamentos especiais ou restrições no método de aprendizado de máquina.
} 
têm obtido taxas de acerto superiores às obtidas por outras técnicas (Zien et al., 2000; Ding and Dubchak, 2001).

Porém, seres humanos têm dificuldade em entender as representações internas utilizadas por técnicas não-simbólicas de Aprendizado de Máquina. Portanto, para fazer proveito das vantagens dessas técnicas no entendimento dos mecanismos utilizados por vários modelos de classificação é necessário algum processo de extração de conhecimento que gere representações mais compreensiveis, mas que mantenham fidelidade com o método não-simbólico originalmente utilizado. Entretanto, no início de nossa pesquisa, não foram encontrados na literatura métodos de extração de conhecimento específicos para Classificadores de Margens Largas. Somente durante o desenvolvimentos dessa pesquisa é que foram surgindo métodos específicos.

Além disso, os métodos existentes até então para a extração de conhecimento de RNAs possuem várias deficiências. Dentre elas podem ser citadas:

- Em métodos decomposicionais, a dificuldade de se associar uma função determinada a um neurônio individual de uma Rede Neural Artificial, devido ao fato de que muitas vezes o conhecimento encontra-se distribuído na rede.

- Em métodos pedagógicos, não há garantias de que as representações extraídas expressem a forma pela qual a Rede Neural Artificial realiza a classificação, pois não fazem nenhuma análise dos parâmetros internos da rede e se a performance de classificação da RNA for elevada, o conjunto de dados por ela rotulado será tão parecido com o conjunto de dados original que pouca informação pode ser extraída sobre a forma utilizada pela RNA para realizar sua classificação.

- Métodos ecléticos não solucionam os problemas das duas anteriores e geralmente são complexos e ineficientes.

\subsection{Organização da Tese}

Esse capítulo apresentou o projeto de pesquisa abordando a sua motivação, objetivos e justificativa. O Capítulo 2 apresentará uma visão geral sobre a área de Aprendizado de Máquina. O Capítulo 3 contém revisão sobre a extração de conhecimento para métodos de Aprendizado de Máquina não-simbólicos. $\mathrm{O}$ Capítulo 4 apresentará o método de extração de conhecimento para técnicas de aprendizado de máquina caixa-preta proposto nessa tese. O Capítulo 5 descreverá os experimentos realizados, discutindo seus resultados. Por fim, o 
Capítulo 6 conclui a tese com algumas considerações sobre o atual estágio do trabalho. 

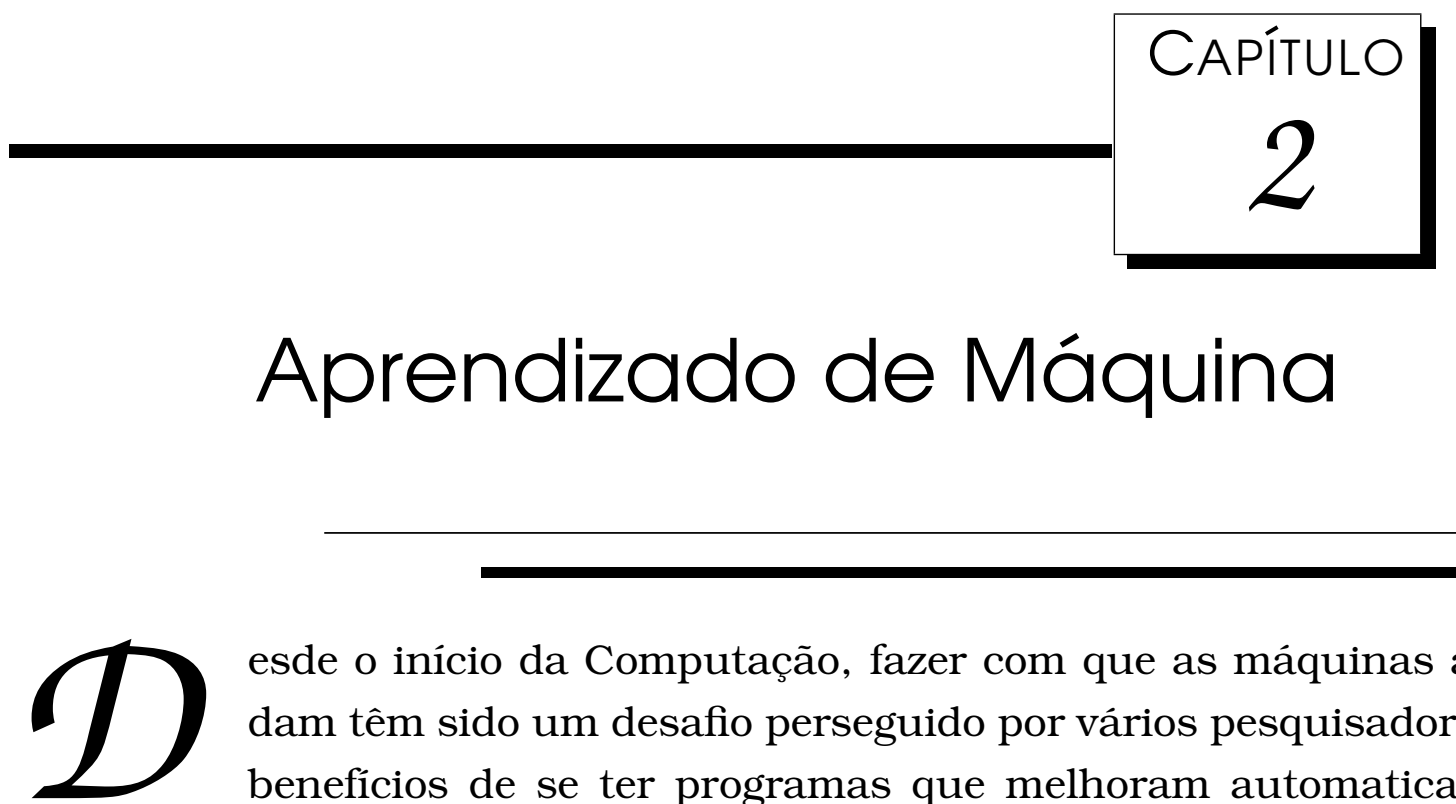

esde o início da Computação, fazer com que as máquinas aprendam têm sido um desafio perseguido por vários pesquisadores. Os benefícios de se ter programas que melhoram automaticamente através de experiência são inestimáveis. Alguns avanços têm sido realizados em direção a esse objetivo e a linha de pesquisa que aborda esse tema é chamada Aprendizado de Máquina (AM) (Mitchel, 1997).

Nesse trabalho, o principal interesse está na tarefa particular de aprender (induzir) funções gerais a partir de exemplos de treinamento. Os paradigmas de aprendizado por exemplos mais utilizados são o aprendizado supervisionado, o aprendizado não-supervisionado e o aprendizado por reforço. Na Seção 2.1 são descritos esses três paradigmas.

A área de AM pode ser dividida em duas grandes sub-áreas: Aprendizado de Máquina simbólico e Aprendizado de Máquina não-simbólico ou subsimbólico. As técnicas de AM simbólico são aquelas em que o conhecimento aprendido é representado em uma forma de fácil compreensão por seres humanos. Exemplos dessas técnicas incluem os algoritmos de indução de árvores de decisão e regras de decisão (ver Figura 2.1 e Tabela 2.5). Já as técnicas de AM não-simbólico utilizam representações de dificil compreensão por seres humanos, em sua maioria, modelos matemáticos complexos. Por esse motivo, essas técnicas são usualmente chamadas de técnicas caixa-preta. Redes Neurais Artificiais (RNAs) (Braga et al., 2000; Haykin, 1998) e Máquinas de Vetores de Suporte (Support Vector Machines - SVMs) (Cristianini and Shawe-Taylor, 2000) são exemplos destas técnicas.

Não se pode dizer que uma única dessas técnicas é superior às outras para todos os casos. Portanto, para cada problema de aprendizado, devese analisar qual técnica possui as melhores características para lidar com o problema. As características que fazem uma técnica de aprendizado ser 
melhor para determinados tipos de problema são coletivamente chamadas na literatura da área de bias indutivo (Mitchel, 1997).

Para muitos problemas, como os de análise de conjuntos de dados de alta dimensionalidade, as técnicas de AM não-simbólico possuem um bias indutivo mais apropriado. Por exemplo, em análise de expressão gênica, as bases de dados são grandes e de alta dimensionalidade (milhares de atributos). Muitos métodos tradicionais têm dificuldades em lidar com esse tipo de dados enquanto as SVMs são apropriadas para lidar com dados de alta dimensionalidade (Furey et al., 2000; Brown et al., 2000; Ding and Dubchak, 2001). Porém, para muitos destes problemas, o entendimento do conhecimento adquirido pela técnica para a resolução do problema é de grande importância. Surgiu então a necessidade da elaboração de métodos de extração de conhecimento para técnicas de AM não-simbólico. Esses métodos são discutidos no Capítulo 3.

Nas Seções 2.2 e 2.3, serão apresentadas algumas técnicas de AM, tanto simbólico como não-simbólico, com o objetivo de dar ao leitor um maior entendimento das diferentes abordagens empregadas e a Seção 2.5 conclui o capítulo com algumas considerações finais.

\section{1 Paradigmas de Aprendizado}

De acordo com o tipo da tarefa de aprendizado e as informações disponíveis para o treinamento, é possivel dividir as técnicas de aprendizado de máquina em três paradigmas: aprendizado supervisionado, aprendizado não-supervisionado e aprendizado por reforço. Nessa seção esses três paradigmas serão sucintamente apresentados.

\subsubsection{Aprendizado Supervisionado}

No aprendizado supervisionado, é apresentado ao sistema de aprendizado um conjunto de exemplos rotulado. Isso significa que entre os vários atributos de um exemplo, um é destinado à saída desejada, o rótulo. Ou seja, há um mapeamento explícito entre os atributos do exemplo e a saída correta que o sistema de aprendizado, após treinado, deve retornar ao lhe ser apresentado o exemplo. Ele é chamado de aprendizado supervisionado pois é como se houvesse um professor informando qual a saída correta para cada exemplo.

O aprendizado supervisionado pode ser ainda dividido em dois grupos, classificação e regressão, de acordo com o tipo de saída retornada pelo sistema de aprendizado.

Nas tarefas de classificação, o sistema de aprendizado possui um conjunto discreto e determinado de saídas possíveis. O tipo mais simples de 
classificação é a que tem saída binária, ou seja, a que pode retornar apenas uma entre duas classes: sim ou não; 0 ou 1; presente ou ausente; etc. Existe também a classificação multi-classes, em que mais de duas classes são possíveis para a saída: Vermelho, Verde ou Azul; 0, 1, 2, 3 ou 4; Adenina (A), Citosina (C), Guanina (G) e Timina (T); etc. Finalmente, existe a classificação hierárquica, em que as classes obedecem uma hierarquia. Nesse tipo de classificação, os exemplos são classificados em classes de uma árvore de categorias. Em uma árvore de categorias, cada nó corresponde a uma classe. Como resultado, existe um relacionamento hierárquico entre as classes representadas pela árvore.

Já em tarefas de regressão, a saída do sistema de aprendizado é um valor contínuo. Exemplos: Altura de uma pessoa, variando numa faixa entre 1,00m até 2,55m; O ângulo que um robô deve girar para seguir uma rota, variando entre 0 e 360 graus.

Os sistemas de aprendizado normalmente utilizam uma base de exemplos para realizar a etapa de treinamento. Nessa etapa, os exemplos são apresentados ao sistema de aprendizado para que ele formule sua hipótese sobre a função alvo a ser aprendida. Esses exemplos geralmente são representados na forma de tabelas atributo-valor. Um exemplo de uma tabela atributo-valor para a tarefa de classificação binária está na Tabela 2.1. Os atributos (Qualidade, Entrega, Preço, Pagamento e Garantia) de cada exemplo representam as condições de compra de um produto analisadas por um cliente. A última coluna, o rótulo, representa a decisão tomada pelo cliente. Nesse caso, o objetivo do sistema é prever se o cliente irá ou não comprar um produto, dadas determinadas condições.

\begin{tabular}{c|c|c|c|c|c|c} 
Exemplo & Qualidade & Entrega & Preço & Pagamento & Garantia & Comprar \\
\hline \hline 1 & Alta & Imediata & Alto & A vista & 1 ano & Sim \\
\hline 2 & Baixa & Imediata & Alto & Parcelado & 6 meses & Não \\
\hline 3 & Alta & 30 dias & Alto & Parcelado & 1 ano & Não \\
\hline 4 & Média & Imediata & Alto & A vista & 2 anos & Sim \\
\hline 5 & Média & 30 dias & Baixo & Parcelado & 1 ano & Não \\
\hline 6 & Baixa & Imediata & Baixo & A vista & 1 ano & Sim \\
\hline 7 & Alta & 30 dias & Baixo & Parcelado & 2 anos & Sim \\
\hline 8 & Média & 30 dias & Baixo & Parcelado & 1 ano & Não \\
\hline 9 & Baixa & 30 dias & Baixo & A vista & 6 meses & Não
\end{tabular}

Tabela 2.1: Tabela atributo valor com exemplos para classificação.

Um exemplo de uma tabela atributo-valor para a tarefa de regressão está na Tabela 2.2. O atributo Ângulo é a entrada e o rótulo Seno é a saída da função 
Seno(Ângulo). Nesse caso, o objetivo do sistema de aprendizado é induzir uma função que aproxima a função Seno.

\begin{tabular}{c|r|r} 
Exemplo & Ângulo & Seno \\
\hline \hline 1 & 0 & 0 \\
\hline 2 & 30 & 0,5 \\
\hline 3 & 60 & 0,86603 \\
\hline 4 & 90 & 1 \\
\hline 5 & 120 & 0,86603 \\
\hline 6 & 150 & 0,5 \\
\hline 7 & 180 & 0 \\
\hline 8 & 210 & $-0,5$ \\
\hline 9 & 240 & $-0,86603$ \\
\hline 10 & 270 & -1 \\
\hline 11 & 300 & $-0,86603$ \\
\hline 12 & 330 & $-0,5$ \\
\hline 13 & 360 & 0
\end{tabular}

Tabela 2.2: Tabela atributo valor com exemplos para regressão.

\subsubsection{Aprendizado Não-Supervisionado}

No aprendizado não-supervisionado, os exemplos de treinamento não são rotulados, ou seja, a função a ser aprendida não é definida explicitamente. Ao invés disso, o sistema de aprendizado deve descobrir padrões nos dados que permitam agrupar os exemplos apresentados. O número de grupos formado pode ser definido pelo usuário do sistema de aprendizado, ou o próprio sistema pode tentar descobrir quantos grupos devem ser formados. Essa tarefa, o agrupamento, é mais conhecida na comunidade por seu nome em inglês: clustering.

O agrupamento pode ser utilizado em bioinformática, por exemplo, para agrupar genes que tenham função semelhante, facilitando a descoberta da função de novos genes.

No aprendizado não-supervisionado também são usadas tabelas atributovalor para a fase de treinamento. A Tabela 2.3 apresenta um exemplo de tabela atributo valor para o aprendizado não-supervisionado. Essa tabela foi baseada no conjunto de dados Íris, do Repositório de AM da UCI (Blake and Merz, 1998). As entradas representam os valores de 4 atributos: comprimento da sépala, largura da sépala, comprimento da pétala e largura da pétala. Todos os valores estão em formato contínuo (ponto flutuante) com uma casa decimal. Os exemplos estão distribuídos em 3 grupos de flores: Íris setosa, 
Íris versicolor e Íris virginica. Porém, como pode ser observado, não há um rótulo na tabela para indicar o tipo de flor.

\begin{tabular}{c|c|c|c|c} 
Exemplo & Comp. Sépala & Larg. Sépala & Comp. Pétala & Larg. Pétala \\
\hline \hline 1 & 5.1 & 3.5 & 1.4 & 0.2 \\
\hline 2 & 4.9 & 3.0 & 1.4 & 0.2 \\
\hline 3 & 4.7 & 3.2 & 1.3 & 0.2 \\
\hline 4 & 5.0 & 3.6 & 1.4 & 0.2 \\
\hline 5 & 7.0 & 3.2 & 4.7 & 1.4 \\
\hline 6 & 6.4 & 3.2 & 4.5 & 1.5 \\
\hline 7 & 6.9 & 3.1 & 4.9 & 1.5 \\
\hline 8 & 5.5 & 2.3 & 4.0 & 1.3 \\
\hline 9 & 6.3 & 3.3 & 6.0 & 2.5 \\
\hline 10 & 5.8 & 2.7 & 5.1 & 1.9 \\
\hline 11 & 7.1 & 3.0 & 5.9 & 2.1 \\
\hline 12 & 6.3 & 2.9 & 5.6 & 1.8
\end{tabular}

Tabela 2.3: Tabela atributo valor com exemplos para agrupamento.

\subsubsection{Aprendizado por Reforço}

O aprendizado por reforço pode ser considerado como um caso especial do aprendizado supervisionado. A diferença entre eles reside no fato de que, no aprendizado por reforço, não é informado ao sistema de AM a resposta correta para os padrões de entrada, apenas lhe é informado se uma determinada resposta é satisfatória ou não.

Durante o treinamento, a cada ação que leva a estados satisfatórios, o sistema de AM reforça a tendência do sistema em realizar a ação em questão. O contrário ocorre com ações que não levem a estados satisfatórios, ou seja, a tendência do sistema em realizar estas ações é enfraquecida (Braga et al., 2000).

Esta Tese não entra em detalhes sobre o aprendizado por reforço e o aprendizado não-supervisionado pois esses temas estão fora do escopo deste trabalho.

\subsection{Aprendizado de Máquina Simbólico}

Como dito anteriormente, as técnicas de AM simbólico são aquelas em que o conhecimento adquirido pelo sistema de aprendizado é representado em uma forma de fácil compreensão por seres humanos. Nessa seção serão apresentados duas das mais conhecidas técnicas de AM simbólico: Árvores de Decisão e Regras de Decisão. 


\subsection{1 Árvores de Decisão}

Árvores de Decisão são utilizadas para a tarefa de classificação de padrões (aprendizado supervisionado). Uma Árvore de Decisão é uma estrutura de dados em que cada nó intermediário representa um teste com um ou mais atributos e cada nó folha representa uma decisão. O resultado do teste em um nó define por qual filho deste nó o processo de decisão deve continuar. Para decidir a classe de um determinado padrão, começa-se pela raiz da árvore e segue-se efetuando testes até que se chegue a um nó folha. Um exemplo de uma árvore de decisão pode ser visto na Figura 2.1. Essa figura mostra uma árvore de decisão para classificar tipos de veículos.

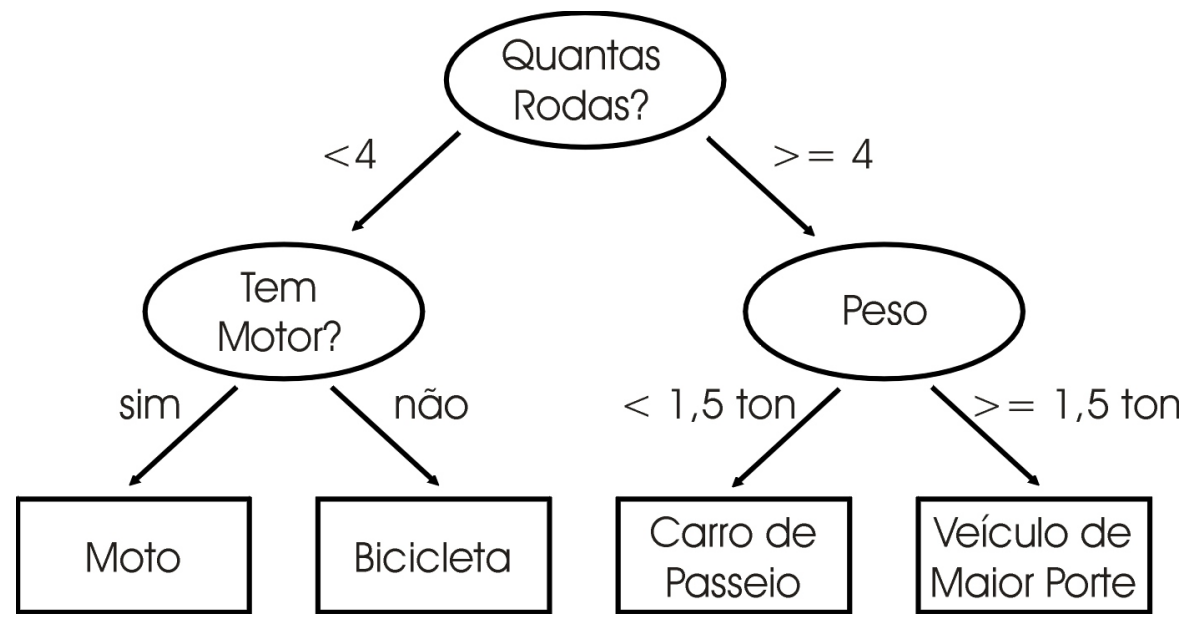

Figura 2.1: Árvore de Decisão.

Para obter uma árvore de decisão para classificar padrões a partir de um certo conjunto de exemplos, é realizado um processo chamado indução de árvores de decisão. Existem diversos algoritmos para realizar a indução de árvores de decisão. Um dos mais conhecidos é o algoritmo C4.5 (Quinlan, 1988).

Assim como o C4.5, a maioria dos algoritmos para indução de árvores de decisão são variações de um algoritmo guloso (greedy) básico, que faz uma busca top-down no espaço de possíveis árvores de decisão (Mitchel, 1997).

Esse algoritmo básico começa escolhendo qual atributo será testado na raiz da árvore. Para isso, todos os atributos são avaliados estatisticamente para determinar quão bem cada atributo, individualmente, classifica os exemplos de treinamento. O melhor é selecionado e utilizado como teste na raiz da árvore. Nós filhos são criados para cada possível valor deste atributo. Os exemplos de treinamento são então divididos entre os nós filhos de acordo com o resultado do teste do nó raiz. O processo é então repetido para cada nó filho, utilizando os exemplos a eles designados. Um nó folha é criado quando 
apenas exemplos de uma única classe são designados a um nó filho. A classe desses exemplos é atribuída a esse nó folha e o processo não é repetido para esse nó.

\subsubsection{Regras de Decisão}

Um conjunto de regras de decisão é uma outra forma de representar o conhecimento adquirido através do treinamento de um sistema de aprendizado simbólico.

Elas podem ser obtidas diretamente do conjunto de exemplos, ou podem ser geradas a partir de uma árvore de decisão. No último caso, cada caminho que parte do nó raiz da árvore de decisão e alcança um nó folha corresponde a uma regra. O algoritmo C4.5rules (Quinlan, 1988) emprega essa abordagem e, além disso, ele generaliza as regras apagando condições irrelevantes que não afetam a conclusão. Já o algoritmo CN2 (Clark and Niblett, 1989a) é um exemplo de algoritmo que induz regras diretamente dos exemplos de treinamento.

Regras de decisão podem ser divididas em dois tipos: regras ordenadas e regras não ordenadas. A seguir serão discutidos esses dois tipos de regras.

\section{Regras Ordenadas}

Nas regras ordenadas, a ordem das regras é importante para a decisão da classe de um exemplo por elas classificado. Começa-se confrontando o exemplo com a primeira regra e se as condições da regra não forem satisfeitas pelo exemplo, segue-se confrontando o exemplo com as outras regras, em ordem, até que as condições de uma das regras do conjunto sejam satisfeitas pelo exemplo, ou acabem as regras induzidas. Nesse caso, a regra padrão, normalmente associada à classe majoritária ${ }^{1}$, é utilizada para classificar o exemplo. Caso as condições de alguma regra sejam satisfeitas, o processo pára e o exemplo é classificado segundo a classe atribuída à conclusão da regra.

Para induzir um conjunto de regras ordenadas a partir dos exemplos de treinamento, costuma-se utilizar a seguinte abordagem. A cada iteração, busca-se por um conjunto de condições que cubram positivamente muitos exemplos do conjunto de treinamento e cubram negativamente poucos ou nenhum exemplo. Cobrir positivamente um exemplo significa que as condições da regra são satisfeitas pelo exemplo e que a classe do exemplo é a mesma da conclusão da regra. Cobrir negativamente significa que apesar de satisfeitas as condições da regra, a classe do exemplo é diferente da classe atribuída à conclusão da regra. Ao encontrar tal conjunto de condições, a regra gerada é adicionada a uma lista de regras e todos os exemplos do conjunto de treina-

\footnotetext{
${ }^{1}$ Classe que possui o maior número de exemplos no conjunto de treinamento.
} 
mento cobertos por essa regra são removidos, tanto os cobertos positivamente quanto os negativamente. O processo é repetido com os exemplos restantes, até que nenhum novo conjunto de condições possa ser encontrado ou não existam mais exemplos a serem cobertos.

Para facilitar a compreensão desse processo, será utilizado um exemplo adaptado de (Milaré, 2003). A Tabela 2.4 apresenta um conjunto de exemplos de treinamento em que cada linha é um exemplo representando um determinado dia. A classe de cada exemplo pode ser viajar ou ficar em casa, dependendo das condições meteorológicas daquele dia, representadas pelos atributos do exemplo.

\begin{tabular}{c|c|c|c|c|c} 
Exemplo & Tempo & Temperatura & Umidade & Vento & Viajar? \\
\hline \hline 1 & ensolarado & 25 & 72 & sim & viajar \\
\hline 2 & ensolarado & 28 & 91 & sim & ficar \\
\hline 3 & ensolarado & 22 & 70 & não & viajar \\
\hline 4 & ensolarado & 23 & 95 & não & ficar \\
\hline 5 & ensolarado & 30 & 85 & não & ficar \\
\hline 6 & nublado & 23 & 90 & sim & viajar \\
\hline 7 & nublado & 29 & 78 & não & viajar \\
\hline 8 & nublado & 19 & 65 & sim & ficar \\
\hline 9 & nublado & 26 & 75 & não & viajar \\
\hline 10 & nublado & 20 & 87 & sim & viajar \\
\hline 11 & chuvoso & 22 & 95 & não & viajar \\
\hline 12 & chuvoso & 19 & 70 & sim & ficar \\
\hline 13 & chuvoso & 23 & 80 & sim & ficar \\
\hline 14 & chuvoso & 25 & 81 & não & viajar \\
\hline 15 & chuvoso & 21 & 80 & não & viajar
\end{tabular}

Tabela 2.4: Conjunto de dados Viagem.

Na Tabela 2.5 é apresentado um conjunto de regras ordenadas induzido a partir desse conjunto de exemplos. Também são apresentados nessa tabela, ao lado de cada regra, os exemplos positivamente cobertos (PC) e os exemplos negativamente cobertos (NC).

\section{Regras Não Ordenadas}

A indução de regras não ordenadas começa com a escolha de uma classe. Em seguida, todas as regras para essa classe são induzidas e esse processo é repetido para todas as outras classes presentes no conjunto de dados.

Para cada classe, começa-se com o conjunto de dados completo e depois da indução de cada regra, removem-se os conjuntos por ela cobertos positivamente. Quando não for mais possível encontrar uma regra que cubra exem- 


\begin{tabular}{c|l|c|c} 
Regra & Condições e Conclusões & $P C$ & $N C$ \\
\hline \hline R1 & se umidade $<83$ então classe = viajar & $\begin{array}{c}1,3,7, \\
9,14,15\end{array}$ & $8,12,13$ \\
& & $2,4,5$ & 6 \\
\hline R2 & senão se temperatura $\geq 23$ então classe = ficar & 11 & \\
\hline R3 & senão se tempo = chuvoso então classe = viajar & 10 &
\end{tabular}

Tabela 2.5: Conjunto de regras ordenadas para o conjunto de dados Viagem.

plos dessa classe, ou quando não há mais exemplos dessa mesma classe, o processo de indução de regras para a próxima classe é iniciado.

O processo de indução de regras termina quando as regras para todas as classes do conjunto de dados tenham sido induzidas e é criada a regra padrão, que assume a classe majoritária e só é disparada caso nenhuma das outras regras sejam disparadas.

Um exemplo de conjunto de regras de decisão não ordenadas para o mesmo conjunto de dados da Tabela 2.4 é apresentado na Tabela 2.6, juntamente com os exemplos positivamente cobertos (PC) e negativamente cobertos (NC) de cada regra.

\begin{tabular}{|c|c|c|c|}
\hline Regra & Condições e Conclusões & PC & $\mathrm{NC}$ \\
\hline $\mathrm{R} 1$ & se tempo $=$ nublado então classe $=$ viajar & $6,7,9,10$ & 8 \\
\hline $\mathrm{R} 2$ & $\begin{array}{l}\text { se }(\text { tempo }=\text { chuvoso }) \wedge(\text { vento }=\text { não }) \text { então } \\
\text { classe }=\text { viajar }\end{array}$ & $11,14,15$ & \\
\hline R3 & $\begin{array}{l}\text { se }(\text { tempo }=\text { ensolarado }) \wedge(\text { umidade }>77) \text { então } \\
\text { classe }=\text { ficar }\end{array}$ & $2,4,5$ & \\
\hline R4 & $\begin{array}{l}\text { se }(\text { tempo }=\text { chuvoso }) \wedge(\text { vento }=\text { sim }) \text { então } \\
\text { classe }=\text { ficar }\end{array}$ & 12,13 & \\
\hline R5 & $\begin{array}{l}\text { se }(\text { tempo }=\text { nublado }) \wedge(\text { temperatura }<20) \text { então } \\
\text { classe }=\text { ficar }\end{array}$ & 8 & \\
\hline R6 & senão classe padrão = viajar & & \\
\hline
\end{tabular}

Tabela 2.6: Conjunto de regras não ordenadas para o conjunto de dados Viagem.

Uma vez que as regras não são ordenadas, para utilizar esse conjunto de regras para predizer a classe de um novo exemplo, deve-se verificar todas elas e determinar quais regras cobrem o novo exemplo. Porém, como o exemplo pode disparar regras que possuem conclusões diferentes, ou seja, classificam o exemplo em classes diferentes, um método para realizar o desempate entre as regras é necessário. Pode-se para isso, adicionar um índice do poder 
preditivo à cada regra.

Uma forma de criar esse índice consiste em contar o número de exemplos que a regra cobre positivamente e negativamente. Para isso, pode-se adicionar a cada regra, uma lista $\left[\eta_{C_{1}}, \eta_{C_{2}}, \ldots, \eta_{C_{N c l}}\right]$. Com $\eta_{C_{i}}$ sendo o total de exemplos da classe $C_{i}$ cobertos pela regra. Para exemplificar essa abordagem, foi adicionado ao conjunto de regras não ordenadas anteriormente induzido uma lista com as freqüências de cobertura de cada regra para cada classe. Isso pode ser visto na Tabela 2.7 .

\begin{tabular}{c|l|c} 
Regra & Condições e Conclusões & $\left(\eta_{\text {viajar }}, \eta_{\text {ficar }}\right)$ \\
\hline \hline R1 & se tempo = nublado então classe = viajar & {$[4,1]$} \\
\hline R2 & $\begin{array}{l}\text { se (tempo = chuvoso } \wedge \text { (vento = não) então } \\
\text { classe = viajar }\end{array}$ & {$[3,0]$} \\
\hline R3 & $\begin{array}{l}\text { se (tempo = ensolarado) } \wedge \text { (umidade }>77) \text { então } \\
\text { classe = ficar }\end{array}$ & {$[0,3]$} \\
\hline R4 & $\begin{array}{l}\text { se (tempo = chuvoso) } \wedge \text { (vento = sim) então } \\
\text { classe = ficar }\end{array}$ & {$[0,2]$} \\
\hline R5 & $\begin{array}{l}\text { se (tempo = nublado) } \wedge \text { (temperatura }<20) \text { então } \\
\text { classe = ficar }\end{array}$ & {$[0,1]$} \\
\hline R6 & senão classe padrão = viajar & {$[9,6]$}
\end{tabular}

Tabela 2.7: Regras não ordenadas com o índice do poder de predição das regras.

Se um novo exemplo disparar as regras R1 e R4, a cobertura total das duas regras será [4,3], uma vez que a regra R1 cobre 4 exemplos da classe viajar e 1 da classe ficar e a regra R4 não cobre nenhum da classe viajar e 2 da classe ficar. Nesse caso, a saída do sistema para esse exemplo será a classificação viajar.

\subsection{Aprendizado de Máquina Não-Simbólico}

Nessa seção serão apresentadas algumas técnicas de AM não-simbólico, que, como já citado, representam o conhecimento adquirido em uma forma de dificil compreensão por seres humanos. Particularmente, serão apresentadas as RNAs e os LMCs, que são de grande interesse para esse trabalho.

\subsubsection{Redes Neurais Artificiais}

Redes Neurais Artificiais são modelos computacionais distribuídos que têm sido utilizados com frequência em problemas de reconhecimento de padrões. Tendo como fonte de inspiração o cérebro humano, foram criados vários modelos de Redes Neurais Artificiais (RNAs) (Braga et al., 2000). O processa- 
mento em RNAs se dá por meio da combinação em rede de diversos nós simples que realizam processamentos independentes, inspirados nos neurônios de sistemas nervosos biológicos. Desse modo, paralelismo e robustez são características inerentes às RNAs.

O mais famoso e utilizado modelo de RNA é o Multi Layer Perceptron (MLP), ou Perceptron de múltiplas camadas. Utilizando o algoritmo de treinamento backpropagation, ele é capaz de aproximar qualquer tipo de função multivariável, incluindo problemas não linearmente separáveis, dados um conjunto de exemplos e uma arquitetura de rede adequados. O aprendizado do backpropagation é do tipo supervisionado (Rumelhart et al., 1986).

Outro modelo importante é o modelo Self Organizing Maps (SOM), também conhecido como Rede de Kohonen. As redes SOM são capazes de realizar a tarefa de agrupamento (aprendizado não-supervisionado). Essa rede apresenta uma forte inspiração neurofisiológica por ser baseada no mapa topológico presente no córtex cerebral (Braga et al., 2000).

A seguir, com o objetivo de exemplificar o conceito de RNAs, os dois modelos já citados serão descritos. Porém, existem dezenas de outros modelos na literatura, como: redes sem pesos, redes recorrentes, redes de Hopfield, redes RBF, entre outros (Haykin, 1998).

\section{Multi Layer Perceptron / Backpropagation}

O modelo MLP é uma extensão do modelo Perceptron de uma camada. A grande vantagem do modelo MLP sobre o Perceptron de uma camada é que ele pode resolver problemas não linearmente separáveis.

Uma rede MLP com uma camada intermediária pode aproximar qualquer função contínua, enquanto uma rede com duas ou mais camadas intermediárias pode aproximar qualquer função matemática (Cybenko, 1988).

Antes de entrar nos detalhes da rede MLP, será apresentado em linhas gerais o modelo Perceptron. O modelo de neurônio utilizado na rede Perceptron contém diversas entradas que são ponderadas por pesos. O aprendizado no Perceptron de uma camada é dado por meio da adaptação dos pesos de suas entradas. A Figura 2.2 mostra um modelo da rede Perceptron.

A seguir será descrito o processo de aprendizado da rede Perceptron. Primeiramente, iniciam-se os pesos com valores aleatórios. Então, apresenta-se cada exemplo do conjunto de treinamento à rede e alteram-se os pesos sempre que a rede erra na classificação de um exemplo. Esse processo é repetido até que a rede não cometa mais erros de classificação ou um determinado número de ciclos de aprendizado seja concluído. Para alterar os pesos, é utilizada a seguinte expressão de ajuste de pesos: 


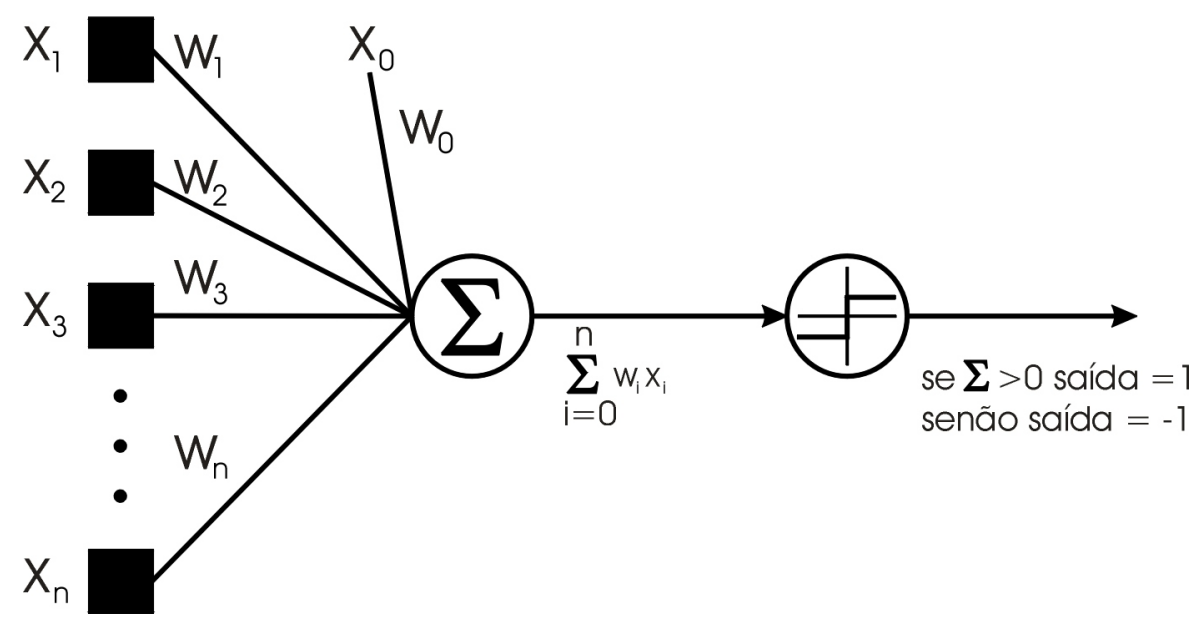

Figura 2.2: Rede Perceptron.

$$
\omega_{i} \longleftarrow \omega_{i}+\Delta \omega_{i}
$$

em que

$$
\Delta \omega_{i}=\eta(d-y) x_{i}
$$

O simbolo $d$ representa a saída esperada para o exemplo apresentado, $y$ é a saída gerada pela rede, e $\eta$ é a taxa de aprendizado. Essa taxa é utilizada para definir os efeitos da alteração dos pesos em cada passo do aprendizado e é tipicamente um valor baixo como 0.1 .

A rede MLP pode ser vista como um conjunto de várias redes Perceptron simples. A rede é disposta em camadas interconectadas. A saída dos nós de uma camada é geralmente conectada à entrada de todos os nós da próxima camada. Um exemplo de uma típica rede MLP pode ser visto na Figura 2.3.

O problema dessa rede está em como corrigir os pesos dos nós das camadas intermediárias. Como determinar o erro nos nós intermediários? Esse problema foi resolvido pelo algoritmo de treinamento backpropagation. Nesse algoritmo, o treinamento ocorre em duas fases, forward e backward. Na fase forward, um exemplo de treinamento é apresentado à rede na camada de entrada. Os valores da entrada são propagados pela rede, passando por seus pesos e funções de ativação até chegar à camada de saída, onde a saída da rede é definida. Na fase backward, a saída desejada e a saída da rede são comparadas para definir o erro na camada de saída, que é utilizado para ajustar os pesos dessa camada. Este erro é então propagado para os nós das camada anteriores, ponderado pelos pesos das conexões entre eles e os nós da camada atual. Através desse erro ponderado, pode-se calcular o ajuste dos pesos para as camadas intermediárias. O Algoritmo 1 descreve o de treinamento backpro- 


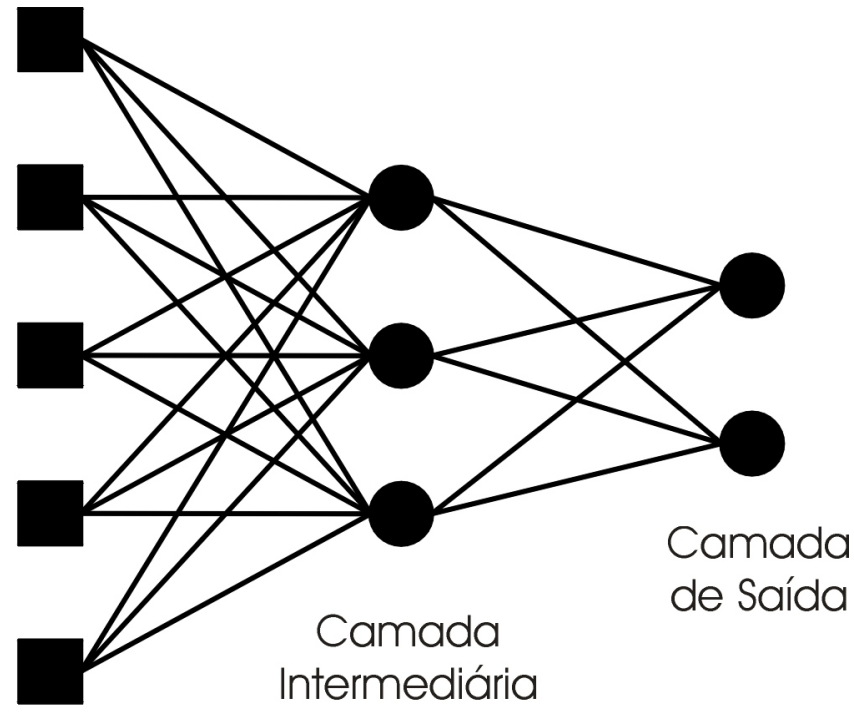

Camada

de Entrada

Figura 2.3: Rede Neural MLP.

pagation em pseudocódigo.

Self Organizing Maps - SOM

A rede SOM realiza um mapeamento dos padrões de entrada, que podem possuir uma alta dimensionalidade, para um espaço de menor dimensão, tipicamente 2D. Nesse processo, procura-se manter as características espaciais do conjunto de exemplos. Ou seja, exemplos que estão próximos no espaço original, serão atribuídos a neurônios próximos topologicamente no mapa de características SOM. Por causa dessa característica, as redes SOM são muito usadas para visualização.

A arquitetura da rede SOM consiste em um reticulado de neurônios. Cada neurônio tem conexões laterais com seus vizinhos. A forma mais comum de uma rede SOM é a de uma grade bidimensional, apesar de existirem redes com 3 ou mais dimensões. Essa arquitetura pode ser visualisada na Figura 2.4.

Cada nó da rede SOM possui um número de pesos igual ao número de atributos do conjunto de treinamento utilizado. A rede SOM realiza o aprendizado competitivo, ou seja, seus nós competem entre si para se aperfeiçoar. A cada exemplo de treinamento apresentado, define-se qual nó possui o conjunto de pesos mais próximo ao conjunto de atributos do exemplo atual segundo uma função de distância, normalmente a distância euclidiana. Esse nó é chamado de nó vencedor. O vencedor e seus vizinhos (definidos por uma região de vizinhança) são então atualizados de forma a ficaram um pouco mais parecidos com o exemplo atual (segundo a taxa de aprendizagem). A vizinhança e a 


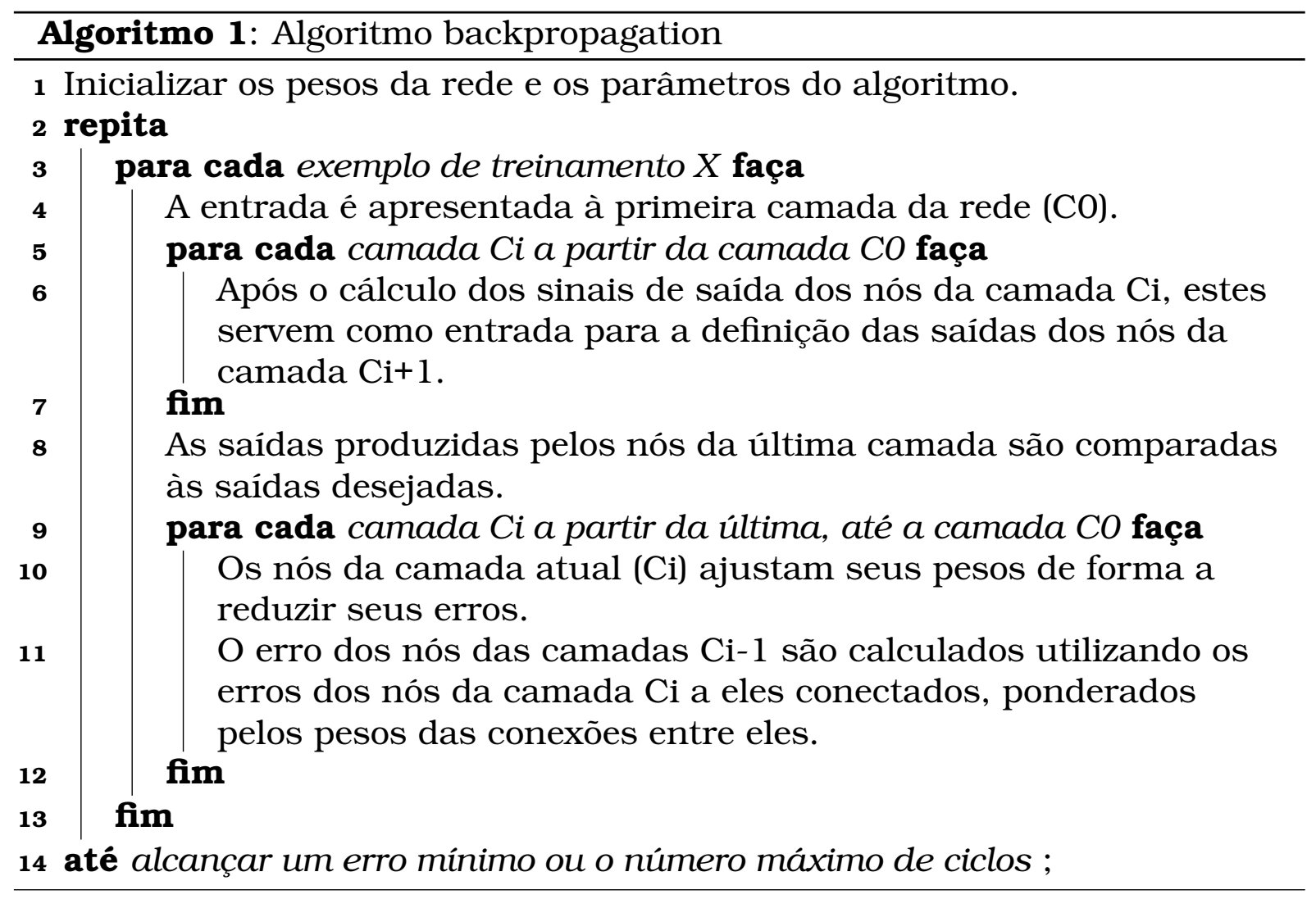

taxa de aprendizagem são definidos com valores altos no início do treinamento. Normalmente, a vizinhança inicial engloba toda a rede e vai diminuindo até incluir somente os nós com ligações diretas com o nó vencedor. O Algoritmo 2 apresenta o treinamento da rede SOM em pseudocódigo.

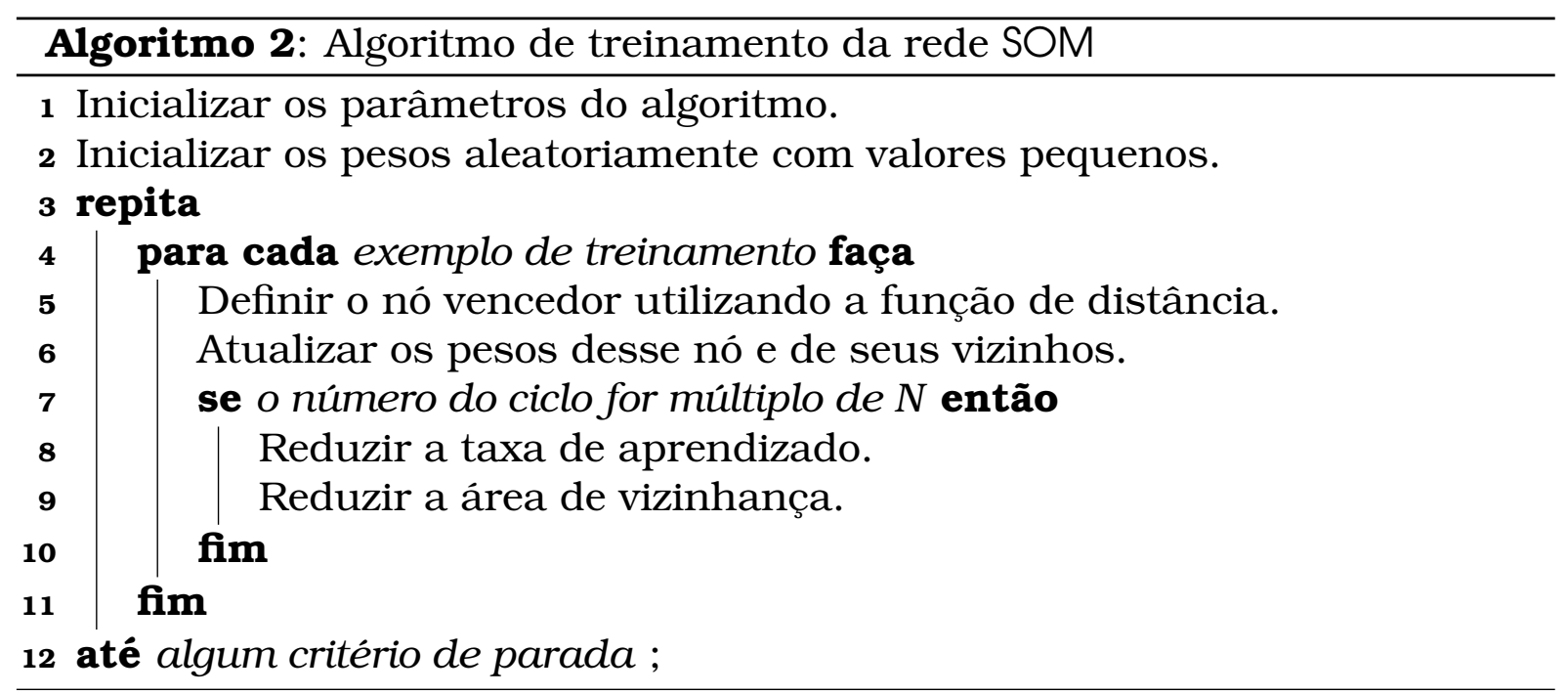

\subsubsection{Classificadores de Margens Largas}

Classificadores de Margens Largas (Large Margin Classifiers - LMCs) são aqueles que implicitamente ou explicitamente utilizam o conceito de maximização 


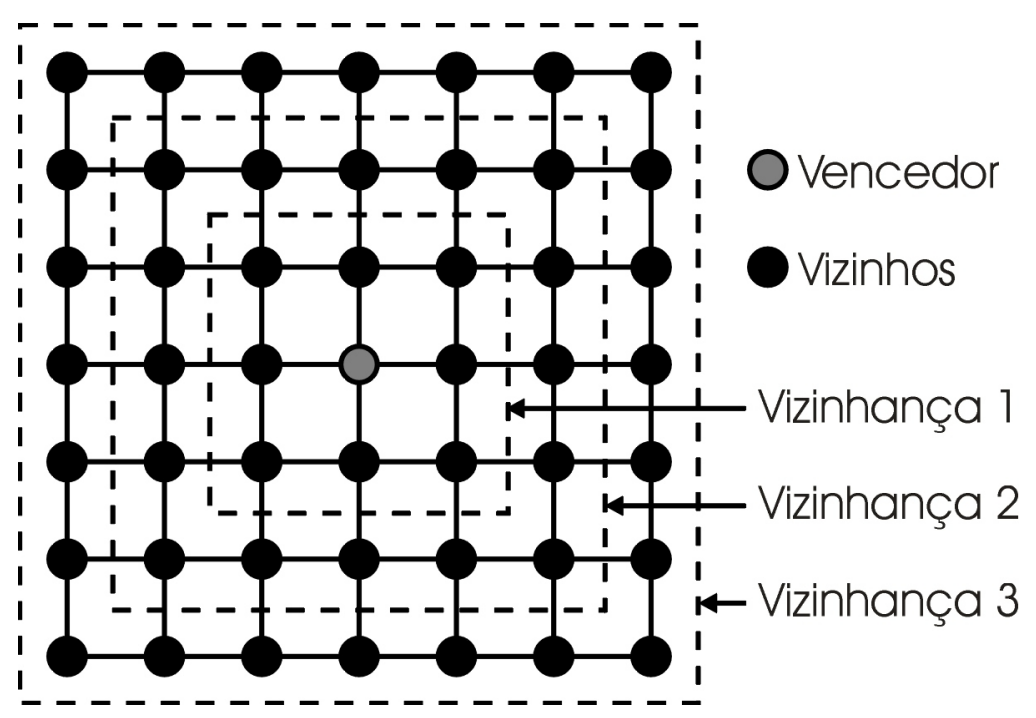

Figura 2.4: Rede Neural SOM.

de margens para a construção de suas fronteiras de decisão. Margem aqui é definida como a distância entre a fronteira de decisão utilizada pelo classificador e os exemplos a ele apresentados. Fundamentados na TAE (Teoria do Aprendizado Estatístico) (Lorena and de Carvalho, 2003), esses classificadores têm provado possuir um grande poder de generalização.

Para ilustrar esse conceito, observe o conjunto de dados linearmente separável da Figura 2.5.

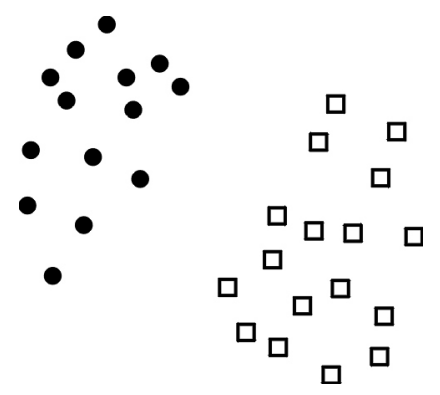

Figura 2.5: Um conjunto de dados linearmente separável.

Um conjunto linearmente separável é aquele no qual é possível separar todos os exemplos de diferentes classes por meio de um hiperplano. A função linear que define esse hiperplano pode ser considerada um classificador linear. A seguinte equação representa um possivel classificador linear:

$$
f(x)=\operatorname{sgn}(w \cdot x+b)
$$

na qual $w \cdot x$ é o produto escalar entre os vetores $w$ e $x, w$ é o vetor normal ao hiperplano, $b$ é o bias e $\operatorname{sgn}()$ é a função sinal.

A tarefa de aprendizado então se resume a definir os valores de $w$ e $b$ apro- 
priados para os dados do conjunto de treinamento. Porém, como pode ser visto na Figura 2.6, várias hipóteses podem ser induzidas para o hiperplano separador. Uma boa heurística então seria escolher a hipótese que apresenta a máxima margem de separação entre os exemplos e o hiperplano separador. A Figura 2.6 mostra duas hipóteses para o hiperplano separador, representadas pelas linhas continuas. As linhas tracejadas representam as margens de separação. A hipótese a) não leva em consideração o conceito de maximização de margens, enquanto a hipótese b) utiliza a um hiperplano que maximiza a margem de separação.

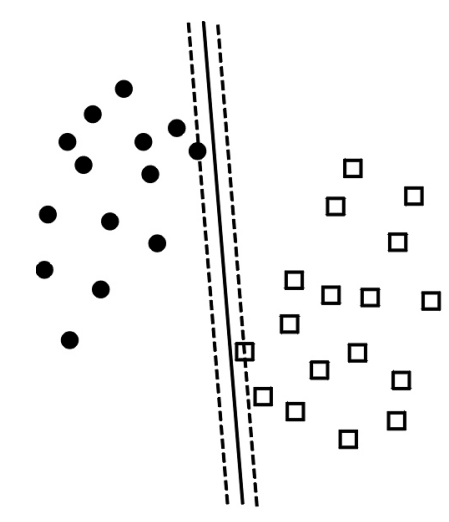

a)

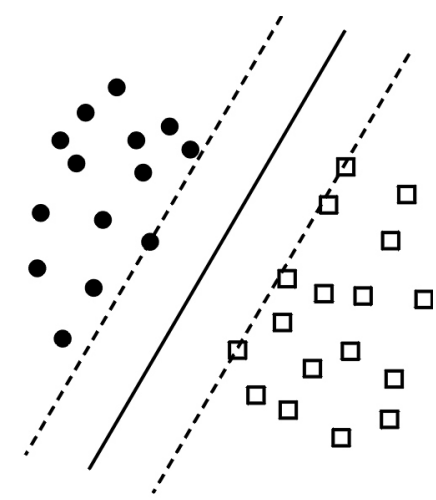

b)

Figura 2.6: Duas formas de separar o mesmo conjunto de dados. O hiperplano de a) não maximiza as margens de separação enquanto do de b) determina uma grande margem de separação entre a fronteira de decisão e os exemplos.

Duas propriedades dos Classificadores de Margens Largas justificam a constatação empírica de que os LMCs induzem hipóteses mais confiáveis. Uma é a robustez em relação aos padrões, pois dado um exemplo $x$ longe da borda de decisão, ocasionais perturbações em $x$ não levarão a classificações incorretas. A outra é a robustez em relação aos parâmetros do modelo, pois se a margem do classificador é grande, uma pequena perturbação nos parâmetros não afeta a classificação dos dados (Smola et al., 1999).

Além disso, a Teoria do Aprendizado Estatístico (TAE) provê limites no erro de um classificador linear para exemplos novos com base na margem. Isso indica que a maximização de margens leva a bons resultados em termos de generalização. O relatório técnico de Lorena and de Carvalho (2003) sobre Classificadores de Margens Largas descreve em detalhes a TAE.

As SVMs são LMCs muito conhecidos e utilizados. A seguir serão descritas sucintamente principais características das SVMs.

Dados os exemplos de treinamento $X_{i}, y_{i}, i=1 \ldots N, y_{i} \in-1,1, X_{i} \in R^{n}$ em que $y_{i}$ é o rótulo da classe, uma SVM primeiramente mapeia os dados para o espaço de características $H$, usando um mapeamento $\Phi$, 


$$
\Phi: R^{n} \rightarrow H
$$

O mapeamento $\Phi$ é implementado por uma função kernel $K$ que satisfaz as condições de Mercer (Cristianini and Shawe-Taylor, 2000) de modo que $K\left(X_{i}, X_{j}\right)=\Phi\left(X_{i}\right) \cdot \Phi\left(X_{j}\right)$. Então, no espaço de características $\mathrm{H}$ de alta dimensão, é encontrado o hiperplano de separação ótimo por meio da maximização da margem e limitação do número de erros de treinamento. A função de decisão pode ser dada por:

$$
\begin{aligned}
& f(X)=\operatorname{sgn}(W \cdot \Phi(X)-b) \\
& f(X)=\operatorname{sgn}\left(\sum_{i=1}^{N} y_{i} \alpha_{i} \Phi\left(X_{i}\right) \cdot \Phi(X)-b\right) \\
& f(X)=\operatorname{sgn}\left(\sum_{i=1}^{N} y_{i} \alpha_{i} K\left(X_{i}, X\right)-b\right)
\end{aligned}
$$

Se $\alpha_{i}$ é diferente de 0, o exemplo correspondente $x_{i}$ é um vetor suporte. Para treinar uma SVM é necessário descobrir $\alpha_{i}, i=1$ até $N$. Isso pode ser feito minimizando a seguinte função de custo quadrática:

$$
\begin{gathered}
\text { maximize } L_{D}(\alpha)=\sum_{i=1}^{N} \alpha_{i}-\frac{1}{2} \sum_{i=1}^{N} \sum_{j=1}^{N} \alpha_{i} \alpha_{j} y_{i} y_{j} K\left(X_{i}, X_{j}\right) \\
0 \leq \alpha_{i} \leq C i=1 \ldots N \\
\sum_{i=1}^{N} \alpha_{i} y_{i}=0
\end{gathered}
$$

em que $C$ é uma parâmetro escolhido pelo usuário. Valores altos de C correspondem a penalidades mais altas alocadas aos erros de treinamento. Uma vez que $K$ é semi-positivo definido e as restrições definem um conjunto convexo, a otimização anterior reduz-se para uma programação quadrática convexa.

\subsection{Algoritmos Genéticos}

Os Algoritmos Genéticos ${ }^{2}$ são programas evolutivos baseados na teoria de seleção natural e na hereditariedade. Eles baseiam-se no pressuposto de que, em uma dada população, indivíduos com boas características genéticas têm maiores chances de sobrevivência e de produzirem indivíduos cada vez mais aptos. Como resultado, os indivíduos menos aptos tenderão a desaparecer.

\footnotetext{
${ }^{2}$ Essa seção é baseada no Capítulo 9 do livro Sistemas Inteligentes (Rezende, 2002)
} 
Assim, Algoritmos Genéticos favorecem a combinação dos indivíduos mais aptos, ou seja, os candidatos mais promissores para a solução de um dado problema.

Quando Algoritmos Genéticos são empregados para resolução de problemas do mundo real, cada indivíduo da população, denominado cromossomo, normalmente corresponde a uma possivel solução para o problema. Um mecanismo de reprodução, baseado em processo evolutivo, é aplicado sobre a população atual com o objetivo de explorar o espaço de busca e encontrar melhores soluções para o problema.

Toda tarefa de busca ou otimização possui vários componentes, entre eles: o espaço de busca, onde são consideradas todas as possibilidades de solução de um determinado problema, e a função de avaliação (ou função de custo), que é uma maneira de avaliar os elementos do espaço de busca. Existem diversos métodos de busca e funções de avaliação (Ginsberg, 1993).

As técnicas de busca e otimização tradicionais iniciam seu processamento com um único candidato que, iterativamente, é manipulado utilizando algumas heurísticas, normalmente estáticas, diretamente associadas ao problema a ser solucionado. Geralmente, estes processos heurísticos não são algorítmicos e sua simulação em computadores pode ser muito complexa. Apesar de estes métodos não serem suficientemente robustos, isto não implica que eles sejam inúteis. Na prática, eles são amplamente utilizados, com sucesso, em inúmeras aplicações (Winston, 1992).

Por outro lado, as técnicas de Computação Evolutiva operam sobre uma população de candidatos em paralelo. Assim, elas podem fazer a busca em diferentes áreas do espaço de solução, alocando um número de membros apropriado para a busca em várias regiões. Como resultado, tais técnicas têm uma maior chance de atingir as áreas mais promissoras do espaço de busca. Os Algoritmos Genéticos diferem dos métodos tradicionais de busca e otimização, principalmente em quatro aspectos:

1. trabalham com uma codificação do conjunto de parâmetros e não com os próprios parâmetros;

2. trabalham com uma população e não com um único ponto;

3. utilizam informações de custo ou recompensa e não derivadas ou outro conhecimento auxiliar e

4. utilizam regras de transição probabilísticas e não determinísticas.

Algoritmos Genéticos têm se mostrado muito eficientes para a busca de soluções ótimas, ou aproximadamente ótimas em uma grande variedade de 
problemas, pois não impõem muitas das limitações encontradas nos métodos de busca tradicionais. Além de seguir uma estratégia de gerar e testar soluções muito elegante, por serem baseados na evolução biológica, são capazes de identificar e explorar aspectos do ambiente onde o problema esta inserido e convergir globalmente para soluções ótimas, ou aproximadamente ótimas (Holland, 1975).

"Quanto melhor um individuo se adaptar ao seu meio ambiente, maior será sua chance de sobreviver e gerar descendentes": este é o conceito básico da seleção natural (Darwin, 1859), mecanismo da evolução genética biológica. A área biológica mais proximamente ligada aos Algoritmos Genéticos é a Genética Populacional.

É interessante observar que pesquisadores e usuários referem-se a "Algoritmos Genéticos” ou a "um Algoritmo Genético" e não "ao Algoritmo Genético", pois Algoritmos Genéticos são uma classe de procedimentos com um conjunto de passos distintos e bem especificados, onde cada uma destes passos possui muitas possíveis variações.

Antes de prosseguir com a análise das características destes algoritmos, alguns conceitos básicos são necessários. Estes conceitos podem ser naturalmente expostos explicando o funcionamento básico destes algoritmos. Inicialmente, é gerada uma população formada por um conjunto aleatório de indivíduos que podem ser vistos como possíveis soluções do problema.

Durante o processo evolutivo, esta população é avaliada: para cada indivíduo é dada uma nota, ou índice, refletindo sua habilidade de adaptação a determinado ambiente. Uma porcentagem dos mais adaptados é mantida, enquanto os outros são descartados (darwinismo). Os membros mantidos pela seleção podem sofrer modificações em suas características fundamentais através de mutações e cruzamento (crossover) ou recombinação genética gerando descendentes para a próxima geração. Este processo, chamado de reprodução, é repetido até que uma solução satisfatória seja encontrada.

Embora possam parecer simplistas do ponto de vista biológico, estes algoritmos são suficientemente complexos para fornecer mecanismos poderosos e robustos de busca adaptativa (Goldberg, 1989).

\subsection{Características Gerais}

Algoritmos Genéticos são algoritmos de otimização global, baseados nos mecanismos de seleção natural e da genética. Eles empregam uma estratégia de busca paralela e estruturada, embora aleatória, direcionada à busca de pontos de "alta aptidão", ou seja, pontos nos quais a função a ser minimizada (ou maximizada) tem valores relativamente baixos (ou altos). Apesar de aleatórios, 
AGs não são buscas aleatórias não direcionadas, pois exploram informações históricas para encontrar novos pontos de busca onde são esperados melhores desempenhos.

Isto é feito através de processos iterativos, onde cada iteração é chamada de geração. Durante cada iteração, os princípios de seleção e reprodução são aplicados a uma população de candidatos que pode variar, dependendo da complexidade do problema e dos recursos computacionais disponíveis. Através da seleção, se determina quais indivíduos conseguirão se reproduzir, gerando um número determinado de descendentes para a próxima geração, com uma probabilidade determinada pelo seu índice de aptidão. Em outras palavras, os indivíduos com maior adaptação relativa têm maiores chances de se reproduzir.

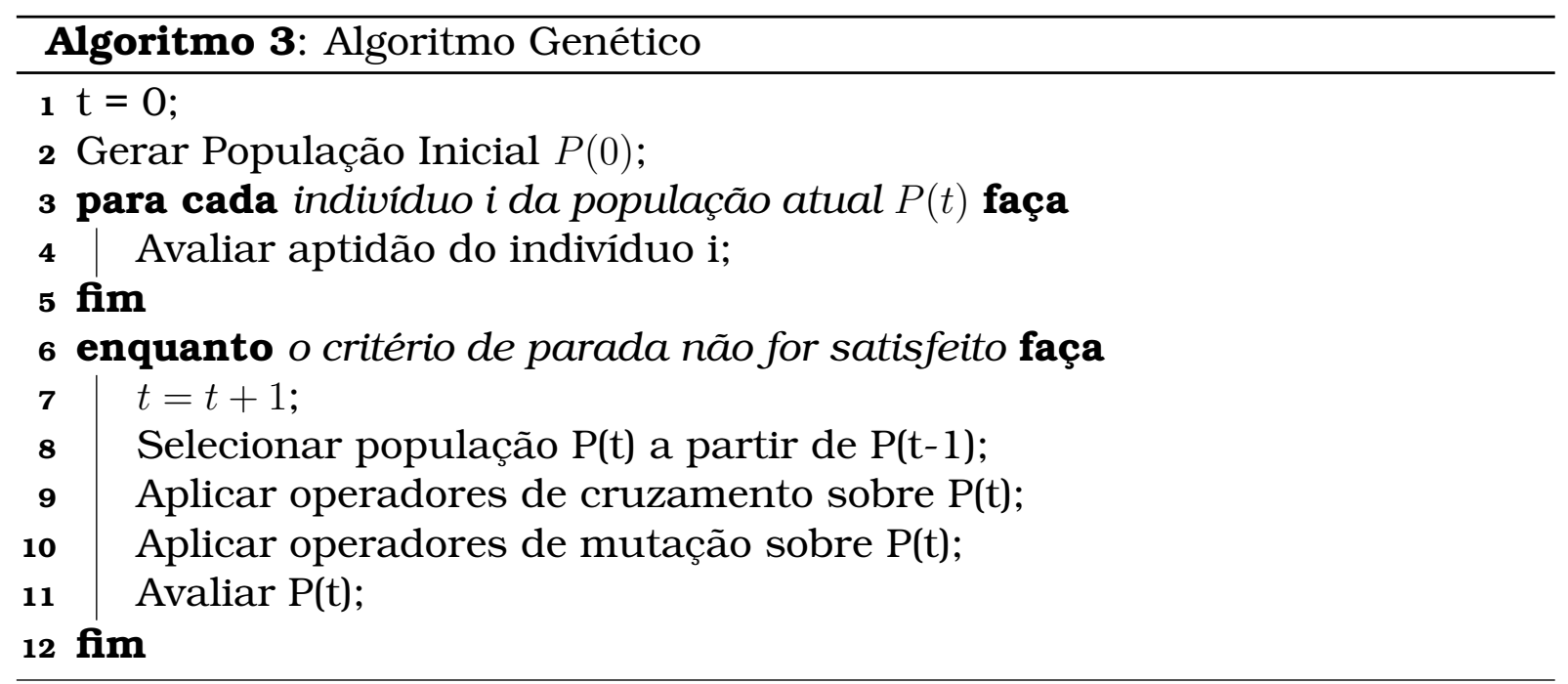

Durante esse processo, os melhores indivíduos, assim como alguns dados estatísticos, podem ser coletados e armazenados para avaliação.

Esse ciclo é geralmente repetido várias vezes até que um critério de para tenha sido satisfeito. O Algoritmo 3 apresenta o funcionamento de um algoritmo genético típico em pseudo-código.

Os AGs, apesar de aparentemente simples, são capazes de resolver problemas complexos de uma forma muito elegante. Além disso, eles não são limitados por suposições sobre o espaço de busca, relativas a continuidade, existência de derivadas, etc. Buscas em problemas reais são repletas de descontinuidades, ruídos e outros problemas. Métodos que dependam fortemente de restrições de continuidade e existência de derivadas são adequados apenas para problemas em um domínio limitado (Goldberg, 1989). 


\subsubsection{Representação}

O primeiro aspecto a ser considerado antes da utilização de AGs para a solução de um problema de busca ou otimização é a representação deste problema de maneira que os AGs possam trabalhar adequadamente sobre ele.

O AG processa populações de indivíduos ou cromossomos. O cromossomo é uma estrutura de dados, geralmente vetores ou cadeias de valores binários (estrutura mais tradicional, porém nem sempre a mais indicada), que representa uma possível solução do problema a ser otimizado. Em geral, o cromossomo representa o conjunto de parâmetros da função objetivo cuja resposta será maximizada ou minimizada. $\mathrm{O}$ conjunto de todas as configurações que o cromossomo pode assumir forma o seu espaço de busca. Se o cromossomo representa $n$ parâmetros de uma função, então o espaço de busca é um espaço com $n$ dimensões. A maioria das representações são genotípicas, utilizam vetores de tamanho finito em um alfabeto também finito.

Tradicionalmente, o genótipo de um indivíduo é representado por um vetor binário, onde cada elemento de um vetor denota a presença (1) ou ausência (0) de uma determinada característica. Os elementos podem ser combinados formando as características reais do indivíduo, ou seja o seu fenótipo . Teoricamente, esta representação é independente do problema, pois uma vez encontrada a representação em vetores binários, as operações padrão podem ser utilizadas, facilitando o seu emprego em diferentes classes de problemas (Spears et al., 1993).

A representação binária é historicamente importante, uma vez que foi utilizado nos trabalhos pioneiros de (Holland, 1975). Esta representação ainda é a mais utilizada, por ser de fácil utilização e manipulação, além de ser simples de analisar teoricamente. Contudo, se um problema tem parâmetros contínuos e o usuário desejar trabalhar com uma maior precisão, provavelmente ele acabará utilizando longos cromossomos para representar soluções, utilizando, assim, uma grande quantidade de memória. Também não há uniformidade nos operadores (Ex.: se o valor real de um gene for codificado por um vetor binário, a mutação nos primeiros valores binários do gene afetará mais a aptidão do cromossomo que a mutação nos seus últimos valores).

A representação do cromossomo usando números reais é mais naturalmente compreendida pelo ser humano do que aquela usando uma cadeia de bits. Além disso, a representação por valores reais requer menos memória.

A utilização de representações em níveis de abstração mais altos tem sido investigada. Como estas representações são mais fenotipicas, facilitariam sua utilização em determinados ambientes, onde essa transformação "fenótipo - 
genótipo" é muito complexa. Neste caso, precisam ser criados os operadores específicos para utilizar estas representações.

\subsubsection{Seleção}

O princípio básico do funcionamento dos AGs é que um critério de seleção vai fazer com que, depois de muitas gerações, o conjunto inicial de indivíduos gere indivíduos mais aptos. O Algoritmo Genético começa com uma população inicial de $N$ cromossomos. Quando não existe nenhum conhecimento prévio sobre a região do espaço de busca onde se encontra a solução do problema, os cromossomos são gerados aleatoriamente. Se houver um conhecimento a priori sobre a região em que está localizada a solução, ou seja, forem conhecidas soluções aceitáveis que podem estar próximas à(s) solução(ões) ótima(s), os cromossomos iniciais podem ser definidos de forma determinística.

Para que o processo de seleção privilegie os indivíduos mais aptos, a cada cromossomo da população é atribuído um valor dado por uma função $f_{a p t}$ denominada função de aptidão. Esta função recebe como entrada os valores do gene do cromossomo e fornece como resultado a sua aptidão. A aptidão pode ser vista como uma nota que mede o quão boa é a solução codificada por um indivíduo. A aptidão é baseada no valor da função objetivo, que é específica para cada problema.

Para alguns métodos de seleção, é desejável que o valor de aptidão de cada indivíduo seja menor que 1 e que a soma de todos os valores de aptidão seja igual $1\left(f_{a p t}<1\right.$ e $\left.\sum\left(f_{a p t}\right)=1\right)$. Para isso, para cada indivíduo é calculada a aptidão relativa $\left(f_{\text {rel }}\right)$. A aptidão relativa para um dado indivíduo é obtida dividindo o valor de sua aptidão pela soma dos valores de aptidão de todos os indivíduos da população.

Uma função objetivo (também chamada de função de avaliação ou função de custo) é geralmente uma expressão matemática que mede o quanto uma solução esta próxima ou distante da solução desejada (satisfaz o objetivo do problema). Muitas vezes ela inclui também restrições que devem ser satisfeitas pela solução. Alguns problemas de otimização procuram maximizar o valor da função objetivo, isto é, encontrar soluções que produzam o maior valor possível para a função objetivo (Ex.: definir o número máximo de caixas que podem ser colocadas dentro de um depósito). Outros problemas procuram minimizar o valor da função objetivo (Ex.: encontrar a solução mais barata). Existem ainda funções que procuram satisfazer a mais de um objetivo, encontradas em problemas de otimização multi-objetivo.

Associada uma nota ou aptidão a cada individuo da população, o processo de seleção escolhe então um subconjunto de indivíduos da população atual, 
gerando uma população intermediária. Vários métodos de seleção têm sido propostos. A maioria deles procura favorecer indivíduos com maiores notas de aptidão, embora não exclusivamente, a fim de manter a diversidade da população. Entre eles, podemos citar o método do Torneio, que foi utilizado neste trabalho.

Quando o método de seleção por torneio é utilizado, $n$ indivíduos da população são escolhidos aleatoriamente, com a mesma probabilidade. O cromossomo com maior aptidão dentre estes $n$ cromossomos é selecionado para a população intermediária. O processo se repete até que a população intermediária seja preenchida. Geralmente, o valor utilizado para $n$ é 3 . A utilização de seleção por torneio para $n=3$ é ilustrada na Figura 2.7.

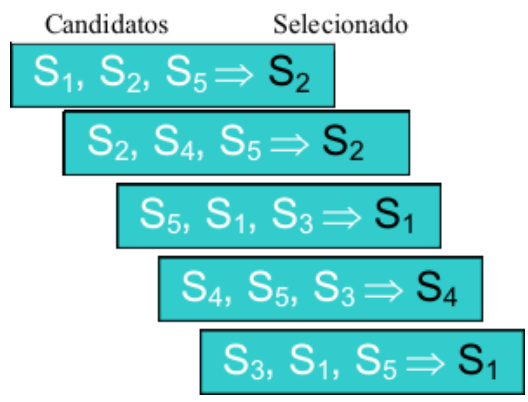

Figura 2.7: Método de seleção por torneio.

\subsubsection{Operadores Genéticos}

Um conjunto de operações é necessário para que, dada uma população, seja possivel gerar populações sucessivas que (espera-se) melhorem sua aptidão com o tempo. Estes operadores são: cruzamento (crossover) e mutação. Eles são utilizados para assegurar que a nova geração seja totalmente nova, mas possua, de alguma forma, características de seus pais, ou seja, a população se diversifica e mantém características de adaptação adquiridas pelas gerações anteriores. Para prevenir que os melhores indivíduos não desapareçam da população pela manipulação dos operadores genéticos, eles podem ser automaticamente colocados na próxima geração, através de uma política elitista.

O princípio básico dos operadores genéticos é transformar a população através de sucessivas gerações, estendendo a busca até chegar a um resultado satisfatório. Os operadores genéticos são necessários para que a população se diversifique e mantenha características de adaptação adquiridas pelas gerações anteriores.

O operador de mutação é necessário para a introdução e manutenção da diversidade genética da população, alterando arbitrariamente um ou mais componentes de uma estrutura escolhida, como é ilustrado na Figura 2.8, 
fornecendo assim, meios para introdução de novos elementos na população. Desta forma, a mutação assegura que a probabilidade de se chegar a qualquer ponto do espaço de busca nunca será zero, além de contornar o problema de mínimos locais, pois com este mecanismo, altera-se levemente a direção da busca. O operador de mutação é aplicado aos indivíduos com uma probabilidade dada pela taxa de mutação $\left(0 \leq P_{m} \leq 1\right)$; geralmente se utiliza uma taxa de mutação pequena $\left(0,001 \leq P_{m} \leq 0,1\right)$, pois é um operador genético secundário.

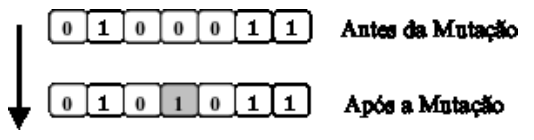

Figura 2.8: Exemplo de mutação.

O cruzamento é o operador responsável pela recombinação de características dos pais durante a reprodução, permitindo que as próximas gerações herdem essas características. Ele é considerado o operador genético predominante, por isso é aplicado com probabilidade dada pela taxa de cruzamento $\left(0 \leq P_{c} \leq 1\right)$, que deve ser maior que a taxa de mutação. Esta taxa é usualmente $0,6 \leq P_{c} \leq 0,99$. Este operador pode, ainda, ser utilizado de várias maneiras. As mais utilizadas são:

Cruzamento de um-ponto: um ponto de cruzamento é escolhido e a partir deste ponto as informações genéticas dos pais serão trocadas. As informações anteriores a este ponto em um dos pais são ligadas às informações posteriores à este ponto no outro pai, como é mostrado no exemplo da Figura 2.9.

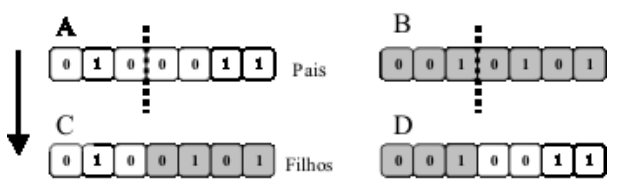

Figura 2.9: Exemplo de cruzamento de um ponto.

Cruzamento multi-pontos: é uma generalização da idéia de troca de material genético através de pontos, onde vários pontos de cruzamento podem ser utilizados. O funcionamento deste operador pode ser visto na Figura 2.10, para o caso de 2 pontos.

Cruzamento uniforme: não utiliza pontos de cruzamento, mas determina, através de uma máscara, quais os genes de cada cromossomo que cada filho herdará. Um exemplo da troca de informações provocada por este operador pode ser visto na Figura 2.11. Um valor 1 na máscara indica que o gene correspondente do pai A será herdado pelo filho $\mathrm{C}$ e o gene correspondente do 


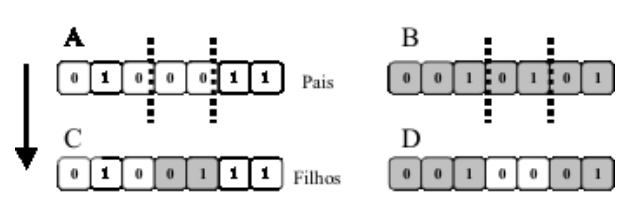

Figura 2.10: Exemplo de cruzamento de dois pontos.

pai B será herdado pelo filho D. Para um valor igual a 0 na máscara, ocorre o inverso.

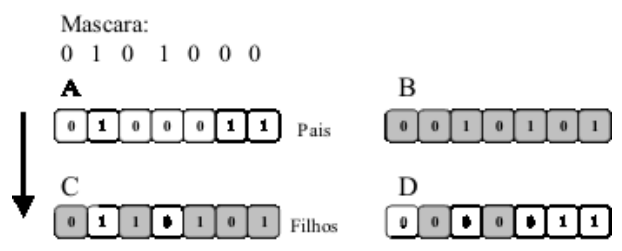

Figura 2.11: Um exemplo de Cruzamentouniforme.

\subsubsection{Parâmetros Genéticos}

O desempenho de um Algoritmo Genético é fortemente influenciado pela definição dos parâmetros a serem utilizados. Portanto, é importante analisar como tais parâmetros podem ser utilizados em face das necessidades do problema e dos recursos disponíveis (Jong, 1980). A seguir são discutidos alguns critérios para a escolha dos principais parâmetros:

- Tamanho da População. O tamanho da população afeta o desempenho global e a eficiência dos AGs. Com uma população pequena o desempenho pode cair, pois deste modo a população fornece uma pequena cobertura do espaço de busca do problema. Uma grande população geralmente fornece uma cobertura representativa do domínio do problema, além de prevenir convergências prematuras para soluções locais ao invés de globais. No entanto, para se trabalhar com grandes populações, são necessários mais recursos computacionais, ou que o algoritmo trabalhe por um período de tempo muito maior.

- Taxa de Cruzamento. Quanto maior for esta taxa, mais rapidamente novas estruturas serão introduzidas na população. Mas se esta for muito alta, estruturas com boas aptidões poderão ser retiradas mais rapidamente que a capacidade da seleção em criar melhores estruturas. Se esta taxa for muito baixa, a busca pode estagnar.

- Taxa de Mutação. Uma baixa taxa de mutação previne que a busca fique estagnada em subregiões do espaço de busca. Além disso, possibilita que 
qualquer ponto do espaço de busca seja atingido. Com uma taxa muito alta a busca se torna essencialmente aleatória.

- Intervalo de Geração. Controla a porcentagem da população que será substituída para a próxima geração. Com um intervalo grande, a maior parte da população será substituída. U intervalo muito grande pode levar à perda de estruturas de alta aptidão. Com um intervalo pequeno, o algoritmo pode se tornar muito lento.

- Critério de Parada. Diferentes critérios podem ser utilizados para terminar a execução de um Algoritmo Genético: após um dado número de gerações, quando a aptidão média ou do melhor indivíduo não melhorar mais ou quando as aptidões dos indivíduos de uma população se tornarem muito parecidas. Quando se conhece a resposta máxima da função objetivo, é possível utilizar este valor como critério de parada.

\subsection{Considerações Finais}

Esse capítulo apresentou uma visão geral sobre os principais conceitos de Aprendizado de Máquina que foram utilizados nesse trabalho. O próximo capítulo irá apresentar alguns métodos de extração de conhecimento para técnicas de aprendizado de máquina não-simbólico encontradas na literatura durante o desenvolvimento dessa tese. 


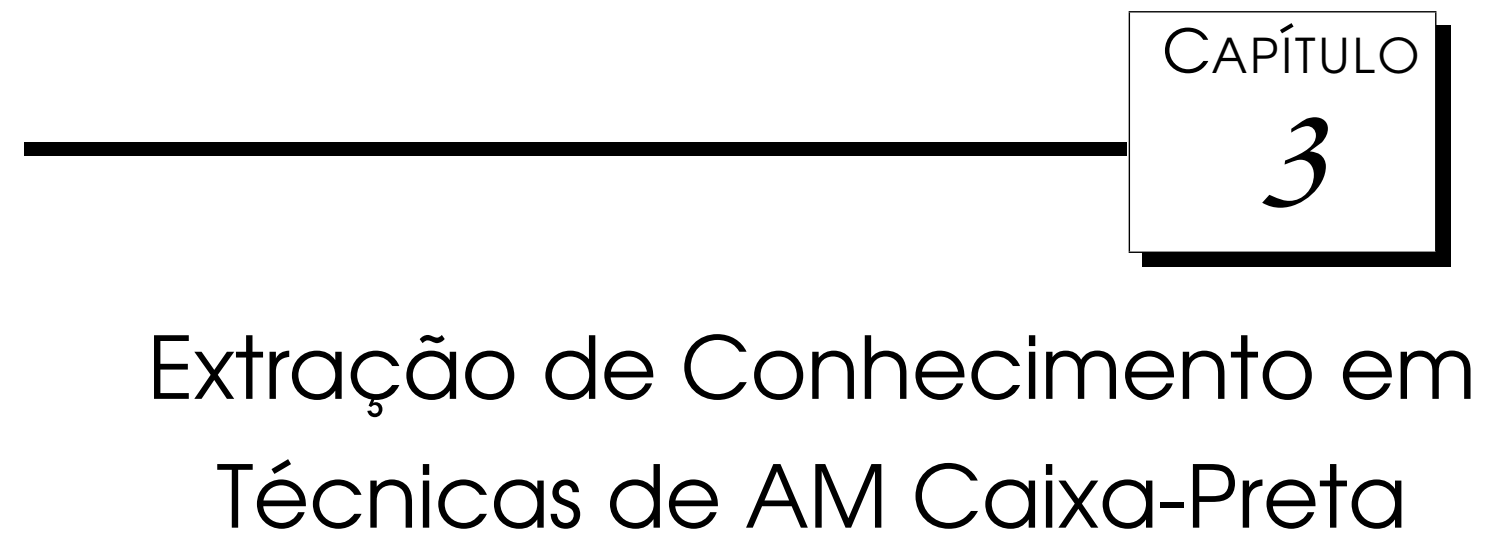

$\mathcal{U}$ m grande esforço já foi dedicado ao estudo de métodos para extração do conhecimento embutido em RNAs treinadas, sendo essa uma área com mais de vinte anos de pesquisas. Nos últimos anos, poucos trabalhos tem sido realizados nessa área. Porém, recentemente surgiu o interesse em métodos de extração específicos para Classificadores de Margens Largas, mais especificamente para as Máquinas de Vetores de Suporte (SVMs).

Apesar de compartilhar muitos dos conceitos já investigados pela área de extração de conhecimento de RNAs, esta nova área de pesquisa ainda encontrase em sua infância e um dos primeiros trabalhos relacionados à esse tema (se não for o primeiro) data de 2002, intitulado "Rule extraction from support vector machines" (Núñez et al., 2002).

Portanto, este capítulo tratará inicialmente da extração de conhecimento de RNAs treinadas, relacionando os trabalhos já realizados na área e os conceitos definidos por esses trabalhos, alguns dos quais podem ser facilmente adaptados para as SVMs e outras técnicas de AM caixa-preta. A seguir, dois dos trabalhos mais recentes na área de extração de regras de SVMs serão sucintamente comentados. Por fim, o Sistema NNRules de extração de conhecimento de RNAs proposto por Milaré (2003) será descrito em maior detalhe, pois ele foi o ponto de partida para o método de extração de conhecimento proposto nessa tese.

São várias as formas de se classificar os métodos de extração de conhecimento de RNAs treinadas encontrados na literatura (Andrews et al., 1995; Tickle et al., 1998). A taxonomia mais usada e abrangente é a que classifica a técnica de acordo com a forma pela qual ela analisa o conhecimento adquirido 
pela RNA. Essa classificação divide os métodos em pedagógicos, decomposicionais e ecléticos. A seguir, essa classificação será descrita e métodos de cada uma de suas classes serão exemplificados, tentando, sempre que possível, generalizar seus conceitos de forma a não restringir sua aplicação às RNAs.

\section{1 Métodos Pedagógicos}

Os métodos pedagógicos extraem o conhecimento sem analisar as características internas do classificador. Essas técnicas realizam um mapeamento entre os atributos de entrada e saída do classificador sem levar em consideração quaisquer passos intermediários.

Exemplos dessa categoria são: o método de Saito and Nakano (1988), que utiliza busca em largura para encontrar combinações de valores para as unidades de entrada que ativam cada uma das unidades de saída; o método de Gallant (1993), que é similar ao de Saito e Nakano e utiliza heurísticas para reduzir o espaço de busca; o método Validity Interval Analysis (Thrun, 1995), que testa as regras propagando intervalos de ativação especificados por meio de programação linear, e denominados intervalos de validade por meio de uma RNA; e o método TREPAN (Craven and Shavlik, 1996), que constrói árvores de decisão utilizando os exemplos de treinamento com que a RNA foi treinada e, em uma de suas variações, inclui exemplos artificiais gerados pelo TREPAN, ambos classificados pela RNA.

Críticas têm sido feitas aos métodos que utilizam exemplos artificiais, pois não é fácil validar a existência de tais exemplos no mundo real, o que pode levar o método a gerar regras desnecessariamente complexas ou com perda de precisão e fidelidade. Porém, um dos problemas dos métodos pedagógicos que não utilizam exemplos artificiais é que quando o classificador do qual se pretende extrair as regras tem um desempenho de classificação próximo ao ótimo, o conjunto de dados por ele rotulado pouco difere do conjunto de dados original utilizado para treiná-lo. Com isso, apesar da fidelidade alcançada por esses métodos (medida pela porcentagem de exemplos em que o classificador concorda com as regras extraídas) ser alta, é pouco provável que as regras reflitam o conhecimento armazenado no classificador. Esse problema tem sido negligenciado em muitos trabalhos da área.

Em geral, os métodos dessa categoria podem ser aplicados em qualquer técnica de aprendizado de máquina, como SVMs e Comitês de Classificadores, sem maiores problemas, uma vez que não fazem nenhuma análise nos parâmetros internos da técnica utilizada. 


\subsection{Métodos Decomposicionais}

Os métodos decomposicionais decompõem uma RNA em diversas redes de apenas uma camada e uma unidade. Cada unidade intermediária e de saída é então descrita por um conjunto de regras. Por fim, estas regras são combinadas em um conjunto que descreve o comportamento da RNA como um todo.

Exemplos dessa categoria são: o método KT (Fu, 1991, 1994), que busca por combinações de pesos que, quando satisfeitos, garantem que uma unidade será ativada independentemente do valor de outras entradas para a unidade; o método M-of-N de Towell and Shavlik (1993), que é similar ao KT e que busca, para cada unidade, por conjuntos de conexões de entrada cuja soma dos pesos excedam o seu bias, independente dos pesos associados a outras conexões de entrada, extraindo regras do tipo $\mathrm{m}-\mathrm{de}-\mathrm{n}^{1}$; o método desenvolvido por Blasig (1994), que utiliza uma função especial de custo para encorajar unidades intermediárias e de saída a assumirem um estado favorável à extração de regras, durante o treinamento, de forma que cada unidade possa ser diretamente traduzida em uma regra; e o método desenvolvido por Setiono and Liu (1995), que modifica o processo de treinamento da RNA para simplificar o processo de extração de regras, extraindo conjuntos de regras concisos de redes que apresentam um número pequeno de unidades intermediárias.

\subsection{Métodos Ecléticos}

Os métodos ecléticos são abordagens híbridas que extraem o conhecimento de RNAs aliando a análise individual das unidades com a análise das entradas e saídas da rede.

Um exemplo de método dessa categoria é o algoritmo DEDEC, proposto por Tickle et al. (1994). Esse método extrai regras if-then de redes MLP treinadas com o algoritmo backpropagation (Braga et al., 2000; Haykin, 1998).

\subsection{Métricas}

Abaixo estão relacionadas algumas das métricas que foram definidas para a avaliação de métodos de extração de conhecimento de RNAs, mas que têm sido aplicadas à outros métodos de extração também (Mitra et al., 2002; Craven and Shavlik, 1999):

- Precisão ou Acurácia: Porcentagem de classificações corretas obtidas pelas regras extraídas.

\footnotetext{
${ }^{1}$ Uma expressão m-de-n é uma expressão booleana que é satisfeita quando ao menos $m$ (um limite inteiro) de $\mathrm{n}$ condições booleanas são satisfeitas.
} 
- Precisão do Usuário: Número de classificações corretas de uma classe dividido pelo número de classificações dessa classe.

- Fidelidade: Porcentagem do conjunto de teste em que as regras extraídas e o método de aprendizado de máquina não-simbólico concordam (classificam o exemplo na mesma classe).

- Cobertura: Porcentagem de exemplos de um conjunto de teste em que pelo menos uma regra é disparada.

- Tamanho da base de regras: Número de regras extraídas. Quanto mais baixo seu valor, mais compacta é a base de regras.

- Complexidade computacional: Medida em termos de tempo de CPU requerido.

- Compreensibilidade: Conjunto de fatores que determinam a facilidade de entendimento de uma regra. Consideração apenas de atributos relevantes, tamanho da base de regras, etc.

- Escalabilidade: Diz respeito a como o tempo de execução e a compreensibilidade dos modelos extraídos variam em função de fatores como dimensionalidade, tamanho do conjunto de treinamento e complexidade do algoritmo de aprendizado de máquina não-simbólico.

- Generalidade: Proporção em que o algoritmo de extração de conhecimento não requer treinamentos especiais ou restrições no algoritmo de aprendizado de máquina não-simbólico.

\subsection{Extração de Conhecimento de SVMs}

Nessa seção serão relacionados sucintamente dois trabalhos recentes de extração de conhecimento de Máquinas de Vetores de Suporte encontrados na literatura.

Um dos poucos métodos de extração de conhecimento projetados especificamente para Máquinas de Vetores de Suporte é o SVM+Prototypes proposto por Núñez et al. (2002). É um método decomposicional que extrai tanto regras proposicionais como regras em que as condições são equaçòes matemáticas de elipsóides.

Esse método realiza um processo iterativo. Seu algoritmo é exposto em pseudocódigo no Algoritmo 4. 


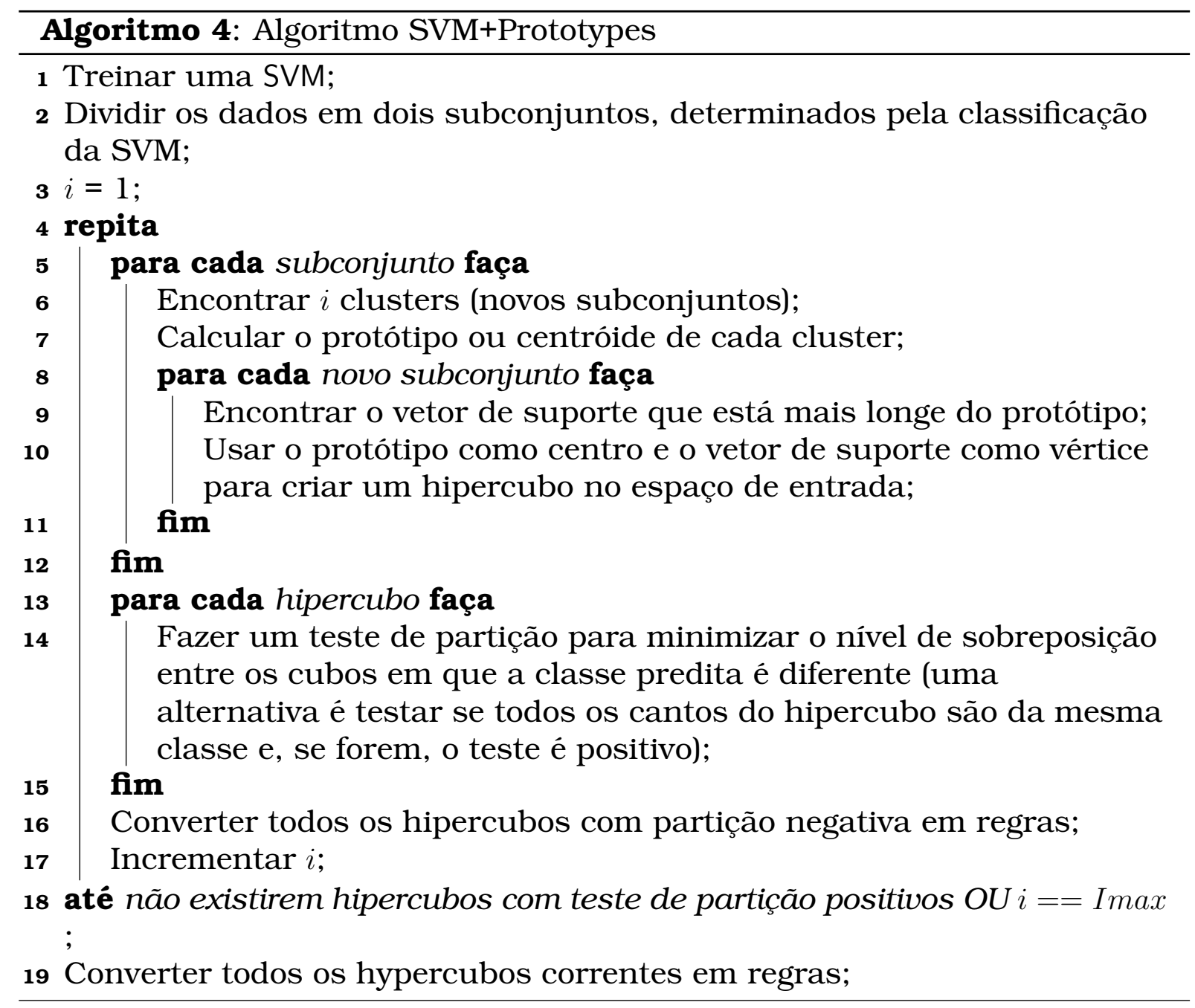


O principal problema desse algoritmo é que as regras extraídas não são nem exclusivas e nem exaustivas, o que resulta em regras conflitantes ou faltantes na classificação de novas instâncias.

Outro trabalho recente realiza a extração de regras de Máquinas de Vetores de Suporte Lineares via Programação Matemática.

Esse trabalho, proposto por Fung et al. (2008) descreve um método para a conversão de SVMs lineares em um conjunto de regras sem sobreposição. Nesse método, cada iteração do algoritmo de extração de regras é formulada como um problema de otimização com restrições.

A vantagem desse método reside na necessidade de resolver apenas problemas de otimização simples, em poucas variáveis.

\subsection{Sistema NNRules}

Nessa seção, os métodos utilizados no sistema NNRules para a extração de conhecimento compreensivel de redes neurais treinadas (RNAs) são sucintamente descritos. Esses métodos foram propostos por Milaré (2003). Alguns experimentos com os métodos do sistema NNRules foram realizados e são apresentados no Capítulo 5

\subsubsection{Método baseado em Aprendizado de Máquina Simbólico}

O método baseado em Aprendizado de Máquina (AM) simbólico utiliza sistemas de AM simbólicos para extrair representações simbólicas de RNAs. Uma das principais características dos sistemas de AM simbólicos é a sua habilidade em representar a hipótese induzida como estruturas simbólicas, geralmente compreensiveis para humanos. A Figura 3.1 mostra um esquema geral desse método.

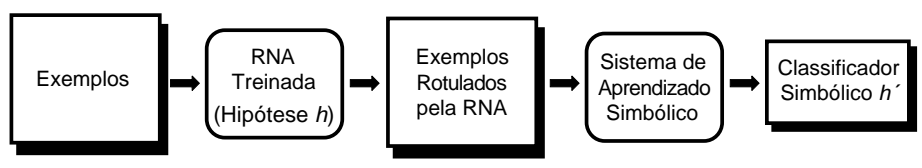

Figura 3.1: Esquema geral do método baseado em sistemas de AM simbólicos.

Nesse método, uma RNA é treinada como o conjunto de dados E. Após o treinamento, a RNA é usada como uma "caixa preta" para classificar o conjunto de dados $E$, criando novos valores para o atributo classe. Os novos valores do atributo classe refletem o conhecimento aprendido pela RNA, isso é, refletem a hipótese $h$ induzida pela RNA. O conjunto de dados rotulado pela RNA é fornecido como entrada para o sistema de AM simbólico. O sistema de AM simbólico induz uma representação simbólica baseada nos novos rótulos atribuídos pela RNA aos exemplos. Desse modo, o classificador simbólico $h^{\prime}$ 
induzido pelo sistema de AM simbólico visa aproximar a hipótese $h$ induzida pela RNA. Esse método é similar ao método TREPAN (Craven, 1996), no entanto ele não gera novos exemplos artificialmente como o TREPAN faz.

Uma das qualidades desse método é que qualquer sistema de AM simbólico pode ser utilizado para induzir um classificador simbólico a partir do conjunto de dados rotulado pela RNA. Desse modo, o método é simples e fácil de usar, uma vez que ele permite o uso de qualquer sistema de AM simbólico. Nesse trabalho, os sistemas de AM simbólico C4.5, C4.5rules (Quinlan, 1988) e CN2 (Clark and Niblett, 1989b) foram utilizados.

\subsubsection{Método Baseado em Algoritmos Genéticos}

O método baseado em Algoritmos Genéticos (AGs) visa otimizar a representação simbólica extraída das RNAs por sistemas de AM simbólicos. A Figura 3.2 mostra um esquema geral desse método.

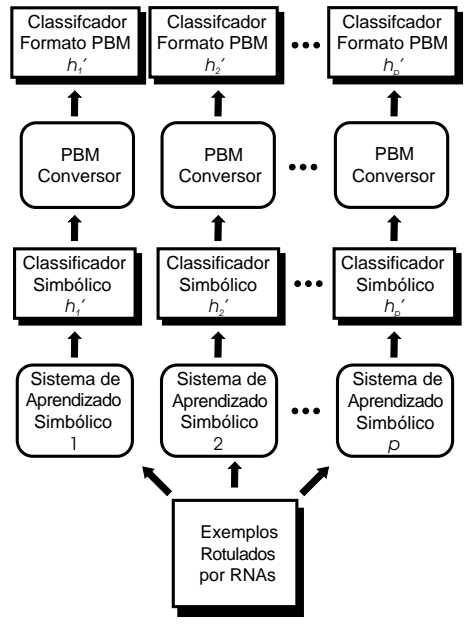

a)

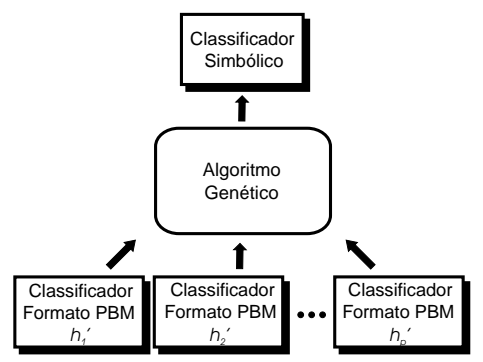

b)

Figura 3.2: Esquema geral do método baseado em AGs.

AGs são métodos de busca e otimização inspirados no processo de evolução e seleção natural. Um AG utiliza uma população de indivíduos para resolver um determinado problema. Cada indivíduo da população corresponde a uma possivel solução para o problema. Um mecanismo de reprodução é aplicado à população atual, gerando uma nova população. A população normalmente evolui através de diversas gerações até que uma solução apropriada seja alcançada. AGs iniciam sua operação gerando uma população inicial formada por um grupo de indivíduos aleatórios, que podem ser vistos como primeiros palpites para resolver um problema em particular. A população inicial é avaliada e para cada indivíduo, uma nota (chamada fitness) é calculada, refletindo a qualidade da solução associada a ela. 
Suponha que uma RNA induz a hipótese $h$ a partir de um conjunto de dados $E$. Como no método baseado em AM simbólico, o conjunto de dados $E$ utilizado para treinar a RNA é rotulado pela RNA, originando o conjunto de dados $E^{\prime}$. Esse conjunto de dados é utilizado como entrada para $p$ sistemas de AM simbólico. Como resultado, os classificadores simbólicos $h_{1}^{\prime}, h_{2}^{\prime}, \ldots h_{p}^{\prime}$ são induzidos. Cada classificador aproxima a hipótese induzida pela RNA para uma partição particular. Infelizmente, cada sistema de AM simbólico representa o conceito induzido em uma linguagem diferente, dificultando a integração desses classificadores. Então, é necessário traduzir a representação desse classificadores para uma linguagem comum. Para fazer tal tradução, foi utilizado o trabalho de Prati et al. (2002), que propõe uma sintaxe padrão para representar regras chamada $\mathcal{P} B M$. Assim, cada classificador simbólico é traduzido para o formato $\mathcal{P} B M$ (Figure 3.2.a).

Em uma segunda fase, um AG é empregado para integrar as $p$ hipóteses $h_{i}^{\prime}$ em uma única hipótese com maior fidelidade com $h$. As regras que compõe os $p$ classificadores podem ser usadas para codificar os vários indivíduos da população inicial do AG. Assim, cada indivíduo na população inicial é formado por um conjunto de regras, em que cada regra é aleatoriamente extraída de um dos $p$ classificadores. Após várias gerações, o melhor indivíduo da população atual é utilizado como o conjunto de regras otimizado. Esse conjunto de regras é então utilizado para explicar o comportamento da RNA (Figure 3.2.b).

Em uma terceira fase opcional, um pós-processamento é aplicado ao melhor indivíduo removendo as regras que não são disparadas. Esse pós-processamento pode aumentar a compreensibilidade do conjunto de regras.

\subsection{Considerações Finais}

Esse capítulo apresentou os conceitos da extração de conhecimento em técnicas de AM caixa-preta e uma revisão de diversos métodos encontrados na literatura. O próximo capítulo irá apresentar o método RankSim, proposto nessa Tese. 


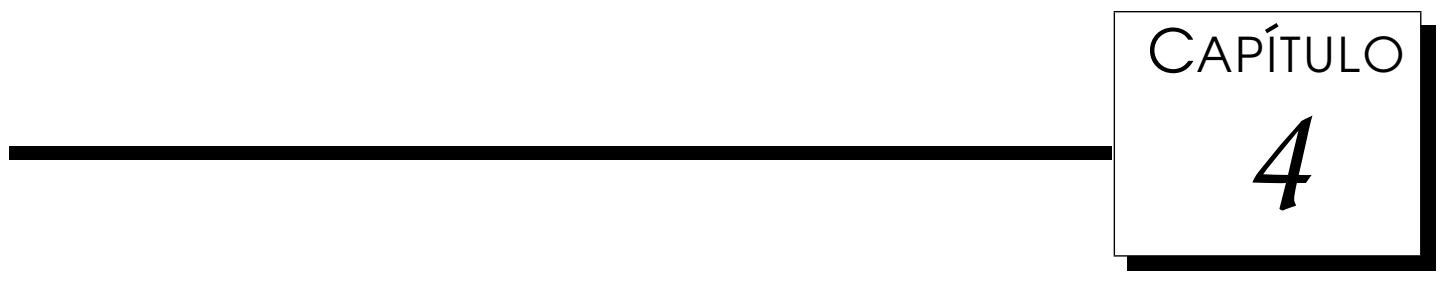

\section{Método Proposto}

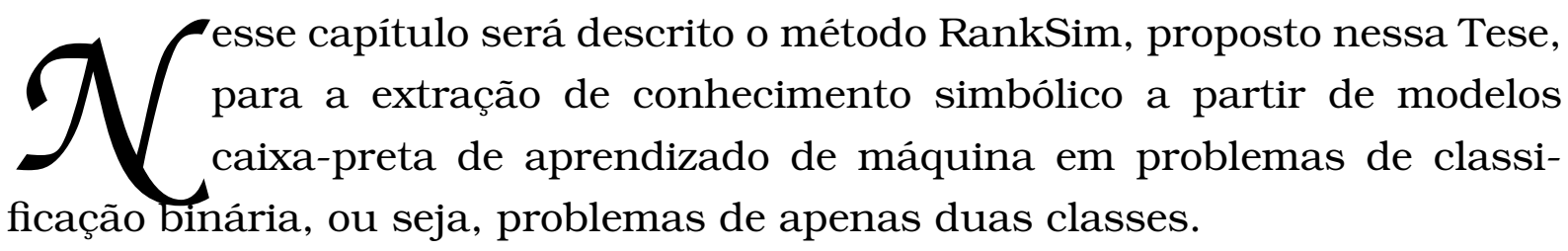

A motivação para esse método vem da percepção de que a maioria dos métodos pedagógicos existentes enfrentam o problema da falta de informação sobre o que foi realmente aprendido pelo modelo não-simbólico (Redes Neurais Artificiais, Máquinas de Vetores de Suporte, entre outros) quando estes apresentam uma alta taxa de acerto. Por exemplo, se uma Máquina de Vetores de Suporte classificar corretamente todos os exemplos que lhes forem apresentados, o conjunto de exemplos por ela rotulado será idêntico ao conjunto de exemplos original. Nesse caso, não é muito interessante utilizar um método pedagógico tradicional, uma vez que isso equivale a usar os exemplos originais para extrair regras. Sendo assim, se o classificador simbólico também tiver uma taxa de acerto elevada, a fidelidade será elevada, mesmo que o classificador simbólico classifique os exemplos com uma fronteira de decisão significativamente diferente da fronteira de decisão utilizada pelo modelo gerado pelo método caixa-preta.

No método proposto nesta tese, utilizamos mais informação do que a disponibilizada pela saída binária de classificação do modelo caixa-preta. Utilizamos a informação da saída numérica dos modelos caixa-preta em um algoritmo genético que otimiza a similaridade dos rankings do modelo caixa-preta e das regras extraídas. A seguir, na Seção 4.1, é feita a descrição da arquitetura do método e na Seção 4.2 é apresentada a função de avaliação utilizada no algoritmo genético. A Seção 4.4 apresenta as considerações finais do capítulo. 


\section{1 Descrição do Método RankSim}

Vários modelos caixa-preta, incluindo Máquinas de Vetores de Suporte e Redes Neurais Artificiais representam sua saída de forma numérica. Para chegar a um valor de classificação, ou classe, é necessário utilizar uma função de limiar para discretizar essa saída numérica. No caso mais comum, a saída então passa a ser binária, classificando as instâncias em rótulos positivos ou negativos.

Métodos pedagógicos tradicionais utilizam apenas a informação desses rótulos, porém, em alguns modelos caixa-preta, a saída numérica nos informa o grau de confiabilidade que o modelo tem em sua resposta. Por exemplo, se um modelo for treinado para retornar +1 para os casos positivos e -1 para os casos negativos, com limiar em 0 , isso significa que respostas próximas de +1 ou - 1 tem maior confiabilidade do que as próximas de 0 .

Sendo assim, é possível criar um ranking ordenado por confiabilidade das saídas do método caixa-preta, partindo do exemplo positivo mais confiável, passando por uma região de incerteza, até o exemplo negativo mais confiável.

Regras induzidas por técnicas de aprendizado de máquina simbólico também podem atribuir um valor de confiabilidade para suas saídas e, sendo assim, também é possivel criar um ranking ordenado das saídas do conjunto de regras.

$\mathrm{Na}$ abordagem proposta, as regras utilizadas são não-ordenadas e todas as regras disparadas para um dado exemplo são avaliadas. A classificação é dada por meio da avaliação das matrizes de contingência das regras disparadas.

As matrizes de contingência indicam as freqüências dos exemplos cobertos pela regra classificados como verdadeiros positivos, falsos positivos, verdadeiros negativos e falsos negativos. Verdadeiros positivos são os exemplos da classe positiva que foram corretamente classificados pela regra. Falsos positivos são os exemplos da classe negativa que foram incorretamente classificados pela regra. Analogamente, os verdadeiros negativos são os exemplos da classe negativa que foram corretamente classificados pela regra e os falsos negativos são os exemplos da classe positiva que foram incorretamente classificados pela regra.

Para decidir a classificação de um novo exemplo, as matrizes de contingência das regras disparadas são totalizadas, fazendo o cálculo do índice de acurácia menos erro das regras, que é calculado subtraindo do percentual de exemplos cobertos corretamente o percentual de exemplos corretos incorretamente, para cada classe. A classe com o melhor índice é a escolhida.

Além de determinar a classificação de novos exemplos, os índices calcu- 
lados por meio da matriz de contingência podem ser utilizados para estimar a probabilidade de que a classificação seja correta. Para isso, pode-se utilizar freqüências calculadas pela Equação 4.1, em que $E C C$ são os exemplos de treinamento cobertos corretamente pelas regras e ECI são os exemplos cobertos incorretamente.

$$
P r o b=\frac{E C C}{E C C+E C I}
$$

Essa análise simples pode gerar estimativas pouco confiáveis em termos absolutos. Uma das formas alternativas encontradas na literatura para a estimação de probabilidades é utilização da correção de Laplace. A correção de Laplace adiciona um exemplo virtual para cada classe como pode ser visto na equação 4.2, na qual k é o número de classes.

$$
\operatorname{Prob}=\frac{E C C+1}{E C C+E C I+k}
$$

Essa correção visa reduzir o impacto das mudanças que pequenas alterações em ECC ou ECI podem provocar na estimativa. Porém, como em nosso método estamos apenas interessados na estimativa da confiabilidade relativa entre os exemplos apresentados para gerar o ranking, que não é alterado utilizando a correção de Laplace, por simplicidade, em nossos experimentos empregamos a Equação 4.1 .

Com isso em vista, o método proposto visa não somente ter fidelidade de classificação mas também maximizar a similaridade entre os rankings dos modelos caixa-preta e os rankings das regras extraídas.

Para isso, utilizamos uma abordagem inspirada no trabalho de Milaré (2003), descrito na Seção 3.6, em que regras são geradas por algoritmos simbólicos e otimizadas por algoritmos genéticos para maximizar a fidelidade.

A diferença é que, ao invés de utilizar a fidelidade como função de avaliação para a otimização do algoritmo genético, criamos uma nova métrica que mede a semelhança entre os rankings para ser utilizada como função de avaliação.

Nessa abordagem, temos duas variações:

- As regras da população inicial do algoritmo genético são induzidas a partir do conjunto de exemplos originais.

- O conjunto de exemplos utilizado para a indução do conjunto de regras da população inicial do algoritmo genético é rotulado pelo modelo caixapreta.

A Figura 4.1 representa a arquitetura do método RankSim. Nela estão contempladas as duas abordagens. 


\subsection{Função de Avaliação}

Para calcular a função de avaliação do algoritmo genético empregado no método proposto, definimos uma métrica para medir a similaridade entre os rankings. Essa métrica visa atribuir alta similaridade para pares de rankings em que a somatória das distâncias entre as posições dos exemplos em um ranking em relação às posições dos exemplos no outro ranking seja mínima. Essa métrica é representada pela Equação 4.3:

$$
\text { RankSim }=1-\frac{\sum_{i=0}^{n}|\operatorname{PosRegras}(i)-\operatorname{PosCPreta}(i)|}{\left\lfloor n^{2} / 2\right\rfloor}
$$

Nessa equação, $n$ é o número de exemplos utilizados para construir o ranking, PosRegras() é uma função que retorna a posição do exemplo $i$ no ranking das regras do indivíduo avaliado, PosCPreta(i) é a um função que retorna a posição do exemplo $i$ no ranking gerado pelo modelo caixa-preta. Desse modo, RankSim é o valor da função de avaliação, que retorna 1 para rankings idênticos, e 0 para o pior caso definido em nossa métrica, em que os rankings estão invertidos. O cálculo é feito somando-se as diferenças entre PosRegras $(i)$ e PosCPreta $(i)$ em módulo para cada exemplo no conjunto de exemplos utilizado no treinamento, dividindo o resultado pelo termo $\left\lfloor n^{2} / 2\right\rfloor$, que garante que o resultado ficará entre zero e um pois representa o pior caso e, por fim, subtrai-se esse valor de 1 para que a resposta seja 1 para rankings de maior similaridade.

Com isso, pudemos obter uma função com saída normalizada entre 0 e 1, o que facilita a execução do algoritmo genético, e que penaliza fortemente exemplos que seriam classificados incorretamente por regras com alta confiabilidade e penaliza apenas minimamente pequenas trocas de posição em locais próximos no ranking.

\subsection{Características do Algoritmo Genético}

No Algoritmo Genético empregado neste trabalho, cada indivíduo é um conjunto de regras.

A população inicial é composta de indivíduos que representam subconjuntos aleatórios de todas as regras geradas por vários indutores simbólicos, à partir de um conjunto de dados que foi utilizado para treinar o modelo caixapreta.

Os operadores genéticos utilizados foram cruzamento e mutação. O cruzamento é assimétrico, ou seja, duas posições são escolhidas, uma para cada indivíduo pai e os filhos são gerados recombinando os segmentos dos pais. Sendo assim, o tamanho dos indivíduos é variável. A mutação é realizada pela 
remoção ou inclusão de regras que não faziam parte dos pais.

Um exemplo de cruzamento é dado na Tabela 4.1. Cada número é um índice para uma das regras da base de regras geral.

Tabela 4.1: Operação de Cruzamento

\begin{tabular}{r|cccccc}
\hline pai1 & 04 & 02 & $\mid$ & 12 & 08 & 14 \\
\hline pai2 & 03 & 05 & 11 & $\mid$ & 09 & 13 \\
\hline filho1 & 04 & 02 & 09 & 13 & & \\
\hline filho2 & 03 & 05 & 11 & 12 & 08 & 14 \\
\hline
\end{tabular}

Os parâmetros do Algoritmo Genético são:

- ng - número de gerações;

- ni - número de indivíduos;

- ti - tamanho inicial do indivíduo (número de regras);

- pc - probabilidade de cruzamento;

- pm - probabilidade de mutação.

Nos experimentos do Capítulo 5 foram utilizados os parâmetros ng $=20$, $\mathrm{ni}=20, \mathrm{ti}=10, \mathrm{pc}=0.25 \mathrm{e} \mathrm{pm}=0.01$ em todos os conjuntos de dados.

\subsection{Considerações Finais}

Em nossos experimentos, utilizamos Máquinas de Vetores de Suporte como o modelo caixa-preta do qual as regras foram extraídas. Nesse tipo de modelo caixa-preta, altos valores em sua saída significam uma maior distância do exemplo em relação à fronteira de decisão traçada pelo modelo. Acreditamos portanto que a otimização da similaridade entre os rankings nesse caso pode levar à indução de regras que aproveitem as características de classificador de margens largas encontradas nas Máquinas de Vetores de Suporte.

A seguir, no Capítulo 5, serão apresentados esses experimentos e as algumas discussões a respeito dos resultados obtidos. 


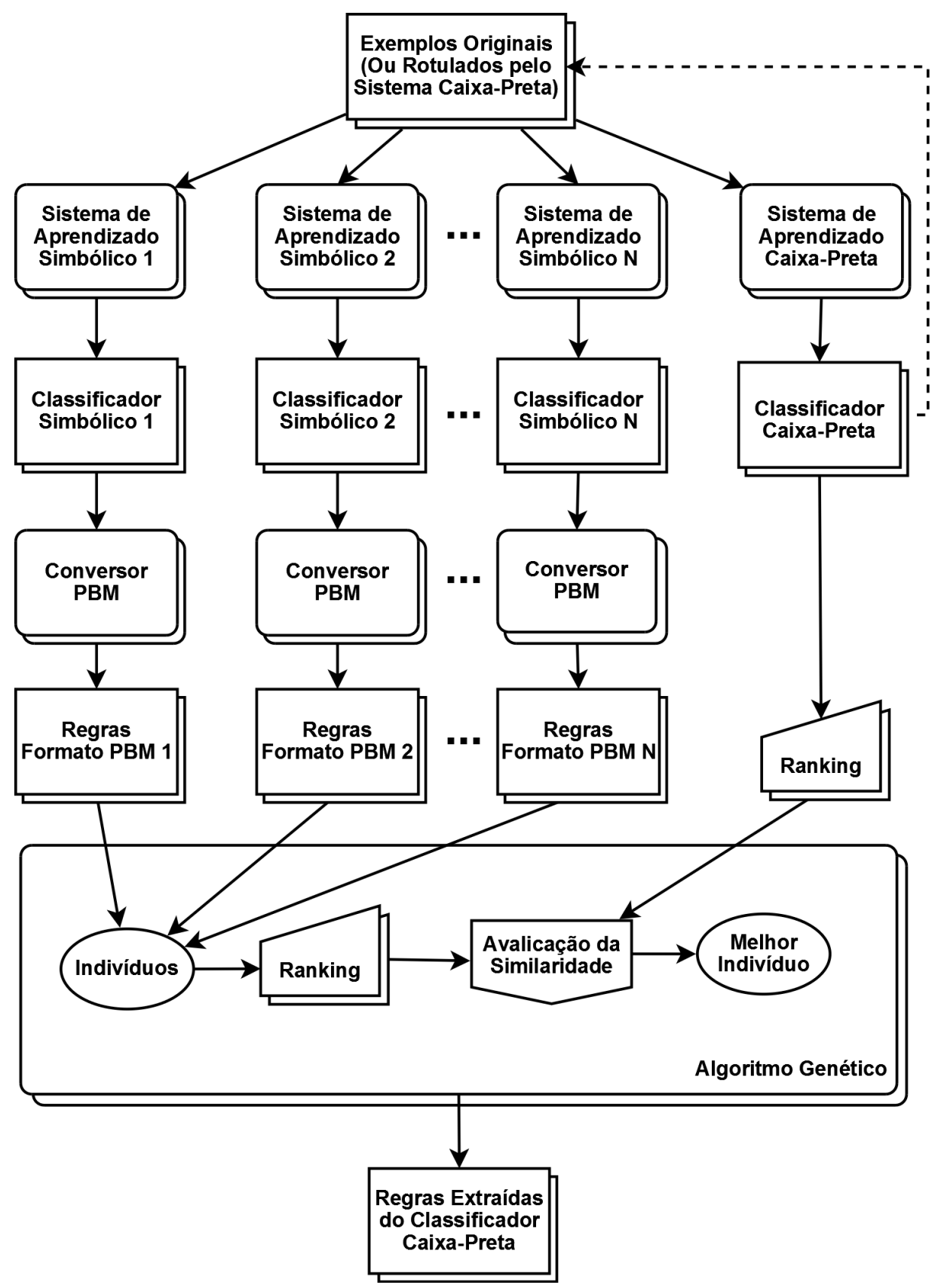

Figura 4.1: Método RankSim 


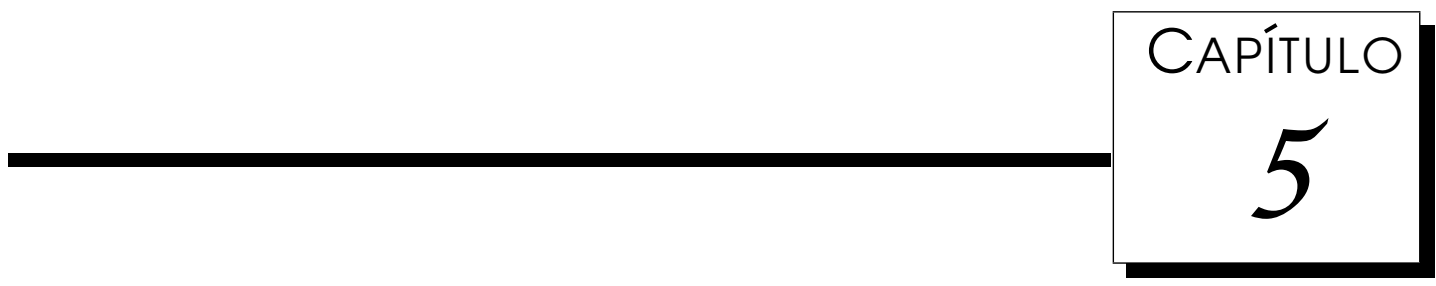

\section{Experimentos Realizados}

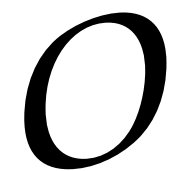

s experimentos descritos a seguir investigam o uso de regras produzidas por sistemas de Aprendizado de Máquina (AM) simbólicos e otimizadas por Algoritmos Genéticos (AGs) para explicar o conhecimento embutido em modelos de aprendizado de máquina caixa-preta.

Os experimentos estão divididos em duas fases. Na primeira fase, os métodos propostos por Milaré (2003), originais e adaptados para a extração de regras de SVMs, foram aplicados para realizar a extração de regras de RNAs e SVMs empregadas para identificar promotores em seqüências de nucleotídeos de E. Coli e para identificar junções de splice de humanos. Na segunda fase, foram realizados experimentos com o método RankSim, proposto nessa tese, para essas mesmas bases e em mais 14 bases do Repositório de AM da UCI (Blake and Merz, 1998).

\subsection{Fase I - Estudo preliminar de extração de regras de RNAs e SVMs por métodos de AM e AGs}

A Seção 5.1.1 explica sucintamente os problemas de biologia molecular investigados. A Seção 5.1.2 apresenta os conjuntos de dados utilizados nos experimentos. A Seção 5.1.3 descreve os experimentos conduzidos. Por fim, a Seção 5.1.4 apresenta os resultados obtidos.

\subsubsection{Identificação de Promotores e Sítios de Splice}

Um dos maiores problemas em biologia molecular é a identificação de genes em seqüências de DNA. A alta complexidade e variabilidade dos genes torna apropriado o uso de técnicas de AM, entre elas estão as RNAs e SVMs. Duas abordagens computacionais usualmente empregadas para o reconhecimento de genes são: busca por sinal e busca por conteúdo. A busca por sinal envolve a localização de marcas na seqüência associados com a presença de um gene. 
Dentre essas marcas, podemos citar promotores e junções de splice (Craven and Shavlik, 1994a).

Na maioria dos organismos, exceto os vírus de RNA, moléculas de DNA (Ácido Desoxirribonucléico) codificam as informações genéticas em uma seqüência de estruturas chamadas nucleotídeos, que podem ser de quatro tipos: Adenina (A), Citosina (C), Guanina (G) e Timina (T). Essa informação é organizada em genes posicionados ao longo da molécula de DNA. Os genes são seqüências de nucleotídeos que são transcritos em mRNA (Ácido Ribonucléico mensageiro) que é então traduzido em proteínas. Esse processo é chamado de expressão gênica (Lewin, 2000).

O processo de transcrição inicia com a ligação da RNA-polimerase a um sítio específico de uma seqüência de DNA. Esse sítio é chamado promotor. O promotor é uma seqüência de DNA que difere das seqüências que são transcritas ou traduzidas, já que sua função é: ser reconhecido por proteínas. Então, ele deve ser longo o suficiente para que possa ser unicamente reconhecido. $\mathrm{O}$ tamanho apropriado varia com o tamanho do genoma. Por exemplo, em um genoma bacterial, doze pares de bases constituem um sinal promotor apropriado.

O problema de reconhecimento de promotores está relacionado a identificar se uma dada seqüência de tamanho fixo contém um promotor (Y) ou não (N). Para realizar essa tarefa, classificadores baseados em RNAs podem ser induzidos.

A expressão gênica em organismos eucariotos é diferente da dos organismos procariotos. Genes eucariotos são compostos de segmentos alternados de exons e introns. Exons são regiões que codificam a proteína final. Introns intermediam os exons e não codificam proteínas. O processo de expressão gênica em eucariotos inclui um passo adicional, a eliminação de introns da molécula de mRNA. Esse processo é conhecido como splicing. A fronteira entre exons e introns é chamada junção de splice (ou sítios de splice).

O problemas do reconhecimento de junções de splice tratado nesse trabalho é a identificação de três tipos de seqüências de tamanho fixo: seqüências contendo um sítio intron/exon (IE), um sítio exon/intron (EI) e seqüências que não contém um sítio de splice.

\subsubsection{Conjuntos de Dados}

O conjunto de dados promoters (Promoter Gene Sequences Database) utilizado nesse trabalho foi extraído do Repositório de AM da UCI (Blake and Merz, 1998). Esse conjunto de dados contém 106 exemplos. Cada um dos 57 atributos pode assumir um de quatro valores representando os nucleotídeos (A, 
C, T, G). Esse é um problema de classificação binária, o que significa que cada exemplo é classificado como sendo um promotor ou não. Esse conjunto de dados é balanceado, tendo $50 \%$ de exemplos em cada classe.

Os conjuntos de dados splicen e spliceEI foram adaptados do "Splicejunction Gene Sequences Database", também extraído do Repositório de AM da UCI. O conjunto de dados spliceEI contém 1527 exemplos de sítios de splice divididos em duas classes: "Exon-Intron" 50\% e "Intron-Exon" 50\%. O conjunto de dados spliceN contém 3175 exemplos divididos em duas classes: "Sítio de Splice" 50\% e "Não Sítio de Splice" 50\%. Em ambos os conjuntos de dados, cada um dos 60 atributos pode assumir valores representando um dos quatro nucleotídeos (A, C, T, G). Exemplos com atributos desconhecidos foram removidos.

\subsubsection{Experimentos}

Os três conjuntos de dados foram divididos utilizando a metodologia $k$-fold stratified cross-validation (Weiss and Kulikowski, 1991), com $\mathrm{k}=10$, obtendo 10 conjuntos de treinamento e 10 conjuntos de teste para cada conjunto de dados. Em seguida, cada conjunto de treinamento foi subdividido em um conjunto de treinamento menor, contendo 90 dos exemplos de treinamento, e conjunto de validação, contendo 10 dos exemplos de treinamento.

Os algoritmos simbólicos C4.5, C4.5rules e CN2 foram executados com seus valores de parâmetros padrão em todas as partições para todos os conjuntos de dados. Como resultado, 90 classificadores foram induzidos. O erro médio estimado dos 10 classificadores de cada sistema de AM simbólico foi medido usando o conjunto de teste.

Várias redes MLP foram treinadas com o algoritmo backpropagation with momentum utilizando seus parâmetros padrão, uma para cada conjunto de dados. A mesma metodologia de validação-cruzada empregada para os sistemas de AM simbólico foi utilizada. A topologia das RNAs treinadas com o conjunto de dados promoters continha uma camada de entrada com 228 unidades, uma camada escondida com 456 unidades e uma camada de saída com uma única unidade. A topologia para as RNAs treinadas para ambos os conjuntos de dados splicen e spliceEI contém uma camada de entrada com 240 unidades, uma camada escondida com 480 unidades e uma camada de saída com uma única unidade. Para realizar os experimentos, o simulador SNNS foi empregado (Zell, 1995). Para determinar a classe da saída de uma RNA, uma função limite foi empregada. A classe da saída da RNA é 1 se o valor do nó de saída for maior que 0.5 , e a classe será 0 , caso contrário.

SVMs com kernel gaussiano e parâmetros padrão foram treinadas, uma 
para cada conjunto de dados. Foi utilizado para isso o indutor SVMTorch (Collobert and Bengio, 2001).

Em seguida, os métodos descritos na Seção 3.6 foram empregados para extrair regras a partir das RNAs treinadas. Os resultados foram medidos e testes de hipóteses foram realizados. Utilizando uma adaptação desses métodos para SVMs, os experimentos foram realizados novamente para extrair regras a partir das SVMs treinadas para comparar os resultados. Esses resultados são apresentados na próxima seção.

\subsubsection{Resultados}

A Tabela 5.1 mostra a taxa de erro obtida pelas RNAs, SVMs e os sistemas de AM simbólico C4.5, C4.5rules e CN2.

Os resultados dos sistemas de AM simbólico com os conjuntos de dados originais foram utilizados apenas para comparação com as RNAs e SVMs. Os melhores resultados estão em negrito. Pode ser observado que a RNA foi melhor que os sistemas de AM simbólicos para os conjuntos de dados promoters e spliceEI. Nesses mesmos conjuntos de dados, a SVM foi melhor que a RNA. O C4.5, um dos sistemas de AM simbólico, obteve o melhor resultado para o conjunto de dados splicen.

Tabela 5.1: Taxa de Erro (média e desvio padrão)(\%).

\begin{tabular}{l|c|c|c}
\hline \hline & promoters & spliceEI & spliceN \\
\hline C4.5 & $16.91 \pm 2.25$ & $4.65 \pm 0.54$ & $\mathbf{4 . 1 6} \pm \mathbf{0 . 3 7}$ \\
\hline C4.5rules & $15.18 \pm 2.11$ & $4.91 \pm 0.40$ & $4.72 \pm 0.46$ \\
\hline CN2 & $26.27 \pm 4.21$ & $5.77 \pm 0.77$ & $5.79 \pm 0.46$ \\
\hline RNA & $14.09 \pm 3.16$ & $4.00 \pm 0.44$ & $6.55 \pm 0.53$ \\
\hline SVM & $\mathbf{1 2 . 3 6} \pm \mathbf{2 . 1 6}$ & $\mathbf{2 . 8 8} \pm \mathbf{0 . 1 5}$ & $5.48 \pm 0.36$ \\
\hline \hline
\end{tabular}

A taxa de infidelidade entre os métodos de extração de conhecimento e as RNAs e SVMs foi medido usando o conjunto de teste. A taxa de infidelidade é a porcentagem dos exemplos do conjunto de teste em que a classificação feita por uma RNA ou SVM discorda da classificação feita pelo método utilizado para explicar o comportamento da RNA ou SVM. A Tabela 5.2 mostra a taxa de infidelidade obtida pelos métodos de extração de conhecimento de RNAs e a Tabela 5.3 mostra a taxa de infidelidade obtida pelos mesmos métodos, adaptados para extração de conhecimento de SVMs. AGPP é o método baseado em AGs com a fase de pós-processamento descrita na Seção 3.6.2.

A compreensibilidade sintática do conhecimento extraído pelos métodos de extração de conhecimento foi medida utilizando o número de regras induzidas e o número médio de condições induzidas por regra. As tabelas 5.4 e 5.5 mostram o número médio de regras induzidas e as tabelas 5.6 e 5.7 mostram 
o número de condições por regra induzida, para os casos de RNAs e SVMs respectivamente. Em todas as tabelas os melhores resultados estão em negrito.

Tabela 5.2: Taxa de infidelidade (RNAs - média e desvio padrão)(\%).

\begin{tabular}{l|c|c|c}
\hline \hline & promoters & spliceEI & spliceN \\
\hline C4.5 & $33.00 \pm 4.28$ & $\mathbf{5 . 9 6} \pm \mathbf{0 . 5 9}$ & $\mathbf{6 . 9 0} \pm \mathbf{0 . 3 8}$ \\
\hline C4.5rules & $28.45 \pm 4.32$ & $6.48 \pm 0.42$ & $6.90 \pm 0.42$ \\
\hline CN2 & $30.09 \pm 4.22$ & $6.22 \pm 0.93$ & $8.66 \pm 0.55$ \\
\hline AG & $28.18 \pm 4.52$ & $6.15 \pm 0.56$ & $9.10 \pm 0.72$ \\
\hline AGPP & $\mathbf{2 7 . 1 8} \pm \mathbf{4 . 1 1}$ & $6.55 \pm 0.65$ & $10.45 \pm 0.89$ \\
\hline \hline
\end{tabular}

Tabela 5.3: Taxa de infidelidade (SVMs - média e desvio padrão)(\%).

\begin{tabular}{l|c|c|c}
\hline \hline & promoters & spliceEI & spliceN \\
\hline C4.5 & $22.63 \pm 3.21$ & $\mathbf{3 . 8 0} \pm \mathbf{0 . 3 2}$ & $\mathbf{5 . 6 4} \pm \mathbf{0 . 3 2}$ \\
\hline C4.5rules & $17.09 \pm 2.78$ & $5.31 \pm 0.71$ & $6.55 \pm 0.40$ \\
\hline CN2 & $23.54 \pm 4.89$ & $8.12 \pm 0.58$ & $7.40 \pm 0.43$ \\
\hline AG & $\mathbf{1 7 . 0 0} \pm \mathbf{4 . 0 0}$ & $4.13 \pm 0.49$ & $6.24 \pm 0.55$ \\
\hline AGPP & $26.27 \pm 4.67$ & $5.37 \pm 0.74$ & $8.54 \pm 1.69$ \\
\hline \hline
\end{tabular}

Tabela 5.4: Número de regras induzidas (RNAs - média e desvio padrão).

\begin{tabular}{l|c|c|c}
\hline \hline & promoters & spliceEI & spliceN \\
\hline C4.5 & $15.70 \pm 0.54$ & $33.40 \pm 1.40$ & $85.90 \pm 1.85$ \\
\hline C4.5rules & $6.90 \pm 0.50$ & $21.90 \pm 0.84$ & $60.40 \pm 1.26$ \\
\hline CN2 & $12.60 \pm 0.34$ & $44.60 \pm 1.34$ & $107.20 \pm 0.90$ \\
\hline AG & $21.10 \pm 2.46$ & $37.60 \pm 5.33$ & $46.00 \pm 11.06$ \\
\hline AGPP & $\mathbf{6 . 8 0} \pm \mathbf{0 . 7 4}$ & $\mathbf{1 6 . 0 0} \pm \mathbf{2 . 6 5}$ & $\mathbf{2 0 . 4 0} \pm \mathbf{4 . 4 6}$ \\
\hline \hline
\end{tabular}

Tabela 5.5: Número de regras induzidas (SVMs - média e desvio padrão).

\begin{tabular}{l|c|c|c}
\hline \hline & promoters & spliceEI & spliceN \\
\hline C4.5 & $15.10 \pm 1.19$ & $34.00 \pm 0.77$ & $85.90 \pm 2.41$ \\
\hline C4.5rules & $7.30 \pm 0.47$ & $22.00 \pm 0.56$ & $61.30 \pm 1.40$ \\
\hline CN2 & $12.30 \pm 0.21$ & $41.80 \pm 0.76$ & $112.00 \pm 1.37$ \\
\hline AG & $15.30 \pm 1.96$ & $50.70 \pm 6.73$ & $89.90 \pm 5.82$ \\
\hline AGPP & $\mathbf{5 . 2 0} \pm \mathbf{0 . 9 2}$ & $\mathbf{1 6 . 2 0} \pm \mathbf{2 . 5 7}$ & $\mathbf{3 1 . 2 0} \pm \mathbf{3 . 8 2}$ \\
\hline \hline
\end{tabular}

O teste de hipóteses 10-fold cross-validated paired test Dietterich (1997) foi utilizado para comparar as taxas de infidelidade e compreensibilidade entre os métodos de extração de conhecimento. De acordo com esse teste, a diferença entre dois algoritmos é estatisticamente significante com 95\% de confiabilidade, se o resultado desse teste é maior do que 2.262 em valor absoluto. 
Tabela 5.6: Número médio de condições por regra induzida (RNAs - média e desvio padrão).

\begin{tabular}{l|c|c|c}
\hline \hline & promoters & spliceEI & spliceN \\
\hline C4.5 & $2.27 \pm 0.03$ & $4.21 \pm 0.08$ & $4.06 \pm 0.04$ \\
\hline C4.5rules & $\mathbf{1 . 4 0} \pm \mathbf{0 . 0 3}$ & $\mathbf{2 . 2 3} \pm \mathbf{0 . 0 3}$ & $\mathbf{2 . 3 9} \pm \mathbf{0 . 0 2}$ \\
\hline CN2 & $1.98 \pm 0.02$ & $2.64 \pm 0.03$ & $3.30 \pm 0.02$ \\
\hline AG & $2.01 \pm 0.03$ & $3.15 \pm 0.08$ & $3.45 \pm 0.03$ \\
\hline AGPP & $1.78 \pm 0.74$ & $2.45 \pm 0.13$ & $2.77 \pm 0.06$ \\
\hline \hline
\end{tabular}

Tabela 5.7: Número médio de condições por regra induzida (SVMs - média e desvio padrão).

\begin{tabular}{l|c|c|c}
\hline \hline & promoters & spliceEI & spliceN \\
\hline C4.5 & $2.24 \pm 0.07$ & $4.20 \pm 0.05$ & $4.06 \pm 0.05$ \\
\hline C4.5rules & $\mathbf{1 . 5 2} \pm \mathbf{0 . 0 5}$ & $\mathbf{2 . 2 4} \pm \mathbf{0 . 0 4}$ & $\mathbf{2 . 3 7} \pm \mathbf{0 . 0 4}$ \\
\hline CN2 & $1.96 \pm 0.02$ & $2.59 \pm 0.03$ & $3.27 \pm 0.02$ \\
\hline AG & $1.99 \pm 0.07$ & $3.42 \pm 0.19$ & $3.32 \pm 0.21$ \\
\hline AGPP & $1.78 \pm 0.09$ & $2.30 \pm 0.04$ & $2.70 \pm 0.14$ \\
\hline \hline
\end{tabular}

As Tabelas 5.8 e 5.9 mostram os resultados do 10 -fold cross-validated paired test para RNAs e SVMs respectivamente. O símbolo $\triangle$ indica que o método baseado em AGs superou o método baseado em AM simbólico enquanto o símbolo $\Delta$ indica que a superação tem um nível de confiança maior que 95. Por outro lado, os símbolos $\nabla$ e $\boldsymbol{\nabla}$ indicam que o método baseado em AM simbólico superou o método baseado em AG.

Começando com as RNAs, em relação à taxa de infidelidade, pode ser visto que o método baseado em AGs foi melhor que as abordagens baseadas em AM simbólico para o conjunto de dados promoters, embora não com 95 de confiabilidade. Para o conjunto de dados splicen, as abordagens baseadas em AM simbólico foram melhores que o método baseado em AGs com 95\% de confiança em quatro experimentos. Para o conjunto de dados spliceEI, os resultados foram similares para todos os métodos.

Olhando o número de regras, o método baseado em AGs foi melhor para ambos os conjuntos de dados spliceEI e splicen. Para o conjunto de dados promoters, as abordagens simbólicas foram melhores do que o método baseado em AGs em três experimentos e piores em dois deles, considerando apenas os experimentos em que o teste de hipóteses apresentou 95\% de confiabilidade.

Finalmente, levando em consideração o número de condições por regra, os resultados obtidos foram similares para todos os conjuntos de dados.

No caso das SVMs, em relação à taxa de infidelidade, pode ser visto que o método baseado em AGs foi melhor que as abordagens baseadas em AM simbólico para o conjunto de dados promoters e sua extensão com a fase de 
Tabela 5.8: Resultados do 10-Fold Cross-Validated Paired t Test (RNAs).

\begin{tabular}{|c|c|c|c|c|c|c|}
\hline & \multicolumn{6}{|c|}{ promoters } \\
\hline & \multicolumn{2}{|c|}{ Infidelidade } & \multicolumn{2}{|c|}{ No. de Regras } & \multicolumn{2}{|c|}{ Cond./Regra } \\
\hline & AG & AGPP & $\mathrm{AG}$ & AGPP & AG & AGPP \\
\hline C4.5 & $\triangle$ & $\triangle$ & $\boldsymbol{\nabla}$ & $\Delta$ & $\Delta$ & $\Delta$ \\
\hline C4.5rules & $\Delta$ & $\Delta$ & $\boldsymbol{\nabla}$ & $\Delta$ & $\nabla$ & $\nabla$ \\
\hline \multirow[t]{4}{*}{ CN2 } & $\triangle$ & $\triangle$ & $\nabla$ & $\Delta$ & $\triangle$ & $\triangle$ \\
\hline & \multicolumn{6}{|c|}{ spliceEI } \\
\hline & \multicolumn{2}{|c|}{ Infidelidade } & \multicolumn{2}{|c|}{ No. de Regras } & \multicolumn{2}{|c|}{ Cond./Regra } \\
\hline & $\mathrm{AG}$ & AGPP & $\mathrm{AG}$ & AGPP & $\mathrm{AG}$ & AGPP \\
\hline C4.5 & $\nabla$ & $\nabla$ & $\nabla$ & $\Delta$ & $\Delta$ & $\Delta$ \\
\hline C4.5rules & $\Delta$ & $\nabla$ & $\Delta$ & $\Delta$ & $\boldsymbol{\nabla}$ & $\nabla$ \\
\hline \multirow[t]{4}{*}{ CN2 } & $\triangle$ & $\nabla$ & $\triangle$ & $\Delta$ & $\nabla$ & $\nabla$ \\
\hline & \multicolumn{6}{|c|}{ spliceN } \\
\hline & \multicolumn{2}{|c|}{ Infidelidade } & \multicolumn{2}{|c|}{ No. de Regras } & \multicolumn{2}{|c|}{ Cond./Regra } \\
\hline & $A G$ & AGPP & $\mathrm{AG}$ & AGPP & $A G$ & AGPP \\
\hline C4.5 & $\nabla$ & $\nabla$ & $\Delta$ & $\Delta$ & $\Delta$ & $\Delta$ \\
\hline C4.5rules & $\nabla$ & $\nabla$ & $\triangle$ & $\Delta$ & $\nabla$ & $\nabla$ \\
\hline $\mathrm{CN} 2$ & $\nabla$ & $\nabla$ & $\Delta$ & $\Delta$ & $\nabla$ & $\Delta$ \\
\hline
\end{tabular}

pós-processamento (AGPP) foi pior em todos os casos, embora não com 95\% de confiabilidade. Para o conjunto de dados spliceEI, o método baseado em AGs foi melhor que as abordagens baseadas em AM simbólico com 95\% de confiabilidade em dois experimentos e pior em um deles. Para o conjunto de dados splicen, o método baseado em AGs foi melhor com 95\% de confiabilidade em apenas um experimento.

Quanto ao número de regras, o método baseado em AGs com a fase de pósprocessamento (AGPP) foi melhor em todos experimentos em todos os conjuntos de dados com 95\% de confiabilidade. A versão sem a fase de pósprocessamento foi pior em quase todos os experimentos. Somente no conjunto de dados splicen o método baseado em AGs sem o pós-processamento foi melhor em um dos experimentos.

Assim como no caso das RNAs, levando em consideração o número de condições por regra, os resultados obtidos foram similares para todos os conjuntos de dados.

Por fim, o 10-Fold Cross-Validated Paired t Test foi utilizado para comparar os métodos de extração de conhecimento quando utilizados para extrair regras de RNAs e quando utilizados para extrair regras de SVMs.

A Tabela 5.10 apresenta os resultados destes testes. O símbolo $\diamond$ é utilizado para indicar a abordagem que obteve o melhor resultado e o símbolo $\checkmark$ indica que o resultado é estatisticamente significante com mais de $95 \%$ de confiabilidade.

É interessante notar que, em relação à taxa de infidelidade, quase todos os experimentos tiveram melhores resultados quando aplicados a SVMs, sendo 
Tabela 5.9: Resultados do 10-Fold Cross-Validated Paired t Test (SVMs).

\begin{tabular}{|c|c|c|c|c|c|c|}
\hline & \multicolumn{6}{|c|}{ promoters } \\
\hline & \multicolumn{2}{|c|}{ Infidelidade } & \multicolumn{2}{|c|}{ No. de Regras } & \multicolumn{2}{|c|}{ Cond./Regra } \\
\hline & AG & AGPP & $A G$ & AGPP & AG & AGPP \\
\hline C4.5 & $\triangle$ & $\nabla$ & $\nabla$ & $\Delta$ & $\Delta$ & $\Delta$ \\
\hline C4.5rules & $\Delta$ & $\nabla$ & $\nabla$ & $\Delta$ & $\nabla$ & $\nabla$ \\
\hline \multirow[t]{4}{*}{$\mathrm{CN} 2$} & $\triangle$ & $\nabla$ & $\nabla$ & $\Delta$ & $\nabla$ & $\Delta$ \\
\hline & \multicolumn{6}{|c|}{ spliceEI } \\
\hline & \multicolumn{2}{|c|}{ Infidelidade } & \multicolumn{2}{|c|}{ No. de Regras } & \multicolumn{2}{|c|}{ Cond./Regra } \\
\hline & $A G$ & AGPP & $\overline{A G}$ & AGPP & $\mathrm{AG}$ & AGPP \\
\hline C4.5 & $\nabla$ & $\nabla$ & $\nabla$ & $\Delta$ & $\Delta$ & $\Delta$ \\
\hline C4.5rules & $\Delta$ & $\nabla$ & $\nabla$ & $\Delta$ & $\nabla$ & $\nabla$ \\
\hline \multirow[t]{4}{*}{$\mathrm{CN} 2$} & $\Delta$ & $\Delta$ & $\nabla$ & $\Delta$ & $\boldsymbol{\nabla}$ & $\Delta$ \\
\hline & \multicolumn{6}{|c|}{ spliceN } \\
\hline & \multicolumn{2}{|c|}{ Infidelidade } & \multicolumn{2}{|c|}{ No. de Regras } & \multicolumn{2}{|c|}{ Cond./Regra } \\
\hline & $\mathrm{AG}$ & AGPP & $\mathrm{AG}$ & AGPP & $A G$ & AGPP \\
\hline C4.5 & $\nabla$ & $\nabla$ & $\nabla$ & $\boldsymbol{\Delta}$ & $\Delta$ & $\Delta$ \\
\hline C4.5rules & $\triangle$ & $\nabla$ & $\nabla$ & $\Delta$ & $\nabla$ & $\nabla$ \\
\hline $\mathrm{CN} 2$ & $\Delta$ & $\nabla$ & $\Delta$ & $\Delta$ & $\nabla$ & $\Delta$ \\
\hline
\end{tabular}

Tabela 5.10: Comparação da aplicação de métodos de extração de regras em RNAs e em SVMs).

\begin{tabular}{|c|c|c|c|c|c|c|}
\hline & \multicolumn{6}{|c|}{ promoters } \\
\hline & \multicolumn{2}{|c|}{ Infidelidade } & \multicolumn{2}{|c|}{ No. de Regras } & \multicolumn{2}{|c|}{ Cond./Regra } \\
\hline & RNA & SVM & RNA & SVM & RNA & SVM \\
\hline C4.5 & & $\vartheta$ & & $\diamond$ & & $\diamond$ \\
\hline C4.5rules & & $\nabla$ & $\nabla$ & & $\nabla$ & \\
\hline CN2 & & $\diamond$ & & $\diamond$ & & $\diamond$ \\
\hline$A G$ & & $\diamond$ & & $\diamond$ & & $\diamond$ \\
\hline \multirow[t]{4}{*}{ AGPP } & & $\diamond$ & & $\diamond$ & $\diamond$ & \\
\hline & \multicolumn{6}{|c|}{ spliceEI } \\
\hline & \multicolumn{2}{|c|}{ Infidelidade } & \multicolumn{2}{|c|}{ No. de Regras } & \multicolumn{2}{|c|}{ Cond./Regra } \\
\hline & RNA & SVM & RNA & SVM & RNA & SVM \\
\hline C4.5 & & 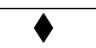 & $\diamond$ & & & $\diamond$ \\
\hline C4.5rules & & $\nabla$ & $\diamond$ & & $\diamond$ & \\
\hline CN2 & $\nabla$ & & & $\diamond$ & & $\diamond$ \\
\hline$A G$ & & $\boldsymbol{\nabla}$ & $\diamond$ & & $\diamond$ & \\
\hline \multirow[t]{4}{*}{ AGPP } & & $\nabla$ & $\diamond$ & & & $\diamond$ \\
\hline & \multicolumn{6}{|c|}{ spliceN } \\
\hline & \multicolumn{2}{|c|}{ Infidelidade } & \multicolumn{2}{|c|}{ No. de Regras } & \multicolumn{2}{|c|}{ Cond./Regra } \\
\hline & RNA & SVM & RNA & SVM & RNA & SVM \\
\hline C4.5 & & $\diamond$ & $\diamond$ & & $\diamond$ & \\
\hline C4.5rules & & $\nabla$ & $\nabla$ & & & $\nabla$ \\
\hline CN2 & & $\nabla$ & $\nabla$ & & & $\diamond$ \\
\hline$A G$ & & $\boldsymbol{\nabla}$ & $\boldsymbol{\nabla}$ & & & $\diamond$ \\
\hline AGPP & & $\diamond$ & $\diamond$ & & & $\diamond$ \\
\hline
\end{tabular}

que 5 obtiveram 95\% de confiabilidade no teste de hipóteses. Apenas um experimento, no conjunto de dados spliceEI, obteve um melhor resultado quando aplicado à RNAs, e mesmo assim, não com 95\% de confiabilidade.

Em relação ao número de regras, os métodos foram melhores quando apli- 
cados a RNAs nos conjuntos de dados spliceEI e splicen e piores para o conjunto promoters, porém, de todos os experimentos, apenas dois obtiveram 95\% de confiabilidade.

Finalmente, em relação ao número de condições por regra, os resultados foram similares e nenhum experimento apresentou 95\% de confiabilidade.

Esses resultados nos motivaram a investigar melhor a aplicação de AGs para otimizar regras geradas por sistemas de AM simbólico para a extração de regras. A comparação entre a extração de regras de RNAs e SVMs utilizando os métodos propostos por Milaré (2003) foi bem interessante. Notou-se que em relação à fidelidade, os métodos obtiveram melhores resultados quando aplicados a SVMs.

Uma possível explicação para isso é o fato de as SVMs terem tido uma acurácia maior na classificação do que as RNAs. Observou-se então que a fidelidade dos métodos é elevada em situações em que ambos os sistemas de aprendizado, caixa-preta e simbólicos, têm acurácia elevada na classificação do conjunto de dados original. Porém, nesses casos em que a SVM tem alta acurácia de classificação, observa-se que o conjunto de dados rotulado pela SVM é muito parecido com o conjunto de dados original e, sendo assim, as regras extraídas, apesar da alta fidelidade, podem não refletir a forma com a qual a SVM classifica os exemplos.

Esse foi um dos fatores que nos motivaram a investir na investigação da extração de regras de SVMs, pois na época não encontramos nenhum trabalho publicado com esse tema.

\subsection{Fase II - Experimentos com o método RankSim}

Nessa fase foram realizados experimentos com diversos conjuntos de dados utilizando o método RankSim para extrair regras dos modelos induzidos por SVMs. Nesses experimentos, o RankSim foi utilizado no modo classe original, isto é, sem que a SVM rotulasse os exemplos para a geração das regras a serem otimizadas pelo algoritmo genético. Nosso objetivo é verificar se, com a informação obtida por meio da comparação da similaridade dos rankings, é possivel extrair regras com boa fidelidade e boa acurácia, mesmo quando não há rótulos atribuídos pela SVM aos exemplos.

A seguir, são apresentados os resultados para os 17 conjuntos de dados utilizados, retirados do Repositório de AM da UCI (Blake and Merz, 1998). Na Tabela 5.11 há um resumo das características desses conjuntos. Assim como na Fase I, os conjuntos de dados foram divididos utilizando a metodologia $k$-fold stratified cross-validation, com $\mathrm{k}=10$, obtendo 10 conjuntos de treinamento e 10 conjuntos de teste para cada conjunto de dados. 
Para cada conjunto de dados, três tabelas são apresentadas. Na primeira tabela, comparamos a acurácia de três indutores simbólicos, da SVM e das regras extraídas pelo RankSim. Para cada uma dessas comparações foi utilizado o teste de hipóteses 10 -fold cross-validated paired test, descrito na seção anterior. Por fim, a fidelidade é apresentada na última coluna. Na segunda tabela, é apresentado o número de regras geradas por cada indutor simbólico e o teste de hipóteses também é utilizado para realizar a comparação com as regras extraídas. Analogamente, na terceira tabela, o número de condições por regra de cada indutor é apresentado e a mesma metodologia de comparação é utilizada.

\begin{tabular}{c||c|c|c|c}
\multicolumn{5}{c}{ Tabela 5.11: Descrição dos Conjuntos de Dados } \\
Conjunto & \# Exemplos & \# Atributos & Classe & Classe Maj. (\%) \\
\hline \hline breast & 683 & 9 & (positive,negative) & 65.00 \\
\hline bupa & 345 & 6 & (positive,negative) & 57.98 \\
\hline ecoli & 336 & 7 & (iMU,remainder) & 89.58 \\
\hline flag & 194 & 28 & (white,remainder) & 91.24 \\
\hline flare & 1066 & 10 & (positive,negative) & 79.41 \\
\hline Glass & 214 & 9 & (Ve-win-float-proc,rem.) & 92.06 \\
\hline Haberman & 306 & 3 & (Die,Survive) & 82.93 \\
\hline heart & 267 & 22 & (positive,negative) & 55.55 \\
\hline pima & 768 & 8 & (1,0) & 65.23 \\
\hline ionosphere & 351 & 33 & (positive,negative) & 64.10 \\
\hline New-thyroid & 215 & 5 & (hypo,remainder) & 83.72 \\
\hline Post-operative & 90 & 8 & (S,remainder) & 73.33 \\
\hline Satimage & 6435 & 36 & (4,remainder) & 90.27 \\
\hline SpliceN & 3175 & 60 & (positive,negative) & 50.00 \\
\hline SpliceEI & 1527 & 60 & (EI,IE) & 50.00 \\
\hline promoters & 106 & 57 & (positive,negative) & 50.00 \\
\hline German & 1000 & 20 & (Bad,Good) & 70.00 \\
\hline
\end{tabular}

\subsubsection{Conjunto breast}

Como pode ser observado na Tabela 5.12, para esse conjunto de dados, todos os classificadores, com exceção do CN2, tiveram uma boa acurácia, com um erro médio baixo. O RankSim, além de obter uma boa acurácia, também obteve uma boa fidelidade. Isso significa que ele conseguiu, por meio da similaridade dos rankings, escolher boas regras, em sua maioria provenientes do C4.5 e C4.5rules, uma vez que a acurácia do CN2 foi baixíssima. No teste de hipóteses, apenas o CN2 foi pior em acurácia, com 95\% de confiabilidade, em relação ao RankSim. A diferença de acurácia entre o RankSim e os outros não é significativa.

Em relação ao números de regras, apresentados na Tabela 5.13, novamente o CN2 foi pior, com 95\% de confiabilidade em relação ao RankSim. Os outros 
Tabela 5.12: Conjunto breast - Acurácia e Fidelidade (\%).

\begin{tabular}{r||r|r|r|r|r||r}
\hline \hline & C4.5 & C4.5Rules & CN2 & SVM & RankSim & Fidelidade \\
\hline \hline Erro Médio & 4.68 & 4.83 & 56.48 & 5.27 & 4.98 & 5.26 \\
\hline Desvio Padrão & 0.47 & 0.54 & 0.59 & 0.80 & 1.25 & 0.98 \\
\hline Teste T & -0.26 & -0.15 & 33.04 & 0.20 & & \\
\hline \hline
\end{tabular}

sistemas induziram menos regras do que o RankSim, mas não tiveram 95\% de confiabilidade no teste de hipóteses.

Tabela 5.13: Conjunto breast - Número de Regras.

\begin{tabular}{r||r|r|r|r}
\hline \hline & C4.5 & C4.5Rules & CN2 & RankSim \\
\hline \hline Regras & 10.60 & 9.40 & 15.30 & 11.90 \\
\hline Desvio Padrão & 0.56 & 0.40 & 0.47 & 1.35 \\
\hline Teste T & -0.83 & -1.73 & 2.68 & \\
\hline \hline
\end{tabular}

Em condições por regra, a Tabela 5.14 mostra que o RankSim foi melhor que o $\mathrm{C} 4.5$ e pior que o $\mathrm{C} 4.5$ rules, com $95 \%$ de confiabilidade, e foi equivalente ao CN2.

Tabela 5. 14: Conjunto breast - Número de Condições por Regra.

\begin{tabular}{r||r|r|r|r}
\hline \hline & C4.5 & C4.5Rules & CN2 & RankSim \\
\hline \hline Condições por Regra & 3.98 & 2.32 & 2.72 & 2.85 \\
\hline Desvio Padrão & 0.12 & 0.05 & 0.04 & 0.17 \\
\hline Teste T & 8.41 & -2.79 & -0.76 & \\
\hline \hline
\end{tabular}

\subsubsection{Conjunto bupa}

Neste conjunto de dados houve um equilíbrio estatístico na acurácia de todos os classificadores, porém, o melhor foi o C4.5rules, como pode ser verificado na Tabela 5.15. É interessante notar que nesse conjunto de dados, a taxa de fidelidade do RankSim é maior que sua taxa de acurácia, apesar de ambos valores serem relativamente altos.

Tabela 5.15: Conjunto bupa - Acurácia e Fidelidade (\%).

\begin{tabular}{r||r|r|r|r|r||r}
\hline \hline & C4.5 & C4.5Rules & CN2 & SVM & RankSim & Fidelidade \\
\hline \hline Erro Médio & 35.08 & 31.29 & 34.44 & 37.97 & 36.29 & 31.89 \\
\hline Desvio Padrão & 2.55 & 1.79 & 3.12 & 2.25 & 1.83 & 1.85 \\
\hline Teste T & -0.36 & -1.83 & -0.50 & 0.49 & & \\
\hline \hline
\end{tabular}

De acordo com a Tabela 5.16, em relação ao número de regras, o C4.5rules 
foi melhor que o RankSim com 95\% de confiabilidade. Os outros indutores foram piores que o RankSim.

Tabela 5.16: Conjunto bupa - Número de Regras.

\begin{tabular}{r||r|r|r|r}
\hline \hline & C4.5 & C4.5Rules & CN2 & RankSim \\
\hline \hline Regras & 29.50 & 15.70 & 31.80 & 28.10 \\
\hline Desvio Padrão & 1.97 & 1.10 & 0.70 & 3.10 \\
\hline Teste T & 0.83 & -4.78 & 1.31 & \\
\hline \hline
\end{tabular}

A Tabela 5.17 mostra que, em relação à quantidade de condições por regra, o RankSim foi melhor que o $\mathrm{C} 4.5$ e pior que o C4.5rules e CN2, todos com 95\% de confiabilidade.

Tabela 5.17: Conjunto bupa - Número de Condições por Regra.

\begin{tabular}{r||r|r|r|r}
\hline \hline & C4.5 & C4.5Rules & CN2 & RankSim \\
\hline \hline Condições por Regra & 5.96 & 3.11 & 3.37 & 4.20 \\
\hline Desvio Padrão & 0.22 & 0.07 & 0.04 & 0.16 \\
\hline Teste T & 20.22 & -6.93 & -5.00 & \\
\hline
\end{tabular}

\subsubsection{Conjunto ecoli}

Assim como no conjunto bupa, pode se verificar no conjunto ecoli, na Tabela 5.18, que a fidelidade do método RankSim foi maior que sua acurácia, porém, nesse caso, tanto a acurácia quanto a fidelidade apresentam boas taxas. Comparativamente, a acurácia do RankSim foi pior que a do C4.5 com 95\% de confiabilidade, pior que a do C4.5rules, porém, foi melhor que a do CN2 com 95\% de confiabilidade e foi praticamente equivalente à da SVM no teste de hipóteses $\mathrm{T}$.

Tabela 5.18: Conjunto ecoli - Acurácia e Fidelidade (\%).

\begin{tabular}{r||r|r|r|r|r||r}
\hline \hline & C4.5 & C4.5Rules & CN2 & SVM & RankSim & Fidelidade \\
\hline \hline Erro Médio & 7.74 & 8.94 & 30.53 & 11.02 & 10.41 & 5.35 \\
\hline Desvio Padrão & 1.27 & 1.19 & 2.99 & 0.91 & 1.01 & 1.45 \\
\hline Teste T & -2.87 & -1.34 & 6.06 & 0.41 & & \\
\hline \hline
\end{tabular}

Como pode ser visto na Tabela 5.19, nesse conjunto de dados, o RankSim foi melhor que todos os outros indutores em relação à quantidade de regras induzidas, sendo que em relação ao C4.5 a diferença é estatisticamente significante com 95\% de confiabilidade. 
Tabela 5.19: Conjunto ecoli - Número de Regras.

\begin{tabular}{r||r|r|r|r}
\hline \hline & C4.5 & C4.5Rules & CN2 & RankSim \\
\hline \hline Regras & 10.00 & 7.40 & 14.40 & 6.80 \\
\hline Desvio Padrão & 1.24 & 0.50 & 0.34 & 0.79 \\
\hline Teste T & 2.63 & 0.97 & 7.58 & \\
\hline \hline
\end{tabular}

Já em relação ao número de condições por regra, a Tabela 5.20 mostra que o RankSim ganha apenas do C4.5, com 95\% de confiabilidade, e perde para os outros indutores.

Tabela 5.20: Conjunto ecoli - Número de Condições por Regra.

\begin{tabular}{r||r|r|r|r}
\hline \hline & C4.5 & C4.5Rules & CN2 & RankSim \\
\hline \hline Condições por Regra & 4.31 & 2.47 & 2.45 & 2.74 \\
\hline Desvio Padrão & 0.31 & 0.10 & 0.04 & 0.30 \\
\hline Teste T & 7.82 & -0.98 & -0.97 & \\
\hline \hline
\end{tabular}

\subsubsection{Conjunto flag}

Na Tabela 5.21 vemos mais um conjunto em que a fidelidade foi maior do que a acurácia do método RankSim. A acurácia do RankSim nesse conjunto de dados foi maior do que a dos dois indutores simbólicos e pior do que a do C4.5rules, porém nenhum resultado obteve 95\% de confiabilidade no teste $\mathrm{T}$.

Tabela 5.21: Conjunto flag - Acurácia e Fidelidade (\%).

\begin{tabular}{r||r|r|r|r|r||r}
\hline \hline & C4.5 & C4.5Rules & CN2 & SVM & RankSim & Fidelidade \\
\hline \hline Erro Médio & 15.45 & 10.79 & 14.81 & 10.84 & 11.84 & 6.16 \\
\hline Desvio Padrão & 2.01 & 1.17 & 0.12 & 1.45 & 1.72 & 1.46 \\
\hline Teste T & 1.50 & -0.82 & 1.66 & -0.59 & & \\
\hline \hline
\end{tabular}

Em relação ao número de regras, é possivel verificar, na Tabela 5.22, que o RankSim foi inferior ao C4.5 e superior ao CN2 com 95\% de confiabilidade. Em relação ao C4.5rules, o RankSim foi inferior, mas não com 95\% de confiabilidade.

Tabela 5.22: Conjunto flag - Número de Regras.

\begin{tabular}{r||r|r|r|r}
\hline \hline & C4.5 & C4.5Rules & CN2 & RankSim \\
\hline \hline Regras & 1.00 & 8.50 & 17.80 & 9.80 \\
\hline Desvio Padrão & 0.00 & 0.69 & 0.42 & 0.92 \\
\hline Teste T & -9.60 & -1.13 & 7.75 & \\
\hline \hline
\end{tabular}


Na Tabela 5.23 verifica-se que, em relação ao número de condições por regra, no conjunto flag, o RankSim foi superior em todos os casos e o resultado do teste $\mathrm{T}$ atestou $95 \%$ de confiabilidade para o C4.5 e CN2.

Tabela 5.23: Conjunto flag - Número de Condições por Regra.

\begin{tabular}{r||r|r|r|r}
\hline \hline & C4.5 & C4.5Rules & CN2 & RankSim \\
\hline \hline Condições por Regra & 3.00 & 1.86 & 2.25 & 1.70 \\
\hline Desvio Padrão & 0.00 & 0.09 & 0.05 & 0.09 \\
\hline Teste T & 14.24 & 2.06 & 7.35 & \\
\hline \hline
\end{tabular}

\subsubsection{Conjunto flare}

Na Tabela 5.24 é possível notar que, apesar do grande erro de classificação das regras geradas pelo CN2, o método RankSim conseguiu filtrar essas regras e selecionar as regras que, pela similaridade de rankings, tivessem mais chance de ter uma boa fidelidade. Nota-se também que a acurácia do método RankSim foi a maior entre todos os classificadores, com 95\% de confiabilidade em relação ao $\mathrm{C} 4.5$ e ao $\mathrm{CN} 2$.

Tabela 5.24: Conjunto flare - Acurácia e Fidelidade (\%).

\begin{tabular}{r||r|r|r|r|r||r}
\hline \hline & C4.5 & C4.5Rules & CN2 & SVM & RankSim & Fidelidade \\
\hline \hline Erro Médio & 19.51 & 18.57 & 80.52 & 18.39 & 17.35 & 7.41 \\
\hline Desvio Padrão & 0.49 & 0.91 & 2.13 & 0.50 & 0.80 & 1.17 \\
\hline Teste T & 3.97 & 1.91 & 28.86 & 1.56 & & \\
\hline \hline
\end{tabular}

É interessante notar também, na Tabela 5.25, que o CN2, que foi o pior classificador, é também o com o maior número de regras. Isso significa que apesar da abundancia das regras do $\mathrm{CN} 2$, que tiveram uma acurácia ruim, o RankSim conseguiu evitar a seleção dessas regras. Quanto ao número de regras do SimRank, ele só teve menos regras que o CN2, sendo superado nessa métrica pelo $\mathrm{C} 4.5$ com $95 \%$ de confiabilidade.

Tabela 5.25: Conjunto flare - Número de Regras.

\begin{tabular}{r||r|r|r|r}
\hline \hline & C4.5 & C4.5Rules & CN2 & RankSim \\
\hline \hline Regras & 2.80 & 13.00 & 83.00 & 14.40 \\
\hline Desvio Padrão & 1.80 & 0.73 & 1.79 & 1.80 \\
\hline Teste T & -4.81 & -0.68 & 27.49 & \\
\hline \hline
\end{tabular}

No número de condições por regra, ilustrado na Tabela 5.26, o RankSim apenas foi melhor que o CN2, com 95\% de confiabilidade. Perdendo para o C4.5rules, com 95\% de confiabilidade, e para o C4.5. 
Tabela 5.26: Conjunto flare - Número de Condições por Regra.

\begin{tabular}{r||r|r|r|r}
\hline \hline & C4.5 & C4.5Rules & CN2 & RankSim \\
\hline \hline Condições por Regra & 3.01 & 2.13 & 3.55 & 3.07 \\
\hline Desvio Padrão & 0.01 & 0.12 & 0.02 & 0.09 \\
\hline Teste T & -0.69 & -5.73 & 5.37 & \\
\hline \hline
\end{tabular}

\subsubsection{Conjunto glass}

No conjunto glass, a Tabela 5.27 mostra que a acurácia do RankSim foi inferior à dos outros indutores. Sua fidelidade, foi um pouco melhor do que sua acurácia.

Tabela 5.27: Conjunto glass - Acurácia e Fidelidade (\%).

\begin{tabular}{r||r|r|r|r|r||r}
\hline \hline & C4.5 & C4.5Rules & CN2 & SVM & RankSim & Fidelidade \\
\hline \hline Erro Médio & 8.42 & 7.97 & 16.23 & 7.92 & 16.47 & 14.13 \\
\hline Desvio Padrão & 1.19 & 1.24 & 0.12 & 0.69 & 4.17 & 5.30 \\
\hline Teste T & -2.01 & -2.19 & -0.06 & -1.99 & & \\
\hline \hline
\end{tabular}

Porém, nesse conjunto o método RankSim foi o que teve o menor número de regras, como pode ser visto na Tabela 5.28.

Tabela 5.28: Conjunto glass - Número de Regras.

\begin{tabular}{r||r|r|r|r}
\hline \hline & C4.5 & C4.5Rules & CN2 & RankSim \\
\hline \hline Regras & 8.00 & 7.80 & 13.80 & 7.70 \\
\hline Desvio Padrão & 0.54 & 0.51 & 0.29 & 0.45 \\
\hline Teste T & 0.41 & 0.15 & 14.08 & \\
\hline \hline
\end{tabular}

Em relação ao número de condições por regra, a Tabela 5.29 indica que o método RankSim foi equivalente ao C4.5rules, melhor que o $\mathrm{C} 4.5$ e pior que o CN2. Esses últimos dois resultados com 95\% de confiabilidade.

Tabela 5.29: Conjunto glass - Número de Condições por Regra.

\begin{tabular}{r||r|r|r|r}
\hline \hline & C4.5 & C4.5Rules & CN2 & RankSim \\
\hline \hline Condições por Regra & 4.13 & 2.36 & 1.85 & 2.55 \\
\hline Desvio Padrão & 0.14 & 0.08 & 0.02 & 0.12 \\
\hline Teste T & 8.80 & -1.70 & -5.46 & \\
\hline \hline
\end{tabular}

\subsubsection{Conjunto haberman}

Esse resultado em especial é bem interessante pois, como pode ser visto na Tabela 5.30, o método RankSim teve uma acurácia melhor do que todos os 
outros indutores, sendo que, para o $\mathrm{C} 4.5$ e $\mathrm{C} 4.5$ rules, o teste $\mathrm{T}$ relatou mais do que 95\% de confiabilidade. E, novamente, o erro médio da fidelidade foi menor do que o erro médio da acurácia.

Tabela 5.30: Conjunto haberman - Acurácia e Fidelidade (\%).

\begin{tabular}{r||r|r|r|r|r||r}
\hline \hline & C4.5 & C4.5Rules & CN2 & SVM & RankSim & Fidelidade \\
\hline \hline Erro Médio & 29.74 & 29.74 & 29.82 & 28.15 & 25.81 & 13.44 \\
\hline Desvio Padrão & 2.03 & 2.03 & 1.64 & 2.03 & 2.08 & 2.23 \\
\hline Teste T & 2.46 & 2.46 & 1.25 & 1.37 & & \\
\hline \hline
\end{tabular}

Conforme exposto na Tabela 5.31, o número de regras induzidas pelo RankSim porém foi bem acima do número de regras induzidas pelo C4.5 e C4.5rules e bem abaixo do número de regras induzido pelo $\mathrm{CN} 2$, todos os resultados com 95\% de confiabilidade no teste $\mathrm{T}$.

Tabela 5.31: Conjunto haberman - Número de Regras.

\begin{tabular}{r||r|r|r|r}
\hline \hline & C4.5 & C4.5Rules & CN2 & RankSim \\
\hline \hline Regras & 3.10 & 4.40 & 51.20 & 15.10 \\
\hline Desvio Padrão & 0.38 & 0.27 & 1.26 & 1.22 \\
\hline Teste T & -12.42 & -8.70 & 16.69 & \\
\hline \hline
\end{tabular}

Em relação ao número de condições por regra, na Tabela 5.32, o RankSim foi melhor que o CN2 e pior que os demais, com 95\% de confiabilidade.

Tabela 5.32: Conjunto haberman - Número de Condições por Regra.

\begin{tabular}{r|r|r|r|r}
\hline \hline & C4.5 & C4.5Rules & CN2 & RankSim \\
\hline \hline Condições por Regra & 2.54 & 1.96 & 3.25 & 3.02 \\
\hline Desvio Padrão & 0.13 & 0.08 & 0.02 & 0.06 \\
\hline Teste T & -3.28 & -11.10 & 3.30 & \\
\hline \hline
\end{tabular}

\subsubsection{Conjunto heart}

Como pode ser visto na Tabela 5.33, o conjunto heart é um dos poucos em que a fidelidade foi pior do que a acurácia do método. Os resultados sugerem que isso se deve à baixa acurácia alcançada pela SVM nesse conjunto de dados e os indutores simbólicos, por terem induzido boas regras, não geraram regras que resultassem em uma alta similaridade.

Conforme a Tabela 5.34, no conjunto heart, o método RankSim apresentou o maior número de regras entre os indutores simbólicos, em dois casos o resultado foi significativo com 95\% de confiabilidade. 
Tabela 5.33: Conjunto heart - Acurácia e Fidelidade (\%).

\begin{tabular}{r||r|r|r|r|r||r}
\hline \hline & C4.5 & C4.5Rules & CN2 & SVM & RankSim & Fidelidade \\
\hline \hline Erro Médio & 22.59 & 19.26 & 46.32 & 40.00 & 20.74 & 36.30 \\
\hline Desvio Padrão & 1.95 & 2.33 & 1.87 & 2.46 & 2.42 & 2.69 \\
\hline Teste T & 0.86 & -0.74 & 8.97 & 8.05 & & \\
\hline \hline
\end{tabular}

Tabela 5.34: Conjunto heart - Número de Regras.

\begin{tabular}{r||r|r|r|r}
\hline \hline & C4.5 & C4.5Rules & CN2 & RankSim \\
\hline \hline Regras & 17.80 & 12.70 & 20.40 & 23.00 \\
\hline Desvio Padrão & 0.79 & 0.93 & 0.58 & 2.13 \\
\hline Teste T & -2.55 & -5.21 & -1.13 & \\
\hline \hline
\end{tabular}

No número de condições por regra, pode ser visto na Tabela 5.35 que o RankSim só foi melhor que o C4.5. Em todos os resultados a significância teve $95 \%$ de confiabilidade.

Tabela 5.35: Conjunto heart - Número de Condições por Regra.

\begin{tabular}{r|r|r|r|r}
\hline \hline & C4.5 & C4.5Rules & CN2 & RankSim \\
\hline \hline Condições por Regra & 4.87 & 2.89 & 3.23 & 3.56 \\
\hline Desvio Padrão & 0.12 & 0.06 & 0.03 & 0.12 \\
\hline Teste T & 13.54 & -4.69 & -2.79 & \\
\hline \hline
\end{tabular}

\subsubsection{Conjunto pima}

Como pode ser visto na Tabela 5.36, em relação a acurácia, o SimRank teve um desempenho melhor do que o CN2 e a SVM com 95\% de confiabilidade. Em relação aos outros indutores a diferença foi pequena. Nesse conjunto, a fidelidade foi um pouco melhor do que a acurácia.

Tabela 5.36: Conjunto pima - Acurácia e Fidelidade (\%).

\begin{tabular}{r||r|r|r|r|r||r}
\hline \hline & C4.5 & C4.5Rules & CN2 & SVM & RankSim & Fidelidade \\
\hline \hline Erro Médio & 24.22 & 25.13 & 44.94 & 35.81 & 26.30 & 25.13 \\
\hline Desvio Padrão & 1.18 & 1.16 & 0.77 & 1.14 & 1.69 & 1.87 \\
\hline Teste T & -1.46 & -0.87 & 8.86 & 5.64 & & \\
\hline \hline
\end{tabular}

Em relação ao número de regras, na Tabela 5.37 pode ser visto que o método RankSim foi melhor que o CN2 e pior que o C4.5rules, com 95\% de confiabilidade. Além disso, o RankSim foi um pouco pior que o C4.5 nesse quesito. 
Tabela 5.37: Conjunto Pima - Número de Regras.

\begin{tabular}{r||r|r|r|r}
\hline \hline & C4.5 & C4.5Rules & CN2 & RankSim \\
\hline \hline Regras & 23.60 & 12.40 & 45.20 & 25.50 \\
\hline Desvio Padrão & 2.16 & 0.88 & 0.85 & 3.89 \\
\hline Teste T & -0.63 & -3.83 & 5.01 & \\
\hline \hline
\end{tabular}

Em condições por regra, na Tabela 5.38 pode ser identificado que o RankSim superou o C4.5 e foi superado pelo C4.5rules e pelo CN2, com 95\% de confiabilidade.

Tabela 5.38: Conjunto Pima - Número de Condições por Regra.

\begin{tabular}{r||r|r|r|r}
\hline \hline & C4.5 & C4.5Rules & CN2 & RankSim \\
\hline \hline Condições por Regra & 5.94 & 3.18 & 3.47 & 4.10 \\
\hline Desvio Padrão & 0.29 & 0.14 & 0.04 & 0.22 \\
\hline Teste T & 12.20 & -5.21 & -2.84 & \\
\hline \hline
\end{tabular}

\subsubsection{Conjunto ionosphere}

Conforme a Tabela 5.39, no conjunto ionosphere, a acurácia do SimRank superou a do CN2 e foi superada pela da SVM, com 95\% de confiabilidade. Nesse conjunto, a fidelidade também teve um resultado melhor que a acurácia.

Tabela 5.39: Conjunto ionosphere - Acurácia e Fidelidade (\%).

\begin{tabular}{r||r|r|r|r|r||r}
\hline \hline & C4.5 & C4.5Rules & CN2 & SVM & RankSim & Fidelidade \\
\hline \hline Erro Médio & 10.26 & 9.69 & 49.95 & 6.56 & 14.78 & 10.51 \\
\hline Desvio Padrão & 1.66 & 1.43 & 1.13 & 1.48 & 2.74 & 1.96 \\
\hline Teste T & -1.53 & -1.87 & 10.29 & -4.00 & & \\
\hline \hline
\end{tabular}

Em relação ao número de regras, a Tabela 5.40 mostra que o RankSim foi melhor que o CN2 com 95\% de confiabilidade. A diferença em relação aos outros indutores não foi estatisticamente significante.

Tabela 5.40: Conjunto ionosphere - Número de Regras.

\begin{tabular}{r||r|r|r|r}
\hline \hline & C4.5 & C4.5Rules & CN2 & RankSim \\
\hline \hline Regras & 14.20 & 10.40 & 18.40 & 12.60 \\
\hline Desvio Padrão & 0.76 & 0.58 & 0.58 & 1.68 \\
\hline Teste T & 1.16 & -1.62 & 3.48 & \\
\hline \hline
\end{tabular}

A Tabela 5.41 mostra que em relação ao número de condições por regra, o método SimRank foi melhor que o C4.5 e pior que os outros indutores simbólicos, com 95\% de confiabilidade. 
Tabela 5.41: Conjunto ionosphere - Número de Condições por Regra.

\begin{tabular}{r|r|r|r|r}
\hline \hline & C4.5 & C4.5Rules & CN2 & RankSim \\
\hline \hline Condições por Regra & 5.80 & 2.35 & 2.58 & 4.10 \\
\hline Desvio Padrão & 0.16 & 0.11 & 0.04 & 0.20 \\
\hline Teste T & 9.06 & -8.38 & -7.32 & \\
\hline \hline
\end{tabular}

\subsection{1 new-thyroid}

No conjunto new-thyroid, pode ser observado na Tabela 5.42 que a acurácia do método foi melhor que a do CN2, com 95\% de confiabilidade e também foi melhor que a do C4.5, perdendo somente para a SVM e para o C4.5rules por uma diferença mínima. A fidelidade do método nesse conjunto foi melhor do que sua acurácia, mesmo com esses valores de erro baixos. É interessante ressaltar que, nesse conjunto de dados, o CN2 teve uma acurácia extremamente baixa, enquanto os outros indutores tiveram uma boa acurácia.

Tabela 5.42: Conjunto new-thyroid - Acurácia e Fidelidade (\%).

\begin{tabular}{r||r|r|r|r|r||r}
\hline \hline & C4.5 & C4.5Rules & CN2 & SVM & RankSim & Fidelidade \\
\hline \hline Erro Médio & 4.59 & 2.77 & 50.39 & 1.86 & 2.79 & 1.84 \\
\hline Desvio Padrão & 1.66 & 1.40 & 1.64 & 1.02 & 1.02 & 1.01 \\
\hline Teste T & 1.47 & -0.03 & 18.38 & -0.82 & & \\
\hline \hline
\end{tabular}

Em relação ao número de regras, a Tabela 5.43 indica que o método só foi pior que o $\mathrm{C} 4.5$, porém, nenhum resultado teve $95 \%$ de confiabilidade no teste T.

Tabela 5.43: Conjunto new-thyroid - Número de Regras.

\begin{tabular}{r||r|r|r|r}
\hline \hline & C4.5 & C4.5Rules & CN2 & RankSim \\
\hline \hline Regras & 4.60 & 5.80 & 6.00 & 5.50 \\
\hline Desvio Padrão & 0.43 & 0.29 & 0.21 & 0.58 \\
\hline Teste T & -1.20 & 0.46 & 0.96 & \\
\hline \hline
\end{tabular}

Na Tabela 5.44 é possivel ver que o RankSim foi melhor que os outros indutores simbólicos, sendo que, no caso do C4.5, foi com 95\% de confiabilidade.

Tabela 5.44: Conjunto new-thyroid - Número de Condições por Regra.

\begin{tabular}{r||r|r|r|r}
\hline \hline & C4.5 & C4.5Rules & CN2 & RankSim \\
\hline \hline Condições por Regra & 2.90 & 1.94 & 2.02 & 1.84 \\
\hline Desvio Padrão & 0.14 & 0.04 & 0.07 & 0.13 \\
\hline Teste T & 9.73 & 0.85 & 1.29 & \\
\hline \hline
\end{tabular}




\subsubsection{Conjunto post-operative}

Nesse conjunto de dados, todos os indutores tiveram uma acurácia baixa, com exceção do CN2 que teve uma excelente acurácia. É interessante notar que, como o objetivo do algoritmo genético é otimizar a similaridade entre os rankings e a SVM teve uma acurácia baixa nesse conjunto de dados, o método RankSim não aproveitou a acurácia das regras do CN2 e a fidelidade do método nesse conjunto foi bem maior do que sua acurácia, como pode ser observado na Tabela 5.45 .

Tabela 5.45: Conjunto post-operative - Acurácia e Fidelidade (\%).

\begin{tabular}{r||r|r|r|r|r||r}
\hline \hline & C4.5 & C4.5Rules & CN2 & SVM & RankSim & Fidelidade \\
\hline \hline Erro Médio & 32.36 & 42.36 & 5.78 & 43.61 & 43.61 & 20.28 \\
\hline Desvio Padrão & 4.20 & 5.54 & 0.14 & 4.83 & 4.22 & 5.14 \\
\hline Teste T & -2.00 & -0.39 & -8.97 & 0.00 & & \\
\hline \hline
\end{tabular}

Na Tabela 5.46 é possivel observar que, em relação ao número de regras, o método RankSim somente foi melhor que o CN2, com 95\% de confiabilidade.

Tabela 5.46: Conjunto post-operative - Número de Regras.

\begin{tabular}{r||r|r|r|r}
\hline \hline & C4.5 & C4.5Rules & CN2 & RankSim \\
\hline \hline Regras & 1.40 & 5.00 & 22.80 & 15.10 \\
\hline Desvio Padrão & 0.27 & 0.26 & 0.53 & 1.18 \\
\hline Teste T & -10.98 & -8.44 & 5.44 & \\
\hline \hline
\end{tabular}

Em relação ao número de condições por regra, novamente o RankSim foi melhor do que o CN2 e pior que o C4.5rules e C4.5, sendo que somente o último resultado não teve $95 \%$ de confiabilidade, como pode ser visto na Tabela 5.47 .

Tabela 5.47: Conjunto post-operative - Número de Condições por Regra.

\begin{tabular}{r||r|r|r|r}
\hline \hline & C4.5 & C4.5Rules & CN2 & RankSim \\
\hline \hline Condições por Regra & 2.73 & 2.42 & 3.04 & 2.89 \\
\hline Desvio Padrão & 0.18 & 0.06 & 0.04 & 0.06 \\
\hline Teste T & -0.72 & -5.12 & 3.32 & \\
\hline \hline
\end{tabular}

\subsubsection{Conjunto satimage}

No conjunto satimage, como mostra a Tabela 5.48, o RankSim foi melhor que o CN2 e pior que os outros indutores no quesito acurácia, com 95\% de confiabilidade. Nesse conjunto a fidelidade também foi mais alta que a acurácia. 
Tabela 5.48: Conjunto satimage - Acurácia e Fidelidade (\%).

\begin{tabular}{r||r|r|r|r|r|r}
\hline \hline & C4.5 & C4.5Rules & CN2 & SVM & RankSim & Fidelidade \\
\hline \hline Erro Médio & 8.97 & 7.60 & 78.13 & 8.35 & 13.04 & 8.64 \\
\hline Desvio Padrão & 0.26 & 0.26 & 0.02 & 0.13 & 1.86 & 3.56 \\
\hline Teste T & -2.05 & -2.66 & 34.93 & -2.52 & & \\
\hline \hline
\end{tabular}

Como mostra a Tabela 5.49, em número de regras, o RankSim foi muito melhor que os outros indutores, com 95\% de confiabilidade.

Tabela 5.49: Conjunto satimage - Número de Regras.

\begin{tabular}{r||r|r|r|r}
\hline \hline & C4.5 & C4.5Rules & CN2 & RankSim \\
\hline \hline Regras & 153.20 & 41.30 & 69.90 & 18.60 \\
\hline Desvio Padrão & 2.35 & 1.90 & 1.28 & 2.65 \\
\hline Teste T & 38.71 & 7.86 & 17.04 & \\
\hline \hline
\end{tabular}

Porém, em relação às condições por regra, o RankSim só foi melhor que o C4.5, com 95\% de confiabilidade, como mostra a Tabela 5.50.

Tabela 5.50: Conjunto satimage - Número de Condições por Regra.

\begin{tabular}{r||r|r|r|r}
\hline \hline & C4.5 & C4.5Rules & CN2 & RankSim \\
\hline \hline Condições por Regra & 12.33 & 4.59 & 3.25 & 7.91 \\
\hline Desvio Padrão & 0.24 & 0.15 & 0.03 & 0.49 \\
\hline Teste T & 8.99 & -6.16 & -9.56 & \\
\hline \hline
\end{tabular}

\subsubsection{Conjunto spliceN}

Nesse conjunto, como pode ser visto na Tabela 5.51, a acurácia do RankSim foi melhor do que a do CN2 e pior do que a dos outros indutores, com 95\% de confiabilidade. A similaridade foi equivalente à acurácia.

Tabela 5.51: Conjunto spliceN - Acurácia e Fidelidade (\%).

\begin{tabular}{r||r|r|r|r|r||r}
\hline \hline & C4.5 & C4.5Rules & CN2 & SVM & RankSim & Fidelidade \\
\hline \hline Erro Médio & 5.95 & 4.47 & 69.97 & 3.28 & 17.42 & 17.73 \\
\hline Desvio Padrão & 0.33 & 0.26 & 0.36 & 0.35 & 4.57 & 4.62 \\
\hline Teste T & -2.60 & -2.85 & 11.10 & -3.28 & & \\
\hline \hline
\end{tabular}

Em relação ao número de regras, como mostra a Tabela 5.52, o método RankSim foi melhor com 95\% de confiabilidade em todos os casos.

Em relação ao número de condições por regra, como mostra a Tabela 5.53, o RankSim foi melhor que o CN2 e com 95\% de confiabilidade foi melhor que o C4.5 e pior que o C4.5rules. 
Tabela 5.52: Conjunto spliceN - Número de Regras.

\begin{tabular}{r||r|r|r|r}
\hline \hline & C4.5 & C4.5Rules & CN2 & RankSim \\
\hline \hline Regras & 88.00 & 63.40 & 120.70 & 23.10 \\
\hline Desvio Padrão & 1.26 & 0.81 & 0.99 & 4.41 \\
\hline Teste T & 14.25 & 8.54 & 21.56 & \\
\hline \hline
\end{tabular}

Tabela 5.53: Conjunto spliceN - Número de Condições por Regra.

\begin{tabular}{r||r|r|r|r}
\hline \hline & C4.5 & C4.5Rules & CN2 & RankSim \\
\hline \hline Condições por Regra & 4.10 & 2.34 & 3.44 & 3.27 \\
\hline Desvio Padrão & 0.03 & 0.02 & 0.01 & 0.08 \\
\hline Teste T & 11.30 & -12.95 & 2.12 & \\
\hline \hline
\end{tabular}

\subsubsection{Conjunto spliceEl}

Na Tabela 5.54 pode ser observado que a acurácia do RankSim foi melhor do que a do CN2 e pior nos outros casos, com 95\% de confiabilidade em todos os testes exceto para o $\mathrm{C} 4.5$.

Tabela 5.54: Conjunto spliceEI - Acurácia e Fidelidade (\%).

\begin{tabular}{r||r|r|r|r|r||r}
\hline \hline & C4.5 & C4.5Rules & CN2 & SVM & RankSim & Fidelidade \\
\hline \hline Erro Médio & 5.76 & 5.10 & 60.94 & 2.16 & 9.09 & 8.64 \\
\hline Desvio Padrão & 0.67 & 0.54 & 0.46 & 0.60 & 1.72 & 1.33 \\
\hline Teste T & -2.05 & -2.60 & 26.69 & -3.93 & & \\
\hline \hline
\end{tabular}

Em relação ao número de regras, como pode ser visto na Tabela 5.55, o RankSim foi melhor que o CN2 com 95\% de confiabilidade, melhor que C4.5 e pior que o C4.5rules.

Tabela 5.55: Conjunto spliceEI - Número de Regras.

\begin{tabular}{r||r|r|r|r}
\hline \hline & C4.5 & C4.5Rules & CN2 & RankSim \\
\hline \hline Regras & 35.20 & 26.10 & 45.20 & 27.10 \\
\hline Desvio Padrão & 1.11 & 0.94 & 1.08 & 3.45 \\
\hline Teste T & 1.92 & -0.27 & 6.17 & \\
\hline \hline
\end{tabular}

Na Tabela 5.56, é possivel verificar que o RankSim foi superior, no quesito número de condições por regra ao C4.5 e inferior aos outros, com 95\% de confiabilidade.

\subsubsection{Conjunto promoters}

Na Tabela 5.57 é possivel ver que no conjunto promoters, a acurácia do método RankSim foi superior a do CN2 com 95\% de confiabilidade, superior 
Tabela 5.56: Conjunto spliceEI - Número de Condições por Regra.

\begin{tabular}{r||r|r|r|r}
\hline \hline & C4.5 & C4.5Rules & CN2 & RankSim \\
\hline \hline Condições por Regra & 4.43 & 2.38 & 2.69 & 2.91 \\
\hline Desvio Padrão & 0.06 & 0.03 & 0.03 & 0.08 \\
\hline Teste T & 13.49 & -6.16 & -2.62 & \\
\hline \hline
\end{tabular}

ao C4.5 e inferior ao C4.5rules.

Tabela 5.57: Conjunto promoters - Acurácia e Fidelidade (\%).

\begin{tabular}{r||r|r|r|r|r||r}
\hline \hline & C4.5 & C4.5Rules & CN2 & SVM & RankSim & Fidelidade \\
\hline \hline Erro Médio & 17.91 & 15.09 & 58.11 & 8.27 & 15.91 & 16.91 \\
\hline Desvio Padrão & 2.86 & 3.51 & 3.14 & 2.13 & 3.30 & 3.77 \\
\hline Teste T & 0.43 & -0.14 & 9.21 & -2.11 & & \\
\hline \hline
\end{tabular}

Já em número de regras, a Tabela 5.58 mostra que o método RankSim foi pior que o C4.5rules com 95\% de confiabilidade, pior que o CN2 e melhor que o C4.5.

Tabela 5.58: Conjunto promoters - Número de Regras.

\begin{tabular}{r||r|r|r|r}
\hline \hline & C4.5 & C4.5Rules & CN2 & RankSim \\
\hline \hline Regras & 16.90 & 9.60 & 14.60 & 15.40 \\
\hline Desvio Padrão & 0.78 & 0.43 & 0.27 & 0.92 \\
\hline Teste T & 1.45 & -4.50 & -0.97 & \\
\hline \hline
\end{tabular}

Em condições por regra, a Tabela 5.59 mostra que o método RankSim foi melhor que o C4.5 e CN2, porém, foi pior que o C4.5rules, com 95\% de confiabilidade.

Tabela 5.59: Conjunto promoters - Número de Condições por Regra.

\begin{tabular}{r||r|r|r|r}
\hline \hline & C4.5 & C4.5Rules & CN2 & RankSim \\
\hline \hline Condições por Regra & 2.43 & 1.67 & 2.06 & 1.97 \\
\hline Desvio Padrão & 0.04 & 0.03 & 0.01 & 0.03 \\
\hline Teste T & 9.19 & -8.79 & 2.51 & \\
\hline \hline
\end{tabular}

\subsubsection{Conjunto german}

No conjunto german, é possível ver na Tabela 5.60, que em acurácia o RankSim foi melhor que o CN2 e que a SVM com 95\% de confiabilidade, melhor que o $\mathrm{C} 4.5$ e pior que o $\mathrm{C} 4.5$ rules. 
Tabela 5.60: Conjunto german - Acurácia e Fidelidade (\%).

\begin{tabular}{r||r|r|r|r|r||r}
\hline \hline & C4.5 & C4.5Rules & CN2 & SVM & RankSim & Fidelidade \\
\hline \hline Erro Médio & 31.90 & 27.80 & 45.38 & 32.80 & 29.80 & 14.40 \\
\hline Desvio Padrão & 0.90 & 1.04 & 1.04 & 0.81 & 0.55 & 1.42 \\
\hline Teste T & 1.63 & -1.47 & 12.48 & 2.54 & & \\
\hline \hline
\end{tabular}

Na Tabela 5.61 é possivel verificar que em relação ao número de regras o RankSim foi melhor que todos os outros indutores, em dois casos com 95\% de confiabilidade no teste $\mathrm{T}$.

Tabela 5.61: Conjunto german - Número de Regras.

\begin{tabular}{r||r|r|r|r}
\hline \hline & C4.5 & C4.5Rules & CN2 & RankSim \\
\hline \hline Regras & 89.50 & 25.40 & 82.50 & 25.20 \\
\hline Desvio Padrão & 3.83 & 2.37 & 2.04 & 5.07 \\
\hline Teste T & 8.33 & 0.03 & 9.44 & \\
\hline \hline
\end{tabular}

Por fim, Tabela 5.62 é possivel verificar que em condições por regra, o RankSim apenas foi melhor que o C4.5, com 95\% de confiabilidade.

Tabela 5.62: Conjunto german - Número de Condições por Regra.

\begin{tabular}{r||r|r|r|r}
\hline \hline & C4.5 & C4.5Rules & CN2 & RankSim \\
\hline \hline Condições por Regra & 5.53 & 2.74 & 3.61 & 4.21 \\
\hline Desvio Padrão & 0.12 & 0.07 & 0.03 & 0.12 \\
\hline Teste T & 12.63 & -11.64 & -5.05 & \\
\hline \hline
\end{tabular}

\subsection{Considerações Finais}

Este capítulo apresentou os resultados experimentais desta Tese. Sumarizando os resultados, são apresentadas as tabelas 5.63, 5.64 , 5.65 e 5.66.

Segundo a Tabela 5.63, o método proposto apresentou elevada fidelidade, com erro inferior a 10\% em 7 dos conjuntos de dados e inferior a $20 \%$ em 13 dos conjuntos. Para vários conjuntos de dados, a acurácia média obtida pelo método proposto, RankSim, foi semelhante a acurácia obtida pelas técnicas simbólicas. É importante observar que as regras do RankSim foram otimizadas para melhorar a fidelidade, não a acurácia. Nesse sentido, observa-se que o objetivo foi atingido pois em 13 dos 17 conjuntos, a fidelidade teve um erro médio menor do que o erro médio da acurácia. Mesmo assim, em dois dos conjuntos de dados investigados, haberman e flare, a acurácia obtida pelo método RankSim foi superior a acurácia obtida por todas as técnica sinbólicas. A menos da base pos-operative, RankSim foi sempre superior à técnica CN2. 
Tabela 5.63: Acurácia e Fidelidade(\%)

\begin{tabular}{r||r|r|r|r|r||r}
\hline \hline & C4.5 & C4.5Rules & CN2 & SVM & RankSim & Fidelidade \\
\hline \hline breast & 4.68 & 4.83 & 56.48 & 5.27 & 4.98 & 5.26 \\
\hline bupa & 35.08 & 31.29 & 34.44 & 37.97 & 36.29 & 31.89 \\
\hline ecoli & 7.74 & 8.94 & 30.53 & 11.02 & 10.41 & 5.35 \\
\hline flag & 15.45 & 10.79 & 14.81 & 10.84 & 11.84 & 6.16 \\
\hline flare & 19.51 & 18.57 & 80.52 & 18.39 & 17.35 & 7.41 \\
\hline glass & 8.42 & 7.97 & 16.23 & 7.92 & 16.47 & 14.13 \\
\hline haberman & 29.74 & 29.74 & 29.82 & 28.15 & 25.81 & 13.44 \\
\hline heart & 22.59 & 19.26 & 46.32 & 40.00 & 20.74 & 36.30 \\
\hline pima & 24.22 & 25.13 & 44.94 & 35.81 & 26.30 & 25.13 \\
\hline ionosphere & 10.26 & 9.69 & 49.95 & 6.56 & 14.78 & 10.51 \\
\hline post-operative & 4.59 & 2.77 & 50.39 & 1.86 & 2.79 & 1.84 \\
\hline satimage & 32.36 & 42.36 & 5.78 & 43.61 & 43.61 & 20.28 \\
\hline spliceN & 5.95 & 7.60 & 78.13 & 8.35 & 13.04 & 8.64 \\
\hline spliceEI & 5.76 & 4.47 & 69.97 & 3.28 & 17.42 & 17.73 \\
\hline promoters & 17.91 & 15.10 & 60.94 & 2.16 & 9.09 & 8.64 \\
\hline German & 31.90 & 27.80 & 45.11 & 8.27 & 15.91 & 16.91 \\
\hline & & & & & & 14.40 \\
\hline
\end{tabular}

As tabelas 5.64 e 5.65 mostram o número médio de regras e o número de médio de condições ou antecedente por regras, que podem ser utilizadas como medidas de compreensibilidade do conjunto de regras. De acordo com os valores apresentados, a compreensibilidade das regras geradas pelo RankSim foram semelhantes aos das técnicas simbólicas. Várias vezes o RankSim apresentou em média menos regras e menor número médio de antecedentes por regra. Na maoiria das vezes, RankSim gerou menos regras que o CN2.

Tabela 5.64: Número de Regras

\begin{tabular}{r||r|r|r|r}
\hline \hline & C4.5 & C4.5Rules & CN2 & RankSim \\
\hline \hline breast & 10.60 & 9.40 & 15.30 & 11.90 \\
\hline bupa & 29.50 & 15.70 & 31.80 & 28.10 \\
\hline ecoli & 10.00 & 7.40 & 14.40 & 6.80 \\
\hline flag & 1.00 & 8.50 & 17.80 & 9.80 \\
\hline flare & 2.80 & 13.00 & 83.00 & 14.40 \\
\hline glass & 8.00 & 7.80 & 13.80 & 7.70 \\
\hline haberman & 3.10 & 4.40 & 51.20 & 15.10 \\
\hline heart & 17.80 & 12.70 & 20.40 & 23.00 \\
\hline pima & 23.60 & 12.40 & 45.20 & 25.50 \\
\hline ionosphere & 14.20 & 10.40 & 18.40 & 12.60 \\
\hline post-operative & 1.40 & 5.00 & 6.00 & 5.50 \\
\hline satimage & 153.20 & 41.30 & 69.90 & 15.10 \\
\hline spliceN & 88.00 & 63.40 & 120.70 & 18.60 \\
\hline spliceEI & 35.20 & 26.10 & 45.20 & 23.10 \\
\hline promoters & 16.90 & 9.60 & 14.60 & 27.10 \\
\hline German & 89.50 & 25.40 & 82.50 & 25.40 \\
\hline & & & &
\end{tabular}


Tabela 5.65: Número de Condições por Regra

\begin{tabular}{r||r|r|r|r}
\hline \hline & C4.5 & C4.5Rules & CN2 & RankSim \\
\hline \hline breast & 3.98 & 2.32 & 2.72 & 2.85 \\
\hline bupa & 5.96 & 3.11 & 3.37 & 4.20 \\
\hline ecoli & 4.31 & 2.47 & 2.45 & 2.74 \\
\hline flag & 3.00 & 1.86 & 2.25 & 1.70 \\
\hline flare & 3.01 & 2.13 & 3.55 & 3.07 \\
\hline glass & 4.13 & 2.36 & 1.85 & 2.55 \\
\hline haberman & 2.54 & 1.96 & 3.25 & 3.02 \\
\hline heart & 4.87 & 2.89 & 3.23 & 3.56 \\
\hline pima & 5.94 & 3.18 & 3.47 & 4.10 \\
\hline ionosphere & 5.80 & 2.35 & 2.58 & 4.10 \\
\hline post-operative & 2.90 & 1.94 & 2.02 & 1.84 \\
\hline satimage & 12.33 & 2.42 & 3.04 & 2.89 \\
\hline spliceN & 4.10 & 4.59 & 3.25 & 7.91 \\
\hline spliceEI & 4.43 & 2.34 & 3.44 & 3.27 \\
\hline promoters & 2.43 & 1.67 & 2.69 & 2.91 \\
\hline German & 5.53 & 2.06 & 1.97 \\
\hline & \multicolumn{3}{|c}{} \\
\hline
\end{tabular}

Por fim, na Tabela 5.66 apresentamos os resultados iniciais de uma comparação, utilizando a métrica fidelidade, entre as duas variantes do método RankSim (uma utilizando exemplos originais e a outra utilizando exemplos rotulados pela SVM) e o método NNRules. Todos os experimentos foram realizados com os mesmos parâmetros do algoritmo genético e da SVM.

Nesses experimentos, foi possivel observar que, dos 13 conjuntos de dados utilizados nesses experimentos, o RankSim Original foi o melhor método em 7 conjuntos, RankSim Rotulado foi o melhor em 3 conjuntos e o NNRules foi o melhor em 3 conjuntos. Mais experimentos e os testes de hipóteses necessários para validar essa comparação serão realizados nos trabalhos futuros.

No próximo capítulo, as principais conclusões deste trabalho são apresentadas. 
Tabela 5.66: Fidelidade: RankSim Original, RankSim Rotulado e NNRules

\begin{tabular}{l|r|r|r}
\hline \hline & RankSim Orig & RankSim Rotulado & NNRules SVM \\
\hline \hline breast & $5.26 \% \pm 0.98$ & $9.22 \% \pm 2.89$ & $4.54 \% \pm 0.51$ \\
\hline bupa & $31.89 \% \pm 1.85$ & $35.31 \% \pm 2.87$ & $35.67 \% \pm 2.15$ \\
\hline ecoli & $5.35 \% \pm 1.45$ & $7.73 \% \pm 1.67$ & $8.63 \% \pm 1.21$ \\
\hline flag & $6.16 \% \pm 1.46$ & $5.13 \% \pm 1.08$ & $12.37 \% \pm 2.37$ \\
\hline flare & $7.41 \% \pm 1.17$ & $7.50 \% \pm 0.98$ & $18.95 \% \pm 0.51$ \\
\hline glass & $14.13 \% \pm 5.30$ & $20.74 \% \pm 5.92$ & $12.21 \% \pm 2.67$ \\
\hline haberman & $13.44 \% \pm 2.23$ & $12.45 \% \pm 2.24$ & $28.12 \% \pm 1.41$ \\
\hline heart & $36.30 \% \pm 2.69$ & $34.44 \% \pm 2.65$ & $20.37 \% \pm 2.01$ \\
\hline pima & $25.13 \% \pm 1.87$ & $28.64 \% \pm 2.08$ & $25.40 \% \pm 1.21$ \\
\hline ionosphere & $10.51 \% \pm 1.96$ & $11.13 \% \pm 2.39$ & $10.83 \% \pm 1.94$ \\
\hline new \pm thyroid & $1.84 \% \pm 1.01$ & $2.75 \% \pm 1.55$ & $4.16 \% \pm 1.72$ \\
\hline post \pm operative & $20.28 \% \pm 5.14$ & $19.17 \% \pm 6.86$ & $40.28 \% \pm 2.52$ \\
\hline German & $14.40 \% \pm 1.42$ & $16.40 \% \pm 2.08$ & $28.20 \% \pm 0.94$ \\
\hline \hline
\end{tabular}




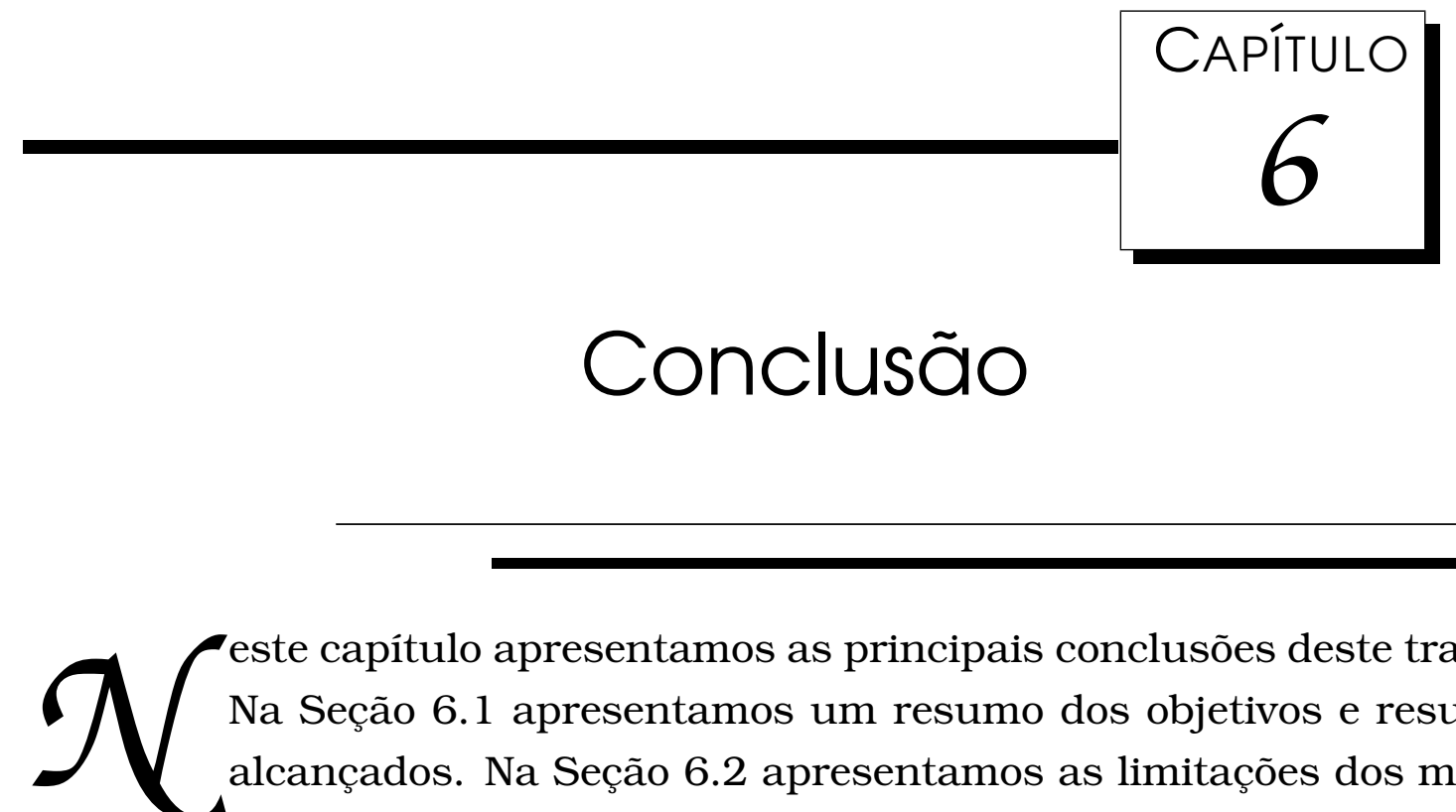

este capítulo apresentamos as principais conclusões deste trabalho. Na Seção 6.1 apresentamos um resumo dos objetivos e resultados alcançados. Na Seção 6.2 apresentamos as limitações dos métodos propostos neste trabalho e,por fim, na Seção 6.3 apresentamos os trabalhos futuros.

\subsection{Resumo dos objetivos e resultados}

O objetivo principal deste trabalho foi investigar e propor métodos para extração de conhecimento, na forma de regras, a partir de modelos de classificadores induzidos por técnicas caixa-preta de Aprendizado de Máquina. No decorrer do trabalho, o foco foi direcionado para as Máquinas de Vetores de Suporte (SVMs), pois era uma área que estava em ascensão e não haviam trabalhos sobre extração de regras para esse tipo de técnica de Aprendizado de Máquina até então. Porém, o método é geral o suficiente para ser aplicado a qualquer técnica de Aprendizado de Máquina caixa-preta em que seja possível criar rankings de suas saídas.

Durante o trabalho, surgiu a questão da falta de informação sobre o conhecimento adquirido por técnicas caixa-preta quando utilizados métodos de extração de regra pedagógicos. Uma alternativa para minimizar este problema proposto é utilizar a informação dos rankings das saídas geradas por essas técnicas e a otimização de regras que também gerem um ranking com alta similaridade com os rankings gerados por essas técnicas.

Optamos então por inovar e propor um método de extração de conhecimento pedagógico que não utiliza o conjunto de dados rotulado pela técnica de aprendizado de máquina caixa-preta para gerar as regras e sim um subconjunto das regras geradas por vários indutores simbólicos sobre o conjunto de dados original. Esse subconjunto é escolhido por meio de um Algoritmo 
Genético que tem como função de avaliação uma métrica que mede a similaridade entre o ranking gerado pela técnica de Aprendizado de Máquina caixa-preta da qual se quer extrair as regras e um indivíduo da população do Algoritmo Genético que representa um subconjunto das regras geradas pelos indutores simbólicos escolhidos.

Os experimentos mostraram que essa é uma abordagem promissora. Não apenas para a explicação do comportamento de técnicas de aprendizado de máquina caixa-preta, mas também pode ser uma abordagem capaz de gerar regras que herdem características desejáveis da técnica caixa-preta da qual as regras foram extraídas, por exemplo, as fronteiras de decisão de margens largas definidas por SVMs.

\subsection{Limitações}

Este trabalho mostra que é possível realizar a extração de regras por similaridade de rankings, porém, muito ainda precisa ser feito para melhorar a qualidade dos rankings e das próprias regras geradas. Em vários casos os resultados indicaram alta fidelidade e acurácia, mas em outros a fidelidade deixou muito a desejar, mostrando que o método ainda não é consistente para todos os domínios de aplicação.

A qualidade do subconjunto final de regras que faz parte do indivíduo escolhido depende diretamente da variabilidade dos bias indutivos nas regras que formam a população inicial. Portanto, julgamos que para obter resultados melhores que os atuais, será necessário aumentar o número de indutores simbólicos utilizados para gerar as regras. Desta forma, o Algoritmo Genético terá mais chance de encontrar um conjunto de regras com bias mais próximo ao da técnica de aprendizado de máquina caixa-preta.

\subsection{Trabalhos futuros}

Uma das variações desse método é gerar as regras da população inicial utilizando conjuntos de dados rotulados pela técnica de Aprendizado de Máquina caixa-preta, assim como nos métodos pedagógicos tradicionais, e então realizar a otimização da similaridade de rankings. Experimentos iniciais já foram realizados, como descrito no Capítulo 5, mas ainda é necessário executar mais experimentos e testes de hipóteses comparando as duas abordagens do método RankSim com outros métodos.

Outro trabalho futuro é a inclusão de mais indutores simbólicos para a geração de regras da população inicial para que, como já comentado, tenhamos maior variabilidade de bias indutivo nas regras dos individuos do Algoritmo Genético. 
Ainda com o objetivo de aumentar a variabilidade do bias indutivo, serão estudadas formas de realizar mutações nos antecedentes das regras extraídas durante a execução do Algoritmo Genético.

Além disso, especializando-se mais ainda no domínio das SVMs, pretendese também explorar a geração de exemplos artificiais a partir dos vetores de suporte definidos pelas SVMs utilizando os próprios vetores como exemplos e criando novos através de operadores de mutação e cruzamento, utilizando os atributos dos vetores de suporte como cromossomos. Então pretende-se utilizar esses exemplos artificiais como conjunto de treinamento no momento de gerar os rankings, de forma que os rankings das regras tenham alta similaridade com um ranking gerado a partir de exemplos que explorem melhor as margens das fronteiras de decisão das SVMs. 



\section{Referências Bibliográficas}

Alexander, J. A. and Dietterich, T. G. (1995). Template-based algorithms for connectionist rule extraction. In Advances in Neural Information Processing Systems, volume 7, pages 609-616, Cambridge, MA. MIT Press.

Andrews, R., Diederich, J., and Tickle, A. B. (1995). Survey and critique of techniques for extracting rules from trained artificial neural networks. Knowledge-Based Systems Journal, 8(6):373-389.

Behloul, F., Lelieveldt, B. P. F., Boudraa, A., and Reiber, J. H. C. (2002). Optimal design of radial basis function neural networks for fuzzy-rule extraction in high dimensional data. Pattern Recognition, 35(3):659-675.

Ben-Hur, A., Horn, D., Siegelmann, H. T., and Vapnik, V. N. (2000). A support vector clustering method. In Proceedings of the International Conference on Pattern Recognition (ICPR'OO), volume 2, pages 724-727.

Blake, C. and Merz, C. (1998). UCI repository of machine learning databases.

Blasig, R. (1994). Gds: Gradient descent generation of symbolic classification rules. In Advances in Neural Information Processing Systems, volume 6, pages 1093-1 100, San Francisco, CA. Morgan Kaufmann.

Braga, A. P., de Carvalho, A. C. P. L. F., and Ludemir, T. B. (2000). Redes Neurais Artificiais: Teoria e aplicações. Livros Técnicos e Científicos.

Brown, M. P. S., Grundy, W. N., Cristianini, N., Sugnet, C. W., Furey, T. S., Jr., M. A., and Haussler, D. (2000). Knowledge-based analysis of microarray gene expression data by using support vector machines. Proc. Natl. Acad. Sci. USA, 97(1):262-267.

Clark, P. and Niblett, T. (1989a). The cn2 induction algorithm. Machine Learning, 3:261-284.

Clark, P. and Niblett, T. (1989b). The CN2 Induction Algorithm. Machine Learning, 3:261-284. 
Collobert, R. and Bengio, S. (2001). SVMTorch: Support vector machines for large-scale regression problems. Journal of Machine Learning Research, $1: 143-160$.

Craven, M. and Shavlik, J. (1996). Extracting tree-structured representations of trained networks. In Advances in Neural Information Processing Systems, volume 8, pages 24-30. MIT Press.

Craven, M. W. (1996). Extracting Comprehensible Models from Trained Neural Networks. PhD thesis, University of Wisconsin - Madison.

Craven, M. W. and Shavlik, J. W. (1994a). Machine learning approaches to gene recognition. IEEE Expert, 9(2):2-10.

Craven, M. W. and Shavlik, J. W. (1994b). Using sampling and queries to extract rules from trained neural networks. In Proceedings of the 11 th International Conference on Machine Learning, pages 37-45. Morgan Kaufmann.

Craven, M. W. and Shavlik, J. W. (1999). Rule Extraction: Where Do We Go from Here? University of Wisconsin Machine Learning Research Group Working Paper 99-1.

Cristianini, N. and Shawe-Taylor, J. (2000). An Introduction to Support Vector Machines and other kernel-based learning methods. Cambridge University Press.

Cybenko, G. (1988). Continuos valued neural networks with two hidden layers are sufficient. Technical report, Department of Computer Science, Tufts University.

Darwin, C. (1859). On the Origin of Species by Means of Natural Selection. Murray, London.

Dietterich, T. G. (1997). Approximate Statistical Tests for Comparing Supervised Classification Learning Algorithms. Neural Computation, 10(7):18951924.

Ding, C. H. Q. and Dubchak, I. (2001). Multi-class protein fold recognition using support vector machines and neural networks. Bioinformatics, 4(17):349-358.

Duch, W., Adamczak, R., Grabczewski, K., Zal, G., and Hayashi, Y. (2000). Fuzzy and crisp logical rule extraction methods in application to medical data. Computational Intelligence and Applications, 23:593-616. 
Fu, L. (1991). Rule learning by searching on adapted nets. In Proceedings of the Ninth National Conference on Artificial Intelligence, pages 590-595. Mit Press.

$\mathrm{Fu}$, L. (1994). Rule generation from neural networks. IEEE Transactions on Systems, Man, and Cybernetics, 24(8):1114-1124.

Fung, G., Sandilya, S., and Rao, R. B. (2008). Rule extraction from linear support vector machines via mathematical programming. In Diederich, J., editor, Rule Extraction from Support Vector Machines, volume 80 of Studies in Computational Intelligence, pages 83-107. Springer.

Furey, T. S., Christianini, N., Christianini, N., Duffy, N., Bednarski, D. W., Schummer, M., and Hauessler, D. (2000). Support vector machine classification and validation of cancer tissue samples using microarray expression data. Bioinformatics, 16(10):906-914.

Gallant, S. I. (1993). Neural Network Learning and Expert Systems. MIT Press.

Ginsberg, M. (1993). Essentials of Artificial Intelligence. Academic Press/Morgan Kaufmann, San Francisco.

Goldberg, D. E. (1989). Genetic Algorithms in Search, Optimization and Machine Learning. Addison-Wesley Publishing Company, Reading, Massachusetts.

Hayashi, Y. (1991). A neural expert system with automated extraction of fuzzy if-then rules. In Advances in Neural Information Processing Systems, volume 3, pages 578-584, San Mateo, CA. Morgan Kaufmann.

Haykin, S. (1998). Neural Networks: A Comprehensive Foundation. Prentice Hall, 2 edition.

Holland, J. H. (1975). Adaptation in Natural and Artificial Systems. University of Michigan Press.

Huss, M., Boström, H., Asker, L., and Coster, J. (2001). Learning to recognize brain specific proteins based on low-level features from on-line prediction servers. In BIOKDDO1 - Workshop on Data Mining in Bioinformatics.

Jackson, J. C. (1995). The Harmonic Siéve: A Novel Application of Fourier Analysis to Machine Learning Theory and Practice. PhD thesis, School of Computer Science, Carneggie Mellon University, Pittsburgh, PA. CMU-CS95-183. 
Jong, K. D. (1980). Adaptive system design: A genetic approach. IEEE Transactions on Systems, Man and Cybernetics, SMC-10(9):566-574.

Lewin, B. (2000). Genes VII. Oxford University Press.

Lorena, A. C., Batista, G. E. A. P. A., Carvalho, A. C. P. L. F., and Monard, M. C. (2002). The influence of noisy patterns in the performance of learning methods in the splice junction recognition problem. In Proceedings of the VII Brazilian Symposium on Neural Networks. IEEE Computer Society Press.

Lorena, A. C. and de Carvalho, A. C. P. L. F. (2003). Introdução aos classificadores de margens largas. Technical Report 195, Instituto de Ciências Matemáticas e de Computação - Universidade de São Paulo, São Carlos SP.

Martineli, E. (1999). Extração de conhecimento de redes neurais artificiais. Master's thesis, ICMC-USP.

Milaré, C. R. (2003). Extração de conhecimento de redes neurais artificiais utilizando sistemas de aprendizado simbólico e algoritmos genéticos. PhD thesis, Universidade de São Paulo, São Carlos - SP.

Milaré, C. R., de Carvalho, A. C. P. L. F., and Monard, M. C. (2002). Extracting knowledge from artificial neural networks: an empirical comparison of trepan and symbolic learning algorithms. In MICAI 2002: Advances in Artificial Intelligence, volume 2313 of Lecture Notes in Computer Science: Lecture Notes in Artificial Intelligence, pages 272-281, Merida, Yucatan, Mexico. Springer.

Milaré, C. R., Batista, G. E. A. P. A., and Monard, M. C. (1997). Uma Ferramenta para Extração de Conhecimento de Redes Neurais. In XXV Seminário Integrado de Software e Hardware - SEMISH, pages 59-70.

Mitchel, T. M. (1997). Machine Learning. McGraw-Hill.

Mitra, S., Pal, S. K., and Mitra, P. (2002). Data mining in soft computing framework: A survey. IEEE Transactions on Neural Networks, 13(1):3-14.

Mukherjee, N. and Mukherjee, S. (2002). Predicting signal peptides with support vector machines. In Pattern Recognition with Support Vector Machines, volume 2388 of Lecture Notes in Computer Science, pages 1-7. Springer.

Núñez, H., Angulo, C., and Català, A. (2002). Rule extraction from support vector machines. In Verleysen, M., editor, ESANN 2002, 10th Eurorean Symposium on Artificial Neural Networks, Bruges, Belgium, April 24-26, 2002, Proceedings, pages 107-112. 
Prati, R. C., Baranauskas, J. A., and Monard, M. C. (2002). Padronização da sintaxe e informações sobre regras induzidas a partir de algoritmos de aprendizado de máquina simbólico. Revista Eletrônica de Iniciação Científica, $2(3)$.

Quinlan, J. R. (1988). C4.5 Programs for Machine Learning. Morgan Kaufmann Publishers, CA.

Rezende, S. O. (2002). Sistemas Inteligentes. Manole.

Rumelhart, D., Hilton, G., and Williams, R. (1986). Learning Internal Representations by Error Propagation. In Parallel Distributed Processing: Explorations in the Microstructure of Cognition, volume 1. MIT Press, Cambridge, MA.

Saito, K. and Nakano, R. (1988). Medical Diagnostic Expert System Based on PDP Model. In Proceedings of the IEEE International Conference on Neural Networks, pages 255-262, San Diego, CA. IEEE Press.

Schellharmmer, I., Diederich, J., Towsey, M., and Brugman, C. (1997). Knowledge extraction and recurrent neural networks: an analysis of an elman network trained on a natural language learning task. Technical Report 97IS1, Queensland University of Technology, Australia.

Schmitz, G. P. J., Aldrich, C., and Gouws, F. S. (1999). Ann-dt: An algorithm for extraction of decision trees from artificial neural networks. IEEE Transactions on Neural Networks, 10(6):1392-1401.

Sethi, I. K. and Yoo, J. H. (1994). Symbolic approximation of feedforward neural networks. In Pattern Recognition in Pratice, volume 4, pages 313324, North-Holland, New York, NY.

Setiono, R. and Liu, H. (1995). Understanding neural networks via rule extraction. In Proceedings of the Fourteenth International Joint Conference on Artificial Intelligence, pages 480-485, Montreal, Quebec. Morgan kaufmann.

Smola, A. J., Barlett, P., Schölkopf, B., and Schuurmans, D. (1999). Advances in Large Margin Classifiers. MIT Press.

Spears, W. M., De Jong, K. A., Bäck, T., Fogel, D. B., and de Garis, H. (1993). An overview of evolutionary computation. In Brazdil, P. B., editor, Proc. of the European Conf. on Machine Learning, pages 442-459, Berlin. Springer. 
Tan, A. H. (1994). Rule learning and extration with self-organizing neural network. In Proceedings of the 1993 Connectionist Models Summer School, pages 192-199, Hillsdale, NJ. Lawrence Erlbaum Associates.

Thrun, S. (1994). Extracting provably correct rules from artificial neural networks. Technical Report IAI-TR-93-5, Institut für Informatik III, Universität Bonn.

Thrun, S. (1995). Extracting rules from artificial neural networks with distributed representations. In Advances in Neural Information Processing Systems, volume 7, pages 505-512, Cambridge, MA. MIT Press.

Tickle, A. B., Andrews, R., Golea, M., and Diederich, J. (1998). The truth will come to light: Directions and challenges in extracting the knowledge embedded within trained artificial neural networks. IEEE Transactions on Neural Networks, 9(6):1057-1068.

Tickle, A. B., Orlowski, M., and Diederich, J. (1994). Dedec: Decision detection by rule extraction from neural network. Technical report, QUT NRC.

Towell, G. and Shavlik, J. W. (1993). The extraction of refined rules from knowledge-based neural networks. Machine Learning, 131(1):71-101.

Weiss, S. M. and Kulikowski, C. A. (1991). Computer Systems that Learn. Classification and Prediction Methods from Statistics, Neural Nets, Machine Learning, and Expert Systems. Morgan Kaufmann, San Mateo, CA.

Winston, P. (1992). Artificial Intelligence. Addison-Wesley.

Zell, A. (1995). Stuttgart Neural Network Simulator. http://www. ra-informatik.uni-tuebingen.de/SNNS/.

Zhou, Z. and Jiang, Y. (2002). Medical diagnosis with c4.5 rule preceded by artificial neural network ensemble. IEEE Transactions on Information Technology in Biomedicine. to appear.

Zien, A., Rätsch, G., Mika, S., Schölkopf, B., Lengaeuer, T., and Müller, K. R. (2000). Engineering suppot vector machine kernels that recognize translation initiation sites in dna. Bioinformatics, 16(9):799-807. 